ISSN 1998-0663 (print), ISSN 2587-8166 (online)

English version: ISSN 2587-814X (print), ISSN 2587-8158 (online)

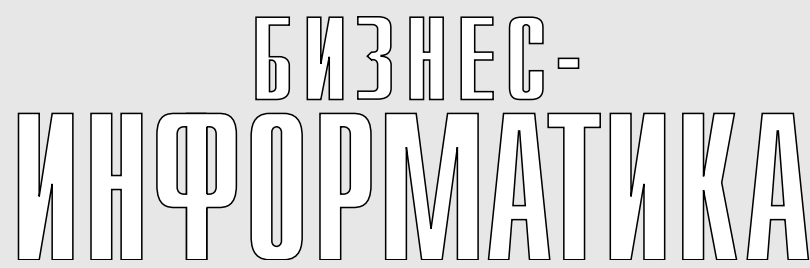

НАУЧНЫЙ ЖУРНАЛ НИУ ВШЭ

\section{СОДЕРЖАНИЕ}

\section{Анализ данных и интеллектуальные системы}

\section{Ю.П. Ехлаков, Е.И. Грибков}

Модель извлечения пользовательских мнений о потребительских свойствах товара на основе рекуррентной нейронной сети

\section{Т.С. Станкевич}

Применение сверточных нейронных сетей для решения задачи оперативного прогнозирования динамики распространения лесных пожаров

\section{Информационные системы и технологии в бизнесе}

\section{Е.В. Васильева, В.Н. Пуляева, В.А. Юдина}

Развитие цифровых компетенций государственных гражданских служащих Российской Федерации

С.П. Новиков, О.В. Михеенко, Н.А. Кулагина, О.Д. Казаков

Цифровизация учета профессиональных компетенций граждан на основе технологий распределенных реестров и смарт-контрактов.

М.А. Штефан, Ю.М. Елизарова

Оценка эффективности и рисков инвестиционных проектов: интегральный подход

\section{Моделирование социальных и экономических систем}

\section{Г.Л. Бекларян}

Система поддержки принятия решений для устойчивого экономического развития Дальневосточного федерального округа

\section{№4(46)-2018}

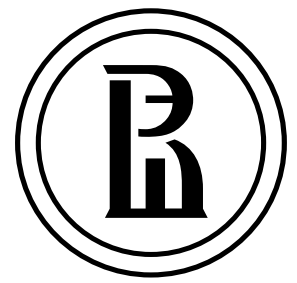

Издатель:

Национальный исследовательский университет «Высшая школа экономики»

Подписной индекс в каталоге агентства «Роспечать» -72315

Выпускается ежеквартально

Журнал включен в Перечень российских рецензируемых научных жмурналов, в которых должны быть опубликованы основные научные результаты диссертаций на соискание ученых степеней доктора и кандидата наук

\section{Главный редактор} А.О. Голосов

Заместители главного редактора С.В. Мальцева

Е.А. Кучерявый

\section{Компьютерная верстка}

О.А. Богданович

Администратор веб-сайта И.И. Хрусталева

Адрес редакции: 105187, г. Москва, ул. Кирпичная, д. 33

Тел./факс: +7 (495) 771-32-38 http://bijournal.hse.ru

E-mail: bijournal@hse.ru

За точность приведенных сведений и содержание данных, не подлежащих открытой публикации несут ответственность авторы

При перепечатке ссылка на журнал «Бизнес-информатика» обязательна Тираж:

русскоязычная версия - 300 экз. англоязычная версия - 300 экз., онлайн-версии на русском и английском свободный доступ

Отпечатано в типографии НИУ ВШЭ г. Москва, Кочновский проезд, 3

(c) Национальный исследовательский университет «Высшая школа экономики» 


\section{O \KУPHA^E}

изнес-информатика»-рецензируемыймеждисциплинарныйнаучныйжурнал, выпускаемый с 2007 года Национальным исследовательским университетом «Высшая школа экономики» (НИУ ВШЭ). Администрирование журнала осуществляется школой бизнес-информатики НИУ ВШЭ. Журнал выпускается ежеквартально.

Миссия журнала - развитие бизнес-информатики как новой области информационных технологий и менеджмента. Журнал осуществляет распространение последних разработок технологического и методологического характера, способствует развитию соответствующих компетенций, а также обеспечивает возможности для дискуссий в области применения современных информационно-технологических решений в бизнесе, менеджменте и экономике.

Журнал публикует статьи по следующей тематике:

\ анализ данных и интеллектуальные системы

४ информационные системы и технологии в бизнесе

математические методы и алгоритмы бизнес-информатики

$\checkmark$ программная инженерия

$\uparrow$ Интернет-технологии

$\downarrow$ моделирование и анализ бизнес-процессов

$\checkmark$ стандартизация, сертификация, качество, инновации

\ правовые вопросы бизнес-информатики

๑ принятие решений и бизнес-интеллект

\ моделирование социальных и экономических систем

๑ информационная безопасность.

В соответствии с решением президиума Высшей аттестационной комиссии Российской Федерации журнал включен в Перечень российских рецензируемых научных журналов, в которых должны быть опубликованы основные научные результаты диссертаций на соискание ученых степеней доктора и кандидата наук, по следующим группам научных специальностей: 05.13.00 - информатика, вычислительная техника и управление; 05.25 .00 - документальная информация; 08.00.00 - экономические науки.

Журнал входит в базу Russian Science Citation Index (RSCI) на платформе Web of Science.

Журнал зарегистрирован Федеральной службой по надзору в сфере связи, информационных технологий и массовых коммуникаций (Роскомнадзор), свидетельство ПИ № ФС77-66609 от 08 августа 2016 г.

Международный стандартный серийный номер (ISSN): 1998-0663 (на русском), 2587-814X (на английском).

Главный редактор: Голосов Алексей Олегович, кандидат технических наук, Президент компании «ФОРС - Центр разработки». 


\section{PЕААКШИОННАЯ КОАМЕГИЯ}

\section{ГЛАВНЫЙ РЕДАКТОР}

Голосов Алексей Олегович

Компания «ФОРС - Центр разработки», Москва, Россия

\section{ЗАМЕСТИТЕЛИ ГЛАВНОГО РЕДАКТОРА}

Малыцева Светлана Валентиновна

Национальный исследовательский университет

«Высшая школа экономики», Москва, Россия

Кучерявый Евгений Андреевич

Технологический университет Тампере, Тампере, Финляндия

\section{ЧЛЕНЫ РЕЛКОЛЛЕГИИ}

\section{Абдульраб Абиб}

Национальный институт прикладных наук, Руан, Франция

Авдошин Сергей Михайлович

Национальный исследовательский университет

«Высшая школа экономики», Москва, Россия

Акопов Андраник Сумбатович

Национальный исследовательский университет

«Высшая школа экономики», Москва, Россия

Алескеров Фуад Тагиевич

Национальный исследовательский университет

«Высшая школа экономики», Москва, Россия

\section{Афанасьев Александр Петрович}

Институт проблем передачи информации им. А.А. Харкевича РАН, Москва, Россия

\section{Афанасьев Антон Александрович}

Центральный экономико-математический институт РАН, Москва, Россия

\section{Бабкин Эдуард Александрович}

Национальный исследовательский университет

«Высшая школа экономики», Нижний Новгород, Россия

Баландин Сергей Игоревич

Ассоциация FRUCT, Хельсинки, Финляндия

Баранов Александр Павлович

Главный научно-исследовательский вычислительный центр Федеральной налоговой службы, Москва, Россия

\section{Барахнин Владимир Борисович}

Институт вычислительных технологий СО РАН,

Новосибирск, Россия

\section{Беккер Йорг}

Университет Мюнстера, Мюнстер, Германия

\section{Белов Владимир Викторович}

Рязанский государственный радиотехнический университет, Рязань, Россия

Вестнер Маркус

Регенсбургский университет прикладных наук, Регенсбург, Германия

Гаврилова Татьяна Альбертовна

Санкт-Петербургский государственный университет,

Санкт-Петербург, Россия

Глотен Эрве

Тулонский университет, Ла-Гард, Франция

Грибов Андрей Юрьевич

Компания «КиберПлат», Москва, Россия

\section{Громов Александр Игоревич}

Национальный исследовательский университет

«Высшая школа экономики», Москва, Россия

\section{Гурвич Владимир Александрович}

Ратгерский университет (Университет Нью-Джерси),

Ратгерс, США

Демидова Лилия Анатольевна

Рязанский государственный радиотехнический университет,

Рязань, Россия

Джейкобс Лоренц

Университет Цюриха, Цюрих, Швейцария

Дискин Иосиф Евгеньевич

Всероссийский центр изучения общественного мнения,

Москва, Россия
Ефимушкин Владимир Александрович

Центральный научно-исследовательский институт связи,

Москва, Россия

Зандкуль Курт

Университет Ростока, Росток, Германия

Иванников Александр Дмитриевич

Институт проблем проектирования в микроэлектронике РАН, Москва, Россия

\section{Ильин Николай Иванович}

Федеральная служба охраны Российской Федерации, Москва, Россия

Исаев Дмитрий Валентинович

Национальный исследовательский университет

«Высшая школа экономики», Москва, Россия

Калягин Валерий Александрович

Национальный исследовательский университет

«Высшая школа экономики», Нижний Новгород, Россия

Кравченко Татьяна Константиновна

Национальный исследовательский университет

«Высшая школа экономики», Москва, Россия

Кузнецов Сергей Олегович

Национальный исследовательский университет

«Высшая школа экономики», Москва, Россия

Лугачев Михаил Иванович

Московский государственный университет

им. М.В. Ломоносова, Москва, Россия

Лин Квей-Жей

Технологический институт Нагои, Нагоя, Япония

Мейор Питер

Комиссия ООН по науке и технологиям, Женева, Швейцария

Миркин Борис Григорьевич

Национальный исследовательский университет

«Высшая школа экономики», Москва, Россия

Моттль Вадим Вячеславович

Тульский государственный университет, Тула, Россия

Назаров Дмитрий Михайлович

Уральский государственный экономический университет,

Екатеринбург, Россия

Пальчунов Дмитрий Евгеньевич

Новосибирский государственный университет,

Новосибирск, Россия

Пардалос Панайот (Панос)

Университет Флориды, Гейнсвилл, США

Пастор Оскар

Политехнический университет Валенсии, Валенсия, Испания

Посегга Йоахим

Университет Пассау, Пассау, Германия

\section{Сюняев Али Рашидович}

Технологический институт Карлсруэ, Карлсруэ, Германия

Таратухин Виктор Владимирович

Университет Мюнстера, Мюнстер, Германия

Триболе Жозе

Университет Лиссабона, Лиссабон, Португалия

Ульянов Михаил Васильевич

Институт проблем управления им В.А. Трапезникова РАН,

Москва, Россия

Ускенбаева Раиса Кабиевна

Международный университет информационных технологий, Алматы, Казахстан

\section{Цуканова Ольга Анатольевна}

Санкт-Петербургский национальный исследовательский

университет информационных технологий, механики и оптики,

Санкт-Петербург, Россия

Чхартишвили Александр Гедеванович

Институт проблем управления им В.А. Трапезникова РАН,

Москва, Россия

Шмидт Юрий Давыдович

Дальневосточный федеральный университет, Владивосток, Россия

Штраус Кристина

Университет Вены, Вена, Австрия 
ISSN 1998-0663 (print), ISSN 2587-8166 (online)

English version: ISSN 2587-814X (print), ISSN 2587-8158 (online)

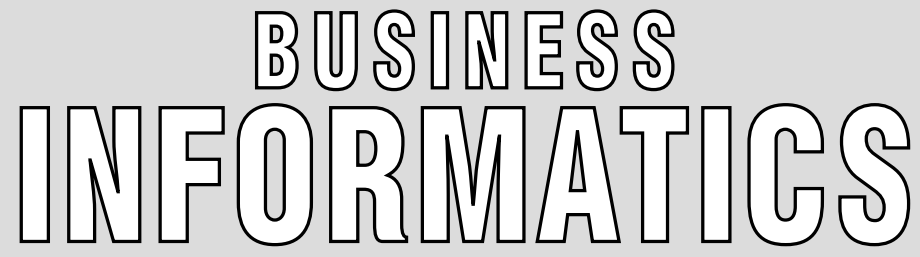

HSE SCIENTIFIC JOURNAL

\section{CONTENTS}

\section{Data analysis and intelligence systems}

Yu.P. Yekhlakov, E.I. Gribkov

User opinion extraction model concerning

consumer properties of products based

on a recurrent neural network

\section{T.S. Stankevich}

The use of convolutional neural networks to forecast

the dynamics of spreading forest fires in real time

\section{Information systems and technologies in business}

E.V. Vasilieva, V.N. Pulyaeva, V.A. Yudina

Digital competence development of state civil servants in the Russian Federation

S.P. Novikov, O.V. Mikheenko, N.A. Kulagina,

O.D. Kazakov

Digital registry of professional competences

of the population drawing on distributed registries

and smart contracts technologies

M.A. Shtefan, J.M. Elizarova

Investment project efficiency and risk evaluation:

an integrated approach

\section{Modeling of social and economic systems}

\section{G.L. Beklaryan}

Decision support system for sustainable economic development of the Far Eastern Federal District 66
№4(46)-2018

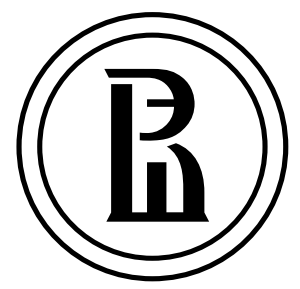

Publisher:

National Research University Higher School of Economics

Subscription index in the Rospechat catalog 72315

The journal is published quarterly

The journal is included

into the list of peer reviewed scientific editions established

by the Supreme Certification

Commission of the Russian Federation

Editor-in-Chief:

A. Golosov

Deputy Editor-in-Chief

S. Maltseva

Y. Koucheryavy

Computer Making-up:

O. Bogdanovich

Website Administration:

I. Khrustaleva

Address:

33, Kirpichnaya Street, Moscow, 105187, Russian Federation

Tel./fax: +7 (495) 771-32-38

http://bijournal.hse.ru

E-mail: bijournal@hse.ru

\footnotetext{
Circulation:

English version - 300 copies,

Russian version - 300 copies, online versions in English and Russian open access
}

Printed in HSE Printing House

3, Kochnovsky Proezd, Moscow, Russian Federation

(C) National Research University Higher School of Economics 


\section{ABOUT \\ THE JOURNAL}

$\mathrm{B}$ usiness Informatics is a peer reviewed interdisciplinary academic journal published since 2007 by National Research University Higher School of Economics (HSE), Moscow, Russian Federation. The journal is administered by School of Business Informatics. The journal is published quarterly.

The mission of the journal is to develop business informatics as a new field within both information technologies and management. It provides dissemination of latest technical and methodological developments, promotes new competences and provides a framework for discussion in the field of application of modern IT solutions in business, management and economics.

The journal publishes papers in the areas of, but not limited to:

$\downarrow$ data analysis and intelligence systems

$\uparrow$ information systems and technologies in business

$\downarrow$ mathematical methods and algorithms of business informatics

$\downarrow$ software engineering

$\downarrow$ Internet technologies

$\downarrow$ business processes modeling and analysis

$\downarrow$ standardization, certification, quality, innovations

$\downarrow$ legal aspects of business informatics

$\downarrow$ decision making and business intelligence

$\uparrow$ modeling of social and economic systems

$\downarrow$ information security.

The journal is included into the list of peer reviewed scientific editions established by the Supreme Certification Commission of the Russian Federation.

The journal is included into Russian Science Citation Index (RSCI) database on the Web of Science platform.

International Standard Serial Number (ISSN): 2587-814X (in English), 1998-0663 (in Russian).

Editor-in-Chief: Dr. Alexey Golosov - President of FORS Development Center, Moscow, Russia. 


\section{EDITORIAL BOARD}

EDITOR-IN-CHIEF

Alexey Golosov

FORS Development Center, Moscow, Russia

\section{DEPUTY EDITOR-IN-CHIEF}

\section{Svetlana Maltseva}

National Research University Higher School of Economics, Moscow, Russia

\section{Yevgeni Koucheryavy}

Tampere University of Technology, Tampere, Finland

\section{EDITORIAL BOARD}

Habib Abdulrab

National Institute of Applied Sciences, Rouen, France

Sergey Avdoshin

National Research University Higher School of Economics, Moscow, Russia

\section{Andranik Akopov}

National Research University Higher School of Economics, Moscow, Russia

\section{Fuad Aleskerov}

National Research University Higher School of Economics, Moscow, Russia

\section{Alexander Afanasyev}

Institute for Information Transmission Problems (Kharkevich Institute), Russian Academy of Sciences, Moscow, Russia

Anton Afanasyev

Central Economics and Mathematics Institute, Russian Academy of Sciences, Moscow, Russia

\section{Eduard Babkin}

National Research University Higher School of Economics, Nizhny Novgorod, Russia

\section{Sergey Balandin}

Finnish-Russian University Cooperation in Telecommunications (FRUCT), Helsinki, Finland

\section{Vladimir Barakhnin}

Institute of Computational Technologies, Siberian Branch of Russian Academy of Sciences, Novosibirsk, Russia

\section{Alexander Baranov}

Federal Tax Service, Moscow, Russia

Jörg Becker

University of Munster, Munster, Germany

Vladimir Belov

Ryazan State Radio Engineering University, Ryazan, Russia

Alexander Chkhartishvili

V.A. Trapeznikov Institute of Control Sciences, Russian Academy of Sciences, Moscow, Russia

Vladimir Efimushkin

Central Research Institute of Communications, Moscow, Russia

Tatiana Gavrilova

Saint-Petersburg University, St. Petersburg, Russia

Hervé Glotin

University of Toulon, La Garde, France

Andrey Gribov

CyberPlat Company, Moscow, Russia

\section{Alexander Gromoff}

National Research University Higher School of Economics, Moscow, Russia

Vladimir Gurvich

Rutgers, The State University of New Jersey, Rutgers, USA

Laurence Jacobs

University of Zurich, Zurich, Switzerland

Liliya Demidova

Ryazan State Radio Engineering University, Ryazan, Russia
Iosif Diskin

Russian Public Opinion Research Center, Moscow, Russia

Nikolay Ilyin

Federal Security Guard of the Russian Federation, Moscow, Russia

Dmitry Isaev

National Research University Higher School of Economics, Moscow, Russia

\section{Alexander Ivannikov}

Institute for Design Problems in Microelectronics, Russian Academy of Sciences, Moscow, Russia

\section{Valery Kalyagin}

National Research University Higher School of Economics, Nizhny Novgorod, Russia

\section{Tatiana Kravchenko}

National Research University Higher School of Economics,

Moscow, Russia

\section{Sergei Kuznetsov}

National Research University Higher School of Economics, Moscow, Russia

Kwei-Jay Lin

Nagoya Institute of Technology, Nagoya, Japan

Mikhail Lugachev

Lomonosov Moscow State University, Moscow, Russia

\section{Peter Major}

UN Commission on Science and Technology for Development,

Geneva, Switzerland

\section{Boris Mirkin}

National Research University Higher School of Economics,

Moscow, Russia

\section{Vadim Mottl}

Tula State University, Tula, Russia

\section{Dmitry Nazarov}

Ural State University of Economics, Ekaterinburg, Russia

Dmitry Palchunov

Novosibirsk State University, Novosibirsk, Russia

Panagote (Panos) Pardalos

University of Florida, Gainesville, USA

Óscar Pastor

Polytechnic University of Valencia, Valencia, Spain

Joachim Posegga

University of Passau, Passau, Germany

Kurt Sandkuhl

University of Rostock, Rostock, Germany

Yuriy Shmidt

Far Eastern Federal University, Vladivostok, Russia

\section{Christine Strauss}

University of Vienna, Vienna, Austria

\section{Ali Sunyaev}

Karlsruhe Institute of Technology, Karlsruhe, Germany

Victor Taratukhin

University of Munster, Munster, Germany

José Tribolet

Universidade de Lisboa, Lisbon, Portugal

\section{Olga Tsukanova}

Saint-Petersburg National Research University of Information

Technologies, Mechanics and Optics, St. Petersburg, Russia

Mikhail Ulyanov

V.A. Trapeznikov Institute of Control Sciences, Russian Academy of Sciences, Moscow, Russia

\section{Raissa Uskenbayeva}

International Information Technology University, Almaty, Kazakhstan

Marcus Westner

Regensburg University of Applied Sciences, Regensburg, Germany 


\title{
Модель извлечения
}

\section{пользовательских мнений}

о потребительских свойствах товара на основе рекуррентной нейронной сети 1

\section{Ю.П. Ехлаков}

доктор технических наук

профессор кафедры автоматизации обработки информации

Томский государственный университет систем управления и радиоэлектроники

Адрес: 634050, г. Томск, пр. Ленина, д. 40

E-mail: upe@tusur.ru

\section{Е.И. Грибков}

аспирант кафедры автоматизации обработки информации

Томский государственный университет систем управления и радиоэлектроники

Адрес: 634050, г. Томск, пр. Ленина, д. 40

E-mail:drnemor@gmail.com

\begin{abstract}
Аннотация
В статье на основе анализа существующих подходов к задаче разметки последовательности предложена модель структурного предсказания с использованием рекуррентной нейронной сети долгой краткосрочной памяти (long short-term memory, LSTM), позволяющая извлекать мнения пользователей из текстов отзывов. Представлены конфигурация модели и набор правил изменения ее состояния, позволяющие использовать как признаки из обрабатываемого предложения, так и прошлые результаты собственных предсказаний. Для обучения и оценки качества работы модели создан размеченный набор текстов отзывов о мобильных телефонах из интернет-магазина Amazon. Описана процедура обучения модели извлечения мнений на наборе отзывов, предложены конкретные значения гиперпараметров модели. Проведено экспериментальное сравнение разработанной модели с моделью на основе условного случайного поля (conditional random field, CRF) с использованием LSTM. Для сравнения моделей использовался критерий F1, характеризующий соотношение полноты и точности извлечения мнений. Результаты экспериментального исследования модели показывают, что предложенная модель дает более высокие по сравнению с аналогом результаты: в случае строго совпадения F1 для аспектов выше на 4,51\%, для оценочных высказываний - на 5,44\%.

В качестве практической апробации предложенной модели было проведено извлечение мнений о потребительских свойствах мобильных телефонов из текстов отзывов, отсутствующих в размеченной выборке. Кроме того, дополнительно были извлечены и представлены мнения из отзывов на другие категории товаров: телевизоры, средства для ухода за кожей, планшеты. Результаты апробации позволяют говорить о том, что модель показала хорошие результаты как для извлечения мнений о мобильных телефонах, так и о других категориях товаров. Полученные результаты могут быть полезны специалистам в области компьютерной лингвистики и машинного обучения, а также руководителям и менеджерам интернет-магазинов для определения потребительских предпочтений потенциальных пользователей, выдачи рекомендаций по приобретению товаров и предоставления развитых средств поиска по каталогу товаров.
\end{abstract}

Ключевые слова: обратная связь пользователей; глубокое обучение; машинное обучение; обработка естественного языка; обработка мнений.

Цитирование: Ехлаков Ю.П., Грибков Е.И. Модель извлечения пользовательских мнений о потребительских свойствах товара на основе рекуррентной нейронной сети // Бизнес-информатика. 2018. № 4 (46). C. 7-16. DOI: 10.17323/1998-0663.2018.4.7.16

1 Работа выполнена в рамках государственного задания Министерства образования и науки

РФ, проект № 8.8184.2017/8.9 


\section{Введение}

$\Pi$ окупка любого достаточно сложного технического устройства (например, телефона, холодильника или телевизора) представляет собой нетривиальную проблему выбора для потенциального потребителя. Присутствие на рынке большого количества производителей и модельных рядов, разнообразие технических характеристик товаров объективно приводят к комбинаторному росту числа возможных вариантов потребительских свойств продуктов-аналогов (товаров). Покупатель либо приобретает товар «на удачу», надеясь на бренд производителя, либо принимает решение о покупке на основе рекламной информации. С развитием Интернета и социальных сетей большинство покупателей-прагматиков при принятии решений о покупке руководствуются не только рекламой, но и мнением покупателей о потребительских свойствах товара, которые выявляются при его длительном использовании.

Компании-производители товаров также заинтересованы в лучшем понимании своих клиентов: какие товары они предпочитают, какие положительные и отрицательные характеристики приобретаемых товаров они выделяют. Опираясь на эти данные, руководство может формировать ассортимент, осуществлять индивидуальный подбор товаров и услуг, делать специальные предложения клиентам и предпринимать другие действия, направленные на повышение лояльности покупателей и улучшение конкурентоспособности.

Существует большое количество источников, из которых можно узнать мнения пользователей о конкретных товарах. Это могут быть тематические форумы, статьи и видеоролики с обзорами, а также группы в социальных сетях. Многие сетевые магазины позволяют своим покупателям оставлять мнения о приобретенных товарах на их страничках. Облегчить задачу поиска информации могут агрегаторы типа «Яндекс.Маркет», которые собирают в одном месте комментарии пользователей, а также предоставляют сообществу возможность оценивать полезность содержащейся в них информации.

Однако большинство подобных платформ решают только проблему сбора информации в одном месте, без ее автоматического анализа и обобщения. Посетители вынуждены самостоятельно изучать и анализировать отзывы, что при большом объеме информации весьма проблематично. Качественное решение задачи по извлечению пользовательских мнений о потребительских свойствах товаров и представление информации в удобном для анализа виде возможны при использовании современных методов машинного обучения в области обработки естественного языка.

В настоящее время большинство работ, посвященных обработке текстов отзывов пользователей, основывается на анализе тональности (эмоционального настроения) текста. При этом тональность рассматривается как атрибут целого текста или его крупных частей (параграфов и предложений) $[1,2]$, чего явно недостаточно для извлечения пользовательских мнений. Исследования в области аспектно-ориентированного анализа тональности посвящены вопросам поиска отдельных упоминаний аспектов (потребительских свойств и характеристик) продуктов и определению отношения пользователей к ним «в целом», путем отнесения к одной из категорий: «хорошее», «плохое», «нейтральное», «неизвестное» [3, 4]. Наиболее проработанной постановкой задачи определения отношения пользователя к продукту является детальный анализ тональности [5], где предлагается выделять в тексте отзывов аспекты и высказывания, в которых пользователь выражает свое отношение к данному аспекту. В ряде работ для детального анализа тональности применяются модели сегментации последовательности на основе условных случайных полей (conditional random field, CRF) [3, 6, 7]. В качестве входных признаков для сегментирования используются результаты работы синтаксических анализаторов: частеречная разметка, деревья зависимостей, деревья непосредственных составляющих и др. Однако такие анализаторы недоступны для многих естественных языков. Кроме того, точность таких анализаторов сильно зависит от природы обучающих данных. Помимо этого, в данных моделях используются словари специальной лексики: эмоциональной, оценочной и т.д. Последние достижения в области статистического моделирования естественного языка с помощью глубокого обучения позволяют избежать использования дополнительных признаков при обучении этих моделей $[8,9]$. Такие модели самостоятельно формируют необходимые для решения задачи признаки, используемые во время обучения.

В данной работе для извлечения пользовательских мнений предлагается модель структурного предсказания на основе рекуррентной нейронной сети долгой краткосрочной памяти (long short-term memory, LSTM), которая не требует наличия таких анализаторов и полагается только на предобученные векторные представления. Для обучения и проверки качества модели используется размеченный авторами корпус (набор данных) отзывов о мобильных телефонах. 


\section{1. Формирование обучающей выборки для извлечения пользовательских мнений из текстов}

В настоящее время существует небольшое количество наборов данных, предназначенных для обучения моделей детального анализа тональности. Так, в работе [10] предлагается размеченный набор отзывов из интернет-магазина Amazon - USAGE, состоящий из 800 отзывов по 8 категориям относительно простых товаров, вроде тостеров и кофе-машин. В основу предлагаемой схемы разметки текстов отзывов пользователей положены следующие сущности:

аспект - важная характеристика или упоминание продукта (дополнительно приводится информация о том, принадлежит ли аспект продукту, о котором написан отзыв);

† оценочное высказывание - текст, содержащий высказанное пользователем мнение об аспекте (отмечается тональность высказывания);

^ разрешение кореференции - для случаев, когда аспект является ссылкой на сущность из другого предложения в отзыве;

связь между аспектом и оценочным высказыванием - если оценочное высказывание было связанно с определенным аспектом.

Несмотря на доступность набора данных, авторами было решено сделать дополнительный размеченный корпус. Это обусловлено двумя причинами. Во-первых - желанием проверить качество работы алгоритмов извлечения мнений на потенциально более технически сложных и многофункциональных товарах (поэтому разметка проводилась на категории мобильных телефонов). Во-вторых - в силу ограниченности человеческих ресурсов авторы использовали более простую схему разметки по сравнению со схемой USAGE (в частности, не проводилось разрешение кореференции и в разметку вносились только пары «аспект - оценочное высказывание»).

Для разметки использовался корпус отзывов пользователей интернет-магазина Amazon [11]. Этот корпус содержит порядка 143 миллионов текстов отзывов о 25 категориях товаров, написанных в период с мая 1996 по июль 2014 года, вместе с метаинформацией, включающей названия, идентификаторы и описания продуктов, категории товаров, информацию о бренде и цене, идентификатор автора и оценку продукта пользователем. Аннотаторам предлагалось выделить в текстах отзывов спаны (непрерывные последовательности слов), содержащие аспекты и оценочные высказывания. В отличие от набора данных USAGE, аспекты и оценочные высказывания выделялись строго парами «аспект - оценочное высказывание», которые вместе формируют пользовательские мнения. Далее мнением будем называть пару

$$
O=\left\langle A\left(a_{\text {begin }}, a_{\text {end }}\right), D\left(d_{\text {begin }}, d_{\text {end }}\right)\right\rangle
$$

где $A\left(a_{b e g i n}, a_{\text {end }}\right)$ - аспект мнения, начинающийся на слове с порядковым номером $a_{b e g i n}$ и заканчивающийся на слове с номером $a_{\text {end }}$;

$D\left(d_{b e g i n}, d_{\text {end }}\right)$ - оценочное высказывание, начинающийся на слове с порядковым номером $d_{\text {begin }}$ и заканчивающийся на слове с номером $d_{\text {end }}$.

При этом спаны разных отзывов не должны пересекаться. Таким образом, размеченное предложение из текста отзыва с мнением $O_{1}$, состоящего из аспекта с соответствующим спаном $A(1,2)$ и оценочным высказыванием $D(4,5)$ будет выглядеть следующим образом:

$$
\left[\text { Battery }_{1} \text { life }_{2}\right]_{A-O_{1}} \text { is }_{3}\left[\text { quite }_{4} \text { impressive }_{5}\right]_{D-O_{1}} !_{6} \text {. }
$$

Всего было размечено 3232 отзыва. Размеченный корпус содержит 9344 мнения, 1994 уникальных аспекта, 5124 уникальные оценочные выражения. Количественные характеристики размеченного корпуса приведены 8 таблице 1.

\section{Количественные характеристики корпуса пользовательских отзывов о мобильных телефонах}

\begin{tabular}{l|c}
\multicolumn{1}{c|}{ Характеристика } & 3начение \\
\hline Количество отзывов & 3232 \\
\hline Количество мнений в корпусе & 9344 \\
\hline Количество уникальных аспектов & 1994 \\
\hline Количество уникальных оценочных выражений & 5124 \\
\hline
\end{tabular}

\section{2. Модель извлечения пользовательских мнений}

Задача извлечения пользовательских мнений может быть представлена как задача разметки последовательности, где для каждого элемента $w_{t}$ входной последовательности $\left\{w_{1}, \ldots, w_{n}\right\}$ необходимо определить метку класса (тег) $y_{t}$. Для этого необходимо преобразовать спаны мнений в последовательность тегов. Одним из наиболее популярных способов за- 
дания спанов в виде последовательности является формат IOB [12]. В нем используется три типа тегов: $\mathbf{O}$ - отсутствие тега; B-X - начало новой сущности $\mathbf{X} ; \mathbf{I}-\mathbf{X}$ - продолжение сущности $\mathbf{X}$. В данной работе предложено выделять два типа сущностей - аспекты и оценочные высказывания, обозначенные словами Aspect и Description. Тогда множество доступных тегов Y будет состоять из следующих элементов: O - отсутствие сущности; B-Aspect - начало аспекта; I-Aspect - продолжение аспекта; B-Description начало оценочного высказывания; I-Description продолжение оценочного высказывания. Таким образом, предложению с набором мнений мы можем однозначно поставить в соответствие набор тегов, как это показано на рисунке 1.

$\begin{array}{llll}{\left[\text { Battery }_{1}\right.} & \left.\text { life }_{2}\right]_{\text {Aspect-O }} & \text { is }_{3} & {\left[\text { good }_{4}\right]_{\text {Description- } O_{1}}} \\ \text { B-Aspect } & \text { I-Aspect } & \text { O } & \text { B-Description }\end{array}$

Рис. 1. Пример преобразования спанов мнений в последовательность тегов в формате IOB

В качестве формального аппарата решения задачи предлагается использовать рекуррентные нейронные сети (РНС). Данный тип нейронных сетей широко применяется для решения самых разнообразных задач машинного обучения: построения лингвистических моделей естественного языка [13], частеречной разметки [8], классификации последовательностей [14], распознавания аудиосигналов [15], прогнозирования временных рядов [16] и др.

На вход РНС на каждом шаге $t$ подается произвольная последовательность, которая на основе рекуррентных связей между последовательностью скрытых состояний преобразуется в последовательность выходов:

$$
h_{t}=f\left(U x_{t}+W h_{t-1}+b\right)
$$

где $x_{t}-$ текущий вход;

$h_{t-1}-$ предыдущее скрытое состояние;

$U$ и $W$ - матрицы входного и рекуррентного взаимодействия;

$b$ - вектор смещений;

$f-$ нелинейная функция.

Наличие рекуррентных связей позволят сети передавать информацию об общем «контексте» обрабатываемой последовательности и учитывать ее при формировании выходов $h_{t}$. Таким образом, можно рассматривать $h_{t}$ как промежуточное представле- ние последовательности, в котором аккумулирована информация о прошлых шагах. В данном случае используем рекуррентную нейронную сеть типа LSTM [17], поскольку она менее подвержена проблеме затухающего градиента (vanishing gradient) [18] по сравнению с обычными РНС:

$$
\begin{gathered}
f_{t}=\sigma\left(W_{f} x_{t}+U_{f} h_{t-1}+b_{f}\right) \\
i_{t}=\sigma\left(W_{i} x_{t}+U_{i} h_{t-1}+b_{i}\right) \\
o_{t}=\sigma\left(W_{o} x_{t}+U_{o} h_{t-1}+b_{o}\right) \\
c_{t}=f_{t} \odot c_{t-1}+i_{t} \odot \tanh \left(W_{c} x_{t}+U_{c} h_{t-1}+b_{c}\right) \\
h_{t}=o_{t} \odot \tanh \left(c_{t}\right) .
\end{gathered}
$$

Для определения меток слов используется классификатор, работающий следующим образом: к каждому выходному значению применяется линейное преобразование с функцией софтмакс, результатом которого является распределение вероятности по возможным меткам:

$$
P\left(\hat{y}_{t} \mid x_{t}\right)_{i}=\frac{\exp \left(W_{t a g} h_{t}+b_{t a g}\right)_{i}}{\sum_{j} \exp \left(W_{t a g} h_{t}+b_{t a g}\right)_{j}} .
$$

Из определения общего вида РНС видно, что информация распространяется по сети в направлении слева направо. В некоторых случаях для повышения эффективности классификации конкретного слова необходимо знать контекст следующих за ним слов. Для того чтобы на каждом шаге предсказания была доступна информация из обоих направлений, применяются двунаправленные нейронные сети, одна из которых обрабатывает входную последовательность слева направо, а другая - справа налево, после чего соответствующие одной позиции скрытые состояния объединяются:

$$
\begin{gathered}
\overleftarrow{h}_{t}=f\left(\overleftarrow{U} x_{t}+\overleftarrow{W} \overleftarrow{h}_{t-1}+\overleftarrow{b}\right), \\
h_{t}=\left[\vec{h}_{t} ; \overleftarrow{h}_{t}\right] .
\end{gathered}
$$

Следует отметить, что в задачах структурного предсказания (к которым относится и задача разметки последовательности) существуют зависимости между метками классов в выходной последовательности. Модели, которые не учитывают данные зависимости, могут получать на выходе некорректные последовательности меток. Например, в случае предсказания меток последовательности в формате IOB последовательность предсказаний O I-Aspect является ошибочной, т.к. элемент класса I-Aspect может следовать только после соответствующего ему B-Aspect. 
Для обработки зависимостей между отдельными предсказаниями предлагается использовать модель условного случайного поля (conditional random field, CRF) предложенную в [19]:

$$
s(W, y)=\sum_{i=0}^{n} A_{y_{i}, y_{i+1}}+\sum_{i=1}^{n} P_{i, y_{i}},
$$

где $A$ - матрица вероятностей переходов от метки $y_{i}$ к метке $y_{i+1}$;

$P_{i, y_{i}}-$ вероятность метки $y_{i}$ в позиции $i$;

$W=\left\{w_{1}, w_{2}, \ldots, w_{n}\right\}-$ входная последовательность;

$y=\left\{y_{1}, \ldots, y_{n}\right\}-$ последовательность предсказаний.

Тогда вероятность последовательности $y$ рассчитывается следующим образом:

$$
p(y \mid W)=\frac{\exp (s(W, y))}{\sum_{y^{\prime}} \exp \left(s\left(W, y^{\prime}\right)\right)},
$$

где суммирование в знаменателе происходит по всем возможным последовательностям $y$.

При обучении модели условного случайного поля максимизируется логарифм вероятности истинной последовательности:

$$
\log (p(y \mid W))=s(W, y)-\log \left(\sum_{\dot{y}} \exp \left(s\left(W, y^{\prime}\right)\right)\right) .
$$

Для поиска оптимальной последовательности предсказаний предлагается использовать метод динамического программирования. При этом оптимальная последовательность меток должна соответствовать максимуму выражения $p(y \mid W)$, а именно:

$$
\hat{y}=\arg \max _{y} p(y \mid W) .
$$

Использование модели условных случайных полей позволяет получить глобально оптимальную структуру предсказания только для случая, когда результатом предсказания является линейная структура, использующая в каждом узле локальные признаки. Данные ограничения привели к развитию методов структурного предсказания, способных обрабатывать более сложные виды структур (например, деревья) и использовать нелокальные признаки (например, результаты классификации слов на предыдущих шагах) [20, 21]. С учетом этого для определения меток слов в предлагается использовать следующее выражение:

$$
P\left(\hat{y}_{t} \mid \phi\left(c_{t}\right)\right)_{i}=\frac{\exp \left(W_{t a g} \phi\left(c_{t}\right)+b_{t a g}\right)_{i}}{\sum_{j} \exp \left(W_{t a g} \phi\left(c_{t}\right)+b_{t a g}\right)_{j}},
$$

где $c_{t}-$ конфигурация модели в момент $t$;

$\phi\left(c_{t}\right)$ - функция, отображающая конфигурацию $c_{t}$ в набор признаков.

Практическое применение выражения (6) для извлечения пользовательских мнений требует задания вида конфигурации $c_{t}$ и функции получения признаков $\phi\left(c_{t}\right)$. Для этого предлагается использовать идеи из модели для построения деревьев зависимостей, представленные в работе [22]. Конфигурация определяется четверкой вида $c=(S, B, l, Y)$, состоящей из буфера $B$, содержащего необработанные на текущий момент элементы входной последовательности, стека $S$, в который складываются слова из найденных на текущий момент сущностей, метки последней найденной сущности $l$ (Aspect или Description) и выходной последовательности меток $Y$. На каждом шаге $t$ формируется вектор признаков $\phi\left(c_{t}\right)$, который используется для определения метки текущего слова $\hat{y}_{t}$ и изменения текущей конфигурации в соответствии с этой меткой. Конфигурация изменяется в соответствии с правилами, представленными в таблице 2. Символом «точка с запятой» в таблице обозначена конкатенация последовательностей.

Таблица 2.

\section{Правила изменения} элементов конфигурации

\begin{tabular}{c|c|c|c|c}
$\hat{y}_{t}$ & $\boldsymbol{S}^{t+1}$ & $\boldsymbol{l}^{t+1}$ & $\boldsymbol{Y}^{t+1}$ & Предусловие \\
$B-y$ & $b_{t} ; S^{t}$ & $y$ & $Y^{t} ; \hat{y}_{t}$ & - \\
\hline$I-y$ & $b_{t} ; S^{t}$ & $l^{t}$ & $Y^{t} ; \hat{y}_{t}$ & $\hat{y}_{t-1} \in\{B-y, I-y\}$ \\
\hline$O$ & $S^{t}$ & $l^{t}$ & $Y^{t} ; \hat{y}_{t}$ & - \\
\hline
\end{tabular}

Исходя из предложенной формы конфигурации $c$ и правил ее изменения, предлагается использовать $\phi\left(c_{t}\right)$ следующего вида:

$$
\phi\left(c_{t}\right)=\left[B_{t}, \ldots, B_{t+M_{B}}, S_{1}^{t-1}, \ldots, S_{M_{S}}^{t-1}, Y_{t-1}^{t-1}, Y_{t-2}^{t-1} E_{l^{t}}\right],
$$

где $B_{i}-i$-й элемент буфера $B$;

$S_{j}^{t}-j$-й элемент стека $S$ на шаге $t$;

$E_{k}-k$-я строка матрицы $E$;

$Y_{n}^{t}-n$-й элемент последовательности меток на шаге $t$.

В качестве элементов буфера используются скрытые состояния, получаемые из последнего слоя многослойной двунаправленной LSTM. Так, каждый элемент в буфере будет содержать информацию не только о слове на соответствующей позиции, но и о предшествующем и последующих контекстах. Авто- 
ры полагают, что информация о словах из стека найденных сущностей будет способствовать корректному обнаружению начала последующих сущностей. Например, найденный аспект «время жизни от батареи» может подсказать модели, что следующее слово «отличное» является оценочным высказыванием. Кроме того, дополнительной подсказкой является метка предыдущей найденной сущности $l^{t+1}$. Признаками для $l$ являются строки матрицы $E \in \mathbb{R}^{2 \times d}$. Входными данными для LSTM являются векторные представления слов, полученные с помощью модели FastText [23]. В данной работе использовались предобученные векторные представления ${ }^{2}$.

При вычислении вероятностей классов $P\left(\hat{y}_{t} \mid \phi\left(c_{t}\right)\right)_{i}$ рассчитываются только вероятности меток класса, которые не противоречат предусловиям из таблицы 2. Это позволяет избежать получения некорректной последовательности предсказаний.

\section{3. Алгоритм разметки последовательности}

Исходя из вышесказанного, алгоритм разметки последовательности можно представить следующим образом.

Пусть исходный текст задан в виде последовательности слов $W\left\{w_{1}, w_{2}, \ldots, w_{n}\right\}$. Требуется определить выходную последовательность меток слов $Y\left\{y_{1}, y_{2} \ldots, y_{n}\right\}$. Для обучения модели используется алгоритм оптимизации Adam [24] с параметрами $l r=0,001, \beta_{1}=0,9, \beta_{2}=0,999$ и нормировкой градиента на уровне 3,0 .

Шаг 1. Инициализируем начальное состояние $B=\varnothing, C=\varnothing, l=0, Y=\varnothing, t=0$.

Шаг 2. Наполняем буфер скрытыми представлениями входной последовательности, полученными с помощью сети LSTM: $\forall t B_{t}=\operatorname{LSTM}\left(w_{t}, B_{t-1}\right)$.

Шаг 3. Если $t<n$, то переход на шаг 4, иначе переход на шаг 6.

Шаг 4. Формируем вектор признаков $\phi\left(c_{t}\right)$ и определяем тег для текущей позиции в буфере: $\hat{y}_{t}=\arg \max P\left(\hat{y}_{t} \mid \phi(t)\right)$.

Шаг 4. Изменяем $S, i, Y$ в соответствии с правилами из таблицы 2 в зависимости от метки $\hat{y}_{t}$.

Шаг 5. $t=t+1$, переход на шаг 3.

Шаг 6. Конец.

Результаты работы предложенных модели и алгоритма на примере обработки отзывов о мобильных телефонах из интернет-магазина Amazon приведены

\footnotetext{
${ }^{2}$ Источник: https://github.com/plasticityai/magnitude
}

в таблище 3. Например, в предложении из отзыва на мобильный телефон «The screen is fantastically large while the overall dimensions of the phone are manageable for those without giant hands» были извлечены мнения «screen is fantastically large» $И$ «dimensions of the phone are manageable».

Таблица 3.

Мнения, извлеченные из отзывов на мобильные телефоны

\begin{tabular}{c|l} 
Toвар & \multicolumn{1}{c}{ Мнения } \\
$\begin{array}{c}\text { Sony } \\
\text { Xperia XA }\end{array}$ & $\begin{array}{l}\text { Phone is awesome; phone is easy to use; phone is perfect } \\
\text { for those who need extra storage; battery life is mediocre; } \\
\text { battery life is absolutely terrible compared; no great sound }\end{array}$ \\
\hline $\begin{array}{c}\text { Apple } \\
\text { iPhone 6S }\end{array}$ & $\begin{array}{l}\text { It didn't work properly from the beginning; it's a decent; } \\
\text { bad charger; worry free product }\end{array}$ \\
\hline $\begin{array}{c}\text { Huawei } \\
\text { P20 }\end{array}$ & $\begin{array}{l}\text { Phone is a flagship performer; phone stopped receiving } \\
\text { phone calls; phone is absolutely amazing for the price; } \\
\text { the screen is fantastically large; camera is simply } \\
\text { amazing; fantastic camera; camera produces great photos }\end{array}$ \\
\hline
\end{tabular}

Кроме того, на базе размеченного набора данных были обработаны мнения пользователей о других категориях товаров (таблица 4). Результаты апробации позволяют говорить о том, что модель показала хорошие результаты как для извлечения мнений о мобильных телефонах, так и о товарах других категорий.

\section{Таблииа 4.}

\section{Мнения, извлеченные из отзывов на товары других категорий}

\begin{tabular}{c|c} 
Toвap & \multicolumn{1}{c}{ Mнения } \\
$\begin{array}{c}\text { EltaMD PM } \\
\text { Therapy Facial } \\
\text { Moisturizer }\end{array}$ & $\begin{array}{l}\text { Is a great night cream product; product highly } \\
\text { emollient without being greasy; product } \\
\text { recommended by my dermatologist; very } \\
\text { moisturized skin feel }\end{array}$ \\
\hline $\begin{array}{c}\text { Samsung } \\
\text { 55-Inch 4K Ultra HD } \\
\text { Smart LED TV }\end{array}$ & $\begin{array}{l}\text { Easy setup TV; TV is not worth the money or } \\
\text { remote is easy to use; remote is ergonomic and } \\
\text { a breeze to use; color is unbelieveable }\end{array}$ \\
\hline $\begin{array}{c}\text { Fire 7 } \\
\text { Tablet with Alexa }\end{array}$ & $\begin{array}{l}\text { Small tablet; amazing little tablet; screen does } \\
\text { not react well to water; screen is freezing; battery } \\
\text { doesn't hold a charge; battery dies to quickly; } \\
\text { charging port its weakness }\end{array}$ \\
\hline
\end{tabular}

\section{4. Экспериментальные исследования модели}

Экспериментальные исследования предложенной модели проводились в сравнении с моделью на основе двунаправленной LSTM и CRF из работы [22], без использования знаковых представлений. Модели обучались методом обратного распростра- 
Результаты извлечения мнений из набора данных

Таблица 5. о мобильных телефонах (строгое соответствие)

\begin{tabular}{|c|c|c|c|c|c|c|}
\hline \multirow{2}{*}{ Модель } & \multicolumn{3}{|c|}{ Аспекты } & \multicolumn{3}{|c|}{ Оценочные высказывания } \\
\hline & $\mathbf{R}$ & $\mathbf{P}$ & F1 & $\mathbf{R}$ & $\mathbf{P}$ & F1 \\
\hline $\mathrm{Bi}-\mathrm{LSTM}+\mathrm{CRF}$ & 39,20 & 50,58 & 44,17 & 41,30 & 54,03 & 46,82 \\
\hline Предложенная модель & 47,87 & 49,51 & 48,68 & 49,70 & 52,93 & 52,26 \\
\hline
\end{tabular}

Результаты извлечения мнений из набора данных о мобильных телефонах (мягкое соответствие)

\begin{tabular}{|c|c|c|c|c|c|c|}
\hline \multirow{2}{*}{ Модель } & \multicolumn{3}{|c|}{ Аспекты } & \multicolumn{3}{|c|}{ Оценочные высказывания } \\
\hline & $\mathbf{R}$ & $\mathbf{P}$ & $\mathbf{F 1}$ & $\mathbf{R}$ & $\mathbf{P}$ & $\mathbf{F 1}$ \\
\hline $\mathrm{Bi}-\mathrm{LSTM}+\mathrm{CRF}$ & 53,93 & 63,05 & 57,83 & 56,09 & 64,93 & 60,19 \\
\hline Предложенная модель & 61,08 & 62,74 & 61,9 & 62,49 & 64,98 & 63,71 \\
\hline
\end{tabular}

нения ошибки. Для оптимизации параметров использовался алгоритм Adam [24] с параметрами $l$ $r=0,001, \beta_{1}=0,9, \beta_{2}=0,999$ и нормировкой градиента на уровне 3,0 .

Для извлечения пользовательских мнений использовался описанный в разделе 1 набор данных. Из-за небольшого объема данных оценки рассчитывались процедурой скользящего контроля с разбиением на пять выборок. Для исключения влияния лексики из обучающей выборки на проверочную выборки для скользящего контроля разделялись на уровне отдельных документов.

B модели CRF и предлагаемой модели использовалась двухслойная двунаправленная LSTM со скрытым состоянием из 100 элементов, на вход которой подавались фиксированные векторы размера 100. Для задания конкретного вида функции $\phi(t)$ в качестве исходных были использованы следующие значения гиперпараметров: $C_{B T}=2, C_{S T}=$ $4, e_{\text {label }} \in \mathbb{R}^{20}$.

При проведении эксперимента использовались стандартные для такого типа задач критерии: точность (precision), полнота (recall) и F-мера (F1measure), определяющая общее качество модели. Численные значения критериев рассчитывались двумя способами: строгим (strict) - когда совпадение засчитывается только в случае полного соответствия найденных спанов с истинными; мягким когда соответствие засчитывается, если истинный и найденный спан имеют хотя бы одно общее слово.
Анализ таблии, 5 и 6 показывает, что для обоих способов расчета критериев предлагаемая модель демонстрирует лучшие по сравнению с моделью на основе Bi-LSTM и CRF результаты. Для строгого соответствия улучшение обнаружения спанов аспектов составляет $4,51 \%$, а спанов оценочных высказываний $-5,44 \%$. Для мягкого соответствия улучшение обнаружения спанов аспектов составляет $3,77 \%$, а спанов оценочных высказываний $3,52 \%$

\section{Заключение}

Предложенный подход, как совокупность размеченного набора данных и модели структурного предсказания с использованием рекуррентной сети типа LSTM, позволяет извлекать из текстов отзывов покупателей мнения о потребительских свойствах как товара в целом, так и его отдельных элементов. Разработанная модель структурного предсказания с использованием рекуррентной нейронной сети способна использовать нелокальные признаки для предсказания сущностей и не требует использования дополнительных синтаксических признаков.

Модель, обученная на наборе данных, показала лучшие по сравнению с моделью на основе CRF результаты: F1 для аспектов выше на 4,51\%, F1 для оценочных высказываний выше на 5,44\%. Экспериментальные исследования показали, что введение дополнительных признаков в базовую модель положительным образом влияет на результаты. 
Полученные результаты могут быть полезны специалистам в области обработки естественного языка и компьютерной лингвистики, а также бизнес-сообществу при реализации товаров и услуг и развитии их потребительских свойств.

Вопросы предсказания связей между аспектами и оценочными высказываниями для улучшения качества извлекаемых мнений, а также внесение в разметку информации о тональности мнений и принадлежности аспекта главному объекту отзыва и кореференции будут рассмотрены в последующих работах.

\section{Литература}

1. Sadegh M., Ibrahim R., Othman Z.A. Opinion mining and sentiment analysis: A survey // International Journal of Computers \& Technology. 2012. Vol. 2. No. 3. P. 171-178.

2. Zhang L., Wang S., Liu B. Deep learning for sentiment analysis: A survey // Wiley Interdisciplinary Reviews: Data Mining and Knowledge Discovery. 2018. Vol. 8. No. 4. P. 1942-4787.

3. SemEval-2016 task 5: Aspect based sentiment analysis / Pontiki M. [et al.] // Proceedings of the 10th International Workshop on Semantic Evaluation (SemEval-2016). San Diego, CA, USA, 16-17 June 2016. P. 19-30.

4. Jo Y., Oh A.H. Aspect and sentiment unification model for online review analysis // Proceedings of the Fourth ACM International Conference on Web Search and Data Mining (WSDM 2011). Hong Kong, China, 9-12 February 2011. P. 815-824.

5. Zirn C., Niepert M., Stuckenschmidt H., Strube M. Fine-grained sentiment analysis with structural features // Proceedings of 5th International Joint Conference on Natural Language Processing (IJCNLP 2011). Chiang Mai, Thailand, 8-13 November 2011. P. 336-344.

6. Yang B., Cardie C. Extracting opinion expressions with semi-Markov conditional random fields // Proceedings of the 2012 Joint Conference on Empirical Methods in Natural Language Processing and Computational Natural Language Learning (EMNLP-CoNLL 2012). Jeju Island, Korea, 12-14 July 2012. P. 1335-1345.

7. Yang B., Cardie C. Joint inference for fine-grained opinion extraction // Proceedings of the 51st Annual Meeting of the Association for Computational Linguistics. Sofia, Bulgaria, 4-9 August 2013. Vol. 1. P. 1640-1649.

8. Natural language processing (almost) from scratch / Collobert R. [et al.] // Journal of Machine Learning Research. 2011. No. 12. P. 24932537.

9. Zhai F., Potdar S., Xiang B., Zhou B. Neural models for sequence chunking // Proceedings of the Thirty-First Conference on Artificial Intelligence (AAAI-17). San Francisco, CA, USA, 4-9 February 2017. P. 3365-3371.

10. Klinger R., Cimiano P. The USAGE review corpus for fine-grained, multi-lingual opinion analysis // Proceedings of the Language Resources and Evaluation Conference (LREC 2014). Reykjavik, Iceland, 26-31 May 2014. P. 2211-2218.

11. He R., McAuley J. Ups and downs: Modeling the visual evolution of fashion trends with one-class collaborative filtering // Proceedings of the 25th International Conference on World Wide Web (WWW 2016). Montreal, Canada, 11-15 April 2016. P. 507-517.

12. Sang E.F., Veenstra J. Representing text chunks // Proceedings of the Ninth Conference on European Chapter of the Association for Computational Linguistics (EACL 1999). Bergen, Norway, 8-12 June 1999. P. 173-179.

13. Recurrent neural network based language model / Mikolov T. [et al.] // Proceedings of the Eleventh Annual Conference of the International Speech Communication Association (INTERSPEECH 2010). Makuhari, Chiba, Japan, 26-30 September 2010. Vol. 2. P. 1045-1048.

14. Ghosh M., Sanyal G. Document modeling with hierarchical deep learning approach for sentiment classification // Proceedings of the 2nd International Conference on Digital Signal Processing (ICDSP 2018). Tokyo, Japan, 25-27 February 2018. P. 181-185.

15. Graves A., Jaitly N., Mohamed A. Hybrid speech recognition with deep bidirectional LSTM // Proceedings of the IEEE Workshop on Automatic Speech Recognition and Understanding (ASRU 2013). Olomouc, Czech Republic, 8-12 December 2013. P. $273-278$.

16. Robust online time series prediction with recurrent neural networks / Guo T. [et al.] // Proceedings of the IEEE International Conference on Data Science and Advanced Analytics (DSAA 2016). Montreal, Canada, 17-19 October 2016. P. 816-825.

17. Hochreiter S., Schmidhuber J. Long short-term memory // Neural Computation. 1997. Vol. 9. No. 8. P. 1735-1780.

18. Bengio Y., Simard P., Frasconi P. Learning long-term dependencies with gradient descent is difficult // IEEE Transactions on Neural Networks. 1994. Vol. 5. No. 2. P. 157-166.

19. Lafferty J., McCallum A., Pereira F.C.N. Conditional random fields: Probabilistic models for segmenting and labeling sequence data // Proceedings of the 18th International Conference on Machine Learning (ICML 2001). Williamstown, MA, USA, 28 June - 1 July 2001. P. 282-289.

20. Chen D., Manning C.D. A fast and accurate dependency parser using neural networks // Proceedings of the 19th Conference on Empirical Methods in Natural Language Processing (EMNLP 2014). Doha, Qatar, $25-29$ October 2014. P. 740-750.

21. Transition-based dependency parsing with stack long short-term memory / Dyer C. [et al.] // Proceedings of the 53rd Annual Meeting of the Association for Computational Linguistics and the 7th International Joint Conference on Natural Language Processing. Beijing, China, 27-31 July 2015. Vol. 1. P. 334-343.

22. Neural architectures for named entity recognition / Lample G. [et al.] // Proceedings of the 15th Annual Conference of the North American Chapter of the Association for Computational Linguistics: Human Language Technologies (NAACL HTL 2016). San Diego, CA, USA, 12-17 June 2016. P. 260-270.

23. Bojanowski P., Grave E., Joulin A., Mikolov T. Enriching word vectors with subword information // Transactions of the Association for Computational Linguistics. 2017. No. 5. P. 135-146.

24. Kingma D.P., Ba J.L. Adam: A method for stochastic optimization // arXiv:1412.6980v9 [cs. LG]. 2017. [Электронный ресурс]: https:// arxiv.org/pdf/1412.6980.pdf (дата обращения 10.10.2018). 


\title{
User opinion extraction model concerning consumer properties of products based on a recurrent neural network ${ }^{3}$
}

\section{Yuri P. Yekhlakov}

Professor, Department of Data Processing Automation

Tomsk State University of Control Systems and Radioelectronics

Address: 40, Prospect Lenina, Tomsk, 634050, Russia

E-mail:upe@tusur.ru

\section{Egor I. Gribkov}

Doctoral Student, Department of Data Processing Automation

Tomsk State University of Control Systems and Radioelectronics

Address: 40, Prospect Lenina, Tomsk, 634050, Russia

E-mail:drnemor@gmail.com

\begin{abstract}
This article offers a long short-term memory (LSTM) based structured prediction model taking into account existing approaches to sequence tagging tasks and allowing for extraction of user opinions from reviews. We propose a model configuration and state transition rules which allow us to use past predictions of the model alongside sentence features. We create a body of annotated user reviews about mobile phones from Amazon for model training and evaluation. The model trained on reviews corpus with recommended hyperparameter values. Experiment shows that the proposed model has a $4.51 \%$ increase in the $\mathrm{F} 1$ score for aspects detection and a $5.44 \%$ increase for aspect descriptions compared to the conditional random field (CRF) model with the use of LSTM when F1 spans are matched strictly.

The extraction of user opinions on mobile phones from reviews outside of the collected corpus was conducted as practical confirmation of the proposed model. In addition, opinions from other product categories like skin care products, TVs and tablets were extracted. The examples show that the model can successfully extract user opinions from different kinds of reviews. The results obtained can be useful for computational linguists and machine learning professionals, heads and managers of online stores for consumer preference determination, product recommendations and for providing rich catalog searching tools.
\end{abstract}

Key words: user feedback; deep learning; machine learning; natural language processing; opinion processing.

Citation: Yekhlakov Yu.P., Gribkov E.I. (2018) User opinion extraction model concerning consumer properties of products based on a recurrent neural network. Business Informatics, no. 4 (46), pp. 7-16. DOI: 10.17323/1998-0663.2018.4.7.16

\section{References}

1. Sadegh M., Ibrahim R., Othman Z.A. (2012 Opinion mining and sentiment analysis: A survey. International Journal of Computers \& Technology, vol. 2, no. 3, pp. 171-178.

2. Zhang L., Wang S., Liu B. (2018) Deep learning for sentiment analysis: A survey. Wiley Interdisciplinary Reviews: Data Mining and Knowledge Discovery, vol. 8, no. 4, pp. 1942-4787.

3. Pontiki M., Galanis D., Papageorgiou H., Androutsopoulos I., Manandhar S., Mohammad Al-S., Al-Ayyoub M., Zhao Y., Qin B., De Clercq O. (2016) SemEval-2016 task 5: Aspect based sentiment analysis. Proceedings of the 10th International Workshop on Semantic Evaluation (SemEval-2016). San Diego, CA, USA, 16-17 June 2016, pp. 19-30.

4. Jo Y., Oh A.H. (2011) Aspect and sentiment unification model for online review analysis. Proceedings of the Fourth ACM International Conference on Web Search and Data Mining (WSDM 2011). Hong Kong, China, 9-12 February 2011, pp. 815-824.

5. Zirn C., Niepert M., Stuckenschmidt H., Strube M. (2011) Fine-grained sentiment analysis with structural features. Proceedings of 5th International Joint Conference on Natural Language Processing (IJCNLP 2011). Chiang Mai, Thailand, 8-13 November 2011, pp. 336-344.

\footnotetext{
${ }^{3}$ This study was conducted under government order of the Ministry of Education and Science of Russia, project No. 8.8184.2017/8.9
} 
6. Yang B., Cardie C. (2012) Extracting opinion expressions with semi-Markov conditional random fields. Proceedings of the 2012 Joint Conference on Empirical Methods in Natural Language Processing and Computational Natural Language Learning (EMNLP-CoNLL 2012). Jeju Island, Korea, 12-14 July 2012, pp. 1335-1345.

7. Yang B., Cardie C. (2013) Joint inference for fine-grained opinion extraction. Proceedings of the 51st Annual Meeting of the Association for Computational Linguistics. Sofia, Bulgaria, 4-9 August 2013. Vol. 1, pp. 1640-1649.

8. Collobert R., Weston J., Bottou L., Karlen M., Kavukcuoglu K., Kuksa P. (2011) Natural language processing (almost) from scratch. Journal of Machine Learning Research, no. 12, pp. 2493-2537.

9. Zhai F., Potdar S., Xiang B., Zhou B. (2017) Neural models for sequence chunking. Proceedings of the Thirty-First Conference on Artificial Intelligence (AAAI-17). San Francisco, CA, USA, 4-9 February 2017, pp. 3365-3371.

10. Klinger R., Cimiano P. (2014) The USAGE review corpus for fine-grained, multi-lingual opinion analysis. Proceedings of the Language Resources and Evaluation Conference (LREC 2014). Reykjavik, Iceland, 26-31 May 2014, pp. 2211-2218.

11. He R., McAuley J. (2016) Ups and downs: Modeling the visual evolution of fashion trends with one-class collaborative filtering. Proceedings of the 25th International Conference on World Wide Web (WWW 2016). Montreal, Canada, 11-15 April 2016, pp. $507-517$.

12. Sang E.F., Veenstra J. (1999) Representing text chunks. Proceedings of the Ninth Conference on European Chapter of the Association for Computational Linguistics (EACL 1999). Bergen, Norway, 8-12 June 1999, pp. 173-179.

13. Mikolov T., Karafiat M., Burget L., Cernocky J., Khudanpur S. (2010) Recurrent neural network based language model. Proceedings of the Eleventh Annual Conference of the International Speech Communication Association (INTERSPEECH 2010). Makuhari, Chiba, Japan, 26-30 September 2010, vol. 2, pp. 1045-1048.

14. Ghosh M., Sanyal G. (2018) Document modeling with hierarchical deep learning approach for sentiment classification. Proceedings of the 2nd International Conference on Digital Signal Processing (ICDSP 2018). Tokyo, Japan, 25-27 February 2018, pp. 181-185.

15. Graves A., Jaitly N., Mohamed A. (2013) Hybrid speech recognition with deep bidirectional LSTM. Proceedings of the IEEE Workshop on Automatic Speech Recognition and Understanding (ASRU 2013). Olomouc, Czech Republic, 8-12 December 2013 , pp. $273-278$.

16. Guo T., Xu Z., Yao X., Chen H., Aberer K., Funaya K. (2016) Robust online time series prediction with recurrent neural networks. Proceedings of the IEEE International Conference on Data Science and Advanced Analytics (DSAA 2016). Montreal, Canada, 17-19 October 2016, pp. 816-825.

17. Hochreiter S., Schmidhuber J. (1997) Long short-term memory. Neural Computation, vol. 9, no. 8, pp. 1735-1780.

18. Bengio Y., Simard P., Frasconi P. (1994) Learning long-term dependencies with gradient descent is difficult. IEEE Transactions on Neural Networks, vol. 5, no. 2, pp. 157-166.

19. Lafferty J., McCallum A., Pereira F.C.N. (2001) Conditional random fields: Probabilistic models for segmenting and labeling sequence data. Proceedings of the 18th International Conference on Machine Learning (ICML 2001). Williamstown, MA, USA, 28 June - 1 July 2001, pp. $282-289$.

20. Chen D., Manning C.D. (2014) A fast and accurate dependency parser using neural networks. Proceedings of the 19th Conference on Empirical Methods in Natural Language Processing (EMNLP 2014). Doha, Qatar, 25-29 October 2014, pp. 740-750.

21. Dyer C., Ballesteros M., Ling W., Matthews A., Smith N.A. (2015) Transition-based dependency parsing with stack long short-term memory. Proceedings of the 53rd Annual Meeting of the Association for Computational Linguistics and the 7th International Joint Conference on Natural Language Processing. Beijing, China, 27-31 July 2015, vol. 1, pp. 334-343.

22. Lample G., Ballesteros M., Subramanian S., Kawakami K., Dyer C. (2016) Neural architectures for named entity recognition. Proceedings of the 15th Annual Conference of the North American Chapter of the Association for Computational Linguistics: Human Language Technologies (NAACL HTL 2016). San Diego, CA, USA, 12-17June 2016, pp. 260-270.

23. Bojanowski P., Grave E., Joulin A., Mikolov T. (2017) Enriching word vectors with subword information. Transactions of the Association for Computational Linguistics, no. 5, pp. 135-146.

24. Kingma D.P., Ba J.L. (2017) Adam: A method for stochastic optimization. arXiv:1412.6980v9 [cs. LG]. Available at: https://arxiv.org/pdf/1412.6980.pdf (accessed 10 October 2018). 


\title{
Применение сверточных нейронных сетей для решения задачи оперативного прогнозирования динамики распространения лесных пожаров 1
}

\author{
Т.С. Станкевич \\ кандидат технических наук \\ доцент кафедры техносферной безопасности \\ Калининградский государственный технический университет \\ Адрес: 236022, г. Калининград, Советский проспект, д. 1 \\ E-mail:tatiana.stankevich@klgtu.ru
}

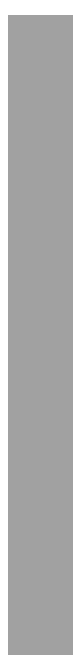

\section{Аннотация}

Работа посвящена актуальной задаче повышения эффективности оперативного прогнозирования динамики развития лесных пожаров. Для решения данной задачи предложено разработать метод оперативного прогнозирования динамики развития лесного пожара при нестационарности и неопределенности на базе перспективных информационных технологий - искусственного интеллекта и глубокого машинного обучения (сверточной нейронной сети). В рамках исследования выполнен анализ современных отечественных и зарубежных моделей прогнозирования распространения лесного пожара и выявлены основные ограничения применения моделей в условиях реального пожара (высокая степень динамичности и неопределенности входных параметров, необходимость обеспечения минимального времени сбора и ввода входных параметров, а также минимального времени отклика модели). На базе полученных результатов обоснована необходимость применения инструментария искусственных нейронных сетей для решения проблемы прогнозирования динамики распространения лесного пожара. Разработана общая логическая схема метода оперативного прогнозирования динамики лесных пожаров, главной особенностью которого является построение дерева сверточных нейронных сетей. Для повышения качества обучения сверточной нейронной сети, реализующей функцию прогнозирования распространения лесного пожара, предложено формирование базы данных о динамике лесных пожаров.

Ключевые слова: лесной пожар; база данных; визуальные данные; искусственный интеллект; глубокое машинное обучение; сверточная нейронная сеть; большие данные; оперативный прогноз.

Цитирование: Станкевич Т.С. Применение сверточных нейронных сетей для решения задачи оперативного прогнозирования динамики распространения лесных пожаров // Бизнес-информатика. 2018. № 4 (46).

C. 17-27. DOI: $10.17323 / 1998-0663.2018 .4 .17 .27$

\section{Введение}

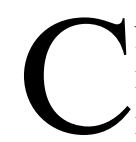
ущественный негативный эффект от лесных пожаров для Российской Федерации наглядно подтверждает статистика Рослес- хоза, представленная в системе ЕМИСС 2 В соответствии со статистикой за период с 2009 по 2017 годы, наблюдается рост площади лесных земель, пройденной лесными пожарами, на $27,92 \%$. За период с 2013 по 2017 годы рост расходов, связан-

\footnotetext{
1 Исследование выполнено при финансовой поддержке Российского фонда фундаментальных исследований, проект № 18-37-00035 «О зависимости динамики развития лесного пожара от влияния факторов окружающей среды, характера лесных насаждений и вида пожара при нестационарности и неопределенности»

${ }^{2}$ https://www.fedstat.ru/organizations/
} 
ных с охраной, защитой и восстановлением лесов, относящихся к лесному фонду Российской Федерации, составил 22,32\%. При этом вышеуказанная динамика показателей наблюдается на фоне снижения общего количества лесных пожаров на территории страны.

Согласно статистике лесных пожаров в Европе, представленной Европейской информационной системой лесных пожаров (EFFIS) [1], за период с 2009 по 2016 годы наблюдается сокращение общего количества лесных пожаров в пяти южных государствах - членах Европейского союза (Португалии, Испании, Франции, Италии и Греции) на $39,8 \%$. Также отмечается снижение общей площади лесных земель, пройденной лесными пожарами, в этих странах на 4,6\%. Однако общая площадь лесных земель, пройденная лесными пожарами, в 2016 году составила 316866 га, что превышает значения предыдуших лет (с 2013 по 2015 годы), а количество лесных пожаров составило 31751 , что ниже долгосрочных средних значений показателя и несколько ниже, чем в предыдущем 2015 году (38 171 пожар), но выше, чем в 2014 году (23 425 пожаров).

Согласно статистическим данным о лесных пожарах в Соединенных Штатах Америки, представленных Национальными центрами экологической информации Национального управления океанических и атмосферных исследований (NCEI NOAA) ${ }^{3}$, за период с 2009 по 2017 годы число пожаров сократилось на 14,5\%, а площадь лесных земель, пройденная лесными пожарами, увеличилась на $65,4 \%$.

Хотя статистические данные значительно варьируются от года к году (что наглядно показывает, насколько лесные пожары зависят от сезонных метеорологических условий), глобальная статистика лесных пожаров демонстрирует аналогичную динамику: уменьшение количества лесных пожаров, увеличение количества районов, пострадавших от лесных пожаров, и увеличение материальных затрат, связанных с лесными пожарами.

Таким образом, задача предупреждения, локализации и ликвидации лесных пожаров как для Российской Федерации, так и для других государств является крайне важной.

Одним из важнейших элементов решения данной задачи является оперативное прогнозирование

\footnotetext{
${ }^{3}$ https://www.ncdc.noaa.gov/sotc/
}

распространения лесного пожара. В настоящее время использование существующих моделей прогнозирования динамики лесных пожаров в сложных условиях реального пожара затруднено в связи с ограниченной функциональностью моделей при нестационарности и неопределенности.

Цель исследования - разработка метода оперативного прогнозирования динамики развития лесного пожара в сложных условиях (при неопределенности и нестационарности) с использованием искусственного интеллекта и глубокого машинного обучения. Для достижения поставленной цели необходимо:

обосновать необходимость применения инструментария искусственных нейронных сетей для решения проблемы прогнозирования динамики распространения лесного пожара;

^ разработать общую логическую схему метода оперативного прогнозирования динамики лесных пожаров;

^ создать базу визуальных данных о динамике развития лесных пожаров.

Данная работа является частью исследовательского проекта по выявлению фундаментальных зависимостей влияния факторов окружающей среды, характера лесных насаждений и вида пожара на динамику развития лесного пожара.

\section{1. Сверточная нейронная сеть как перспективный инструмент оперативного прогнозирования динамики распространения лесных пожаров}

Трудность моделирования пожара в лесу, согласно [2], обусловлена двумя основными причинами: чрезвычайной сложностью физического явления (пожара) из-за гетерогенного топлива и множества влияющих факторов окружающей среды (ветра, относительной влажности и т.п.), а также сложностью проведения натурных экспериментов для валидации разработанных моделей.

В настоящее время отечественными и зарубежными исследователями из разных областей науки разработан обширный набор моделей, базирующихся на различных методах и способах прогнозирования поведения пожара, для сведения к минимуму разрушительных последствий этой чрезвычайной ситуации природного характера [3-5]. 
При изучении моделей прогнозирования развития лесного пожара выявлено деление моделей по уровню моделирования на оперативные, тактические и стратегические [6]. Поскольку каждый уровень моделирования характеризуется определенной целью и соответствующим уровнем принимаемых управленческих решений, уровню соответствует собственный тип модели: для оперативного уровня разрабатываются оперативные модели, для тактического уровня - тактические, для стратегического уровня - стратегические.

Принято выделять следующие основные направления моделирования лесных пожаров [3-6]:

- эмпирические и квазиэмпирические модели, основанные на результатах статистического анализа полученных экспериментальным путем данных для определения статистических зависимостей между входными и выходными параметрами;

^ физические и квазифизические модели, основанные на методах фундаментальной химии и/или физики для описания протекающих при лесном пожаре процессов;

математические модели (в том числе имитационные и волновые модели), использующие формулы для описания динамики пожара, в ряде случаев с применением статистических данных.

Кроме того, по способу отображения результатов моделирования лесного пожара существующие модели делят на пространственные и непространственные. Также в зависимости от наличия или отсутствия среди параметров модели случайных величин выделяют детерминированные и стохастические модели прогнозирования. Поскольку для лесных пожаров характерны сложные условия (неопределенность и нестационарность), то наиболее перспективны стохастические модели.

В работах [3-5] представлены результаты анализа основных типов моделей распространения лесного пожара (эмпирических и квазиэмпирических, физических и квазифизических, математических и имитационных), разработанных с 1990 по 2007 годы. В работе [7] подробно изучены 3\% модель (3\% model), квазиэмпирическая модель Ротермеля (Rothermel model), модель Балби (Balbi model) и нестационарная модель Балби (Balbi non-stationary model). Работы $[8,9]$ посвящены различным моделям прогнозирования по-

\footnotetext{
${ }^{4}$ http://firegrowthmodel.ca

5 https://www.firelab.org/project/flammap

6 https://www.firelab.org/project/farsite
}

жаров в лесах: математической модели распространения поверхностных и верховых лесных пожаров и дискретной модели лесного пожара на верхней полуплоскости.

Некоторые из рассмотренных моделей интегрированы в компьютерные системы и широко применяются на практике. Например, в системах прогнозирования динамики лесных пожаров Prometheus $^{4}$ и FlamMap ${ }^{5}$ применены волновые модели пожара, где процесс горения описывается с помощью принципа Гюйгенса $[6,10]$, а скорость распространения пожара рассчитывается с использованием экспериментальных данных. На применении модели Ван Вагнера и квазиэмпирической модели Ротермеля базируется такая система прогнозирования динамики пожара, как FARSITE $^{6}[2]$.

Однако, несмотря на широкое разнообразие моделей прогнозирования динамики развития лесного пожара, в ходе анализа литературных источников, в которых рассматриваются особенности и функциональные возможности всех типов моделей [2-15], выявлены следующие ограничения, существенно влияющие на точность прогноза:

^ высокая степень динамичности входных параметров (динамически изменяющиеся во времени параметры рассматриваются как постоянные);

- значительная степень неопределенности входных параметров (невозможность получения ряда данных путем прямого измерения).

Кроме того, существенное влияние на возможность применения моделей в условиях реальных пожаров играет время сбора и ввода входных данных, а также время отклика модели. Минимизация этих временных характеристик является важной проблемой в процессе разработки и практического использования моделей.

Недавний прорыв в области информационных технологий, обеспечивший появление и активное совершенствование перспективных технологий, - искусственного интеллекта, систем обработки больших объемов данных и глубокого машинного обучения, - создали беспрецедентные возможности для улучшения пожарной безопасности лесов.

В настоящее время уже существуют и применяются как модели прогнозирования возникновения лесных пожаров, так и модели прогнозирования динамики развития пожаров на базе нейросетевых технологий (в качестве примера можно привести работы $[16,17])$. Хотя модели, использующие ис- 
кусственные нейронные сети, позволяют устранить ряд недостатков, присущих традиционным моделям, построение и практическое применение моделей базе нейросетевых технологий сопряжено с определенными трудностями. В первую очередь, следует отметить сложность сбора достаточного количества обучающих примеров при подготовке тестового и обучающего наборов данных. Кроме того, построение архитектуры сети характеризуется сложностью и трудноемкостью, а процедура обучения сети требует продолжительных временных затрат.

Учитывая вышеизложенные недостатки, предложено разработать метод оперативного прогнозирования динамики развития лесного пожара при нестационарности и неопределенности посредством применения сверточной нейронной сети (convolutional neural network, CNN). Сверточная нейронная сеть, являясь многослойной нейронной сетью, входит в состав технологий глубокого обучения и решает задачу распознавания шаблонов из визуальных данных $[18,19]$. Особенности построения и функционирования сверточных нейронных сетей подробно описаны в работах [18, 19].

Выбор сверточной нейронной сети обусловлен достоинствами данного типа сетей, выявленными в результате анализа отечественных и зарубежных источников $[18,19]$ : они являются высокоточными, устойчивыми к изменениям и искажениям входных данных, оперативными, способными выполнять самонастройку, позволяют реализовать распараллеливание высокопроизводительных вычислений и др. Кроме того, хотя традиционно сверточные нейронные сети применяются для решения задач распознавания и классификации (для классификации изображений, автоматического распознавания речи и др.), они также могут применяться прогнозирования, благодаря своим неоспоримым достоинствам.

Применение сверточной нейронной сети для оперативного прогнозирования динамики развития лесного пожара позволяет сформировать прогноз в сложных условиях (при неопределенности и нестационарности) и минимизировать временные затраты за счет распараллеливания высокопроизводительных вычислений. Таким образом, сверточная нейронная сеть является эффективным инструментом для получения оперативного прогноза распространения лесного пожара в случае применения в реальных условиях.

\section{2. Оперативное прогнозирование \\ динамики лесного пожара \\ в условиях нестационарности \\ и неопределенности \\ на основе сверточной нейронной сети}

В ходе исследования разработан метод оперативного прогнозирования динамики развитии лесного пожара в условиях нестационарности и неопределенности. Особенностью предлагаемого метода является выявление зависимостей влияния факторов окружающей среды, характера лесных насаждений и типа лесного пожара на динамику лесных пожаров с использованием сверточной нейронной сети.

Согласно работам [18, 19], идея функционирования сети CNN заключается в реализации последовательности переходов от конкретных особенностей визуальных входных данных к более абстрактным. Архитектура сети CNN характеризуется чередованием сверточных слоев (convolution layers) и субдискретизирующих слоев (subsampling layers). Основным предназначением сверточных слоев сети является реализация операции свертки (convolution) с последующим формированием карты признаков (feature map). Субдискретизирующие слои сети позволяют уменьшить размерность сформированных ранее карт признаков путем выбора максимального нейрона из ряда соседних нейронов карты и замены данным нейроном всей рассматриваемой совокупности нейронов. В качестве выходного слоя нейронов в сети CNN используются полносвязные слои (fully connected layers), где формируется полносвязная нейронная сеть.

Для разработки сверточной нейронной сети с целью формирования оперативного прогноза лесного пожара предложено использовать программное обеспечение CРython. При этом в качестве входных визуальных данных применена информация о распространении пожара, полученная в режиме реального времени в течение трех часов со спутника с помощью спектрорадиометра с умеренным разрешением (36-канальный спектрорадиометр MODIS, спутники Terra и Aqua) и видимого инфракрасного рентгенограммного набора (VIIRS).

C 1999 года по настоящее время MODIS является одним из самых широко используемых спутниковых инструментов для проведения глобальных и региональных исследований [20]. MODIS позволяет просматривать всю поверхность Земли каж- 
дые один или два дня в 36 спектральных полосах при умеренном разрешении в диапазоне от 0,25 км до 1 км для получения набора данных (температуры поверхности суши и океана, индексов растительности, данных о земном покрове, лесных пожарах, вулканах, облаках, аэрозолях и др.) [20]. VIIRS $^{7}$ - это 22-канальный радиометр, собирающий изображения в видимом, инфракрасном и ультрафиолетовом диапазонах $(0,45-12$ мкм) и осуществляющий радиометрию суши, атмосферы, криосферы и океанов. Пространственное разрешение данных VIIRS находится в диапазоне от 0,38-0,75 км (в надире) до 0,8-1,6 км (на краю зоны) в полосе съемки шириной 3000 км. Визуальные данные о распространении пожара доступны в системе управления ресурсами FIRMS (Fire Information for Resource Management System) NASA.

В рамках разработанного метода прогнозирования динамики лесных пожаров также предусмотрено использование данных о факторах окружающей среды (температуре воздуха, влажности воздуха, скорости ветра), данных о характере лесных насаждений (тип лесных насаждений) и данных о виде пожара. Визуальные данные о факторах окружающей среды получены с использованием Ventusky InMeteo9 ${ }^{9}$, данные о характере лесных насаждений - с использованием Land Cover Map ${ }^{10}$ Института изменения климата и Европейского космического агентства.

Существующая система наблюдения Земли NASA, а также другие глобальные системы позволяют получать достаточно оперативные и точные сведения различного характера о состоянии суши, воды и атмосферы планеты [21]. Эти сведения находятся в открытом доступе и, обогащая глобальное информационное пространство, широко используются для улучшения точности метеорологических прогнозов, мониторинга окружающей среды, контроля загрязнений и т.п.

Несмотря на достоинства аэрокосмической системы наблюдения Земли NASA и других глобальных систем, страны заинтересованы в создании национальных систем спутникового мониторинга. Например, в Мексике в 1999 году внедрена система обнаружения горячих точек (в качестве индикатора возможных лесных пожаров) с использованием

\footnotetext{
${ }^{7}$ https://jointmission.gsfc.nasa.gov/viirs.html

${ }^{8}$ https://firms.modaps.eosdis.nasa.gov/

9 https://www.ventusky.com/

${ }^{10} \mathrm{http}: / /$ maps.elie.ucl.ac.be/CCI/viewer/

${ }^{11}$ http://russianspacesystems.ru/bussines/bezopasnost/maksm/
}

дневных и ночных изображений с датчиков на спутниках NOAA, а в настоящее время рассматривается возможность создания национальной системы [21].

Данная проблема характерна и для Российской Федерации. В настоящее время в России планируется создание национальной аэрокомической системы наблюдения Земли - Многоцелевой аэрокосмической системы прогнозного мониторинга ${ }^{11}$. Однако на данный момент реальная альтернатива использования источников, отличных от использованных в данном исследовании, отсутствует.

В качестве выходных данных предлагаемый метод предусматривает формирование оперативного прогноза динамики развития пожара в виде визуального изображения - карты местности с выделенной областью с координатами области распространения пожара во времени.

Общая логическая схема разработанного метода оперативного прогнозирования динамики лесного пожара при нестационарности и неопределенности на базе сверточной нейронной сети представлена на рисунке 1.

Метод оперативного прогнозирования динамики лесных пожаров при нестационарности и неопределенности, основанный на сверточной нейронной сети, включает следующие этапы:

Этап 1 (ввод данных) - ввод визуальных данных;

Этап 2 (предварительная обработка) - предварительная обработка входных визуальных данных для исключения искаженных элементов входного изображения;

Этап 3 (построение и настройка сверточной нейронной сети) - построение сети с последующим обучением методом обратного распространения ошибки;

Этап 4 (оперативный прогноз лесного пожара) выявление зависимостей влияния факторов окружающей среды, характера лесных насаждений и вида пожара на динамику развития лесного пожара и (с применением выявленных зависимостей) формирование оперативного прогноза динамики лесного пожара.

Главной особенностью предложенного метода является построение дерева сверточных нейронных сетей как ориентированного ациклического графа для анализа значительного количества визуальных данных. Данный граф включает один корневой узел сеть CNN, выполняющий последний этап прогнозирования, и три промежуточных узла - сети CNNs, 


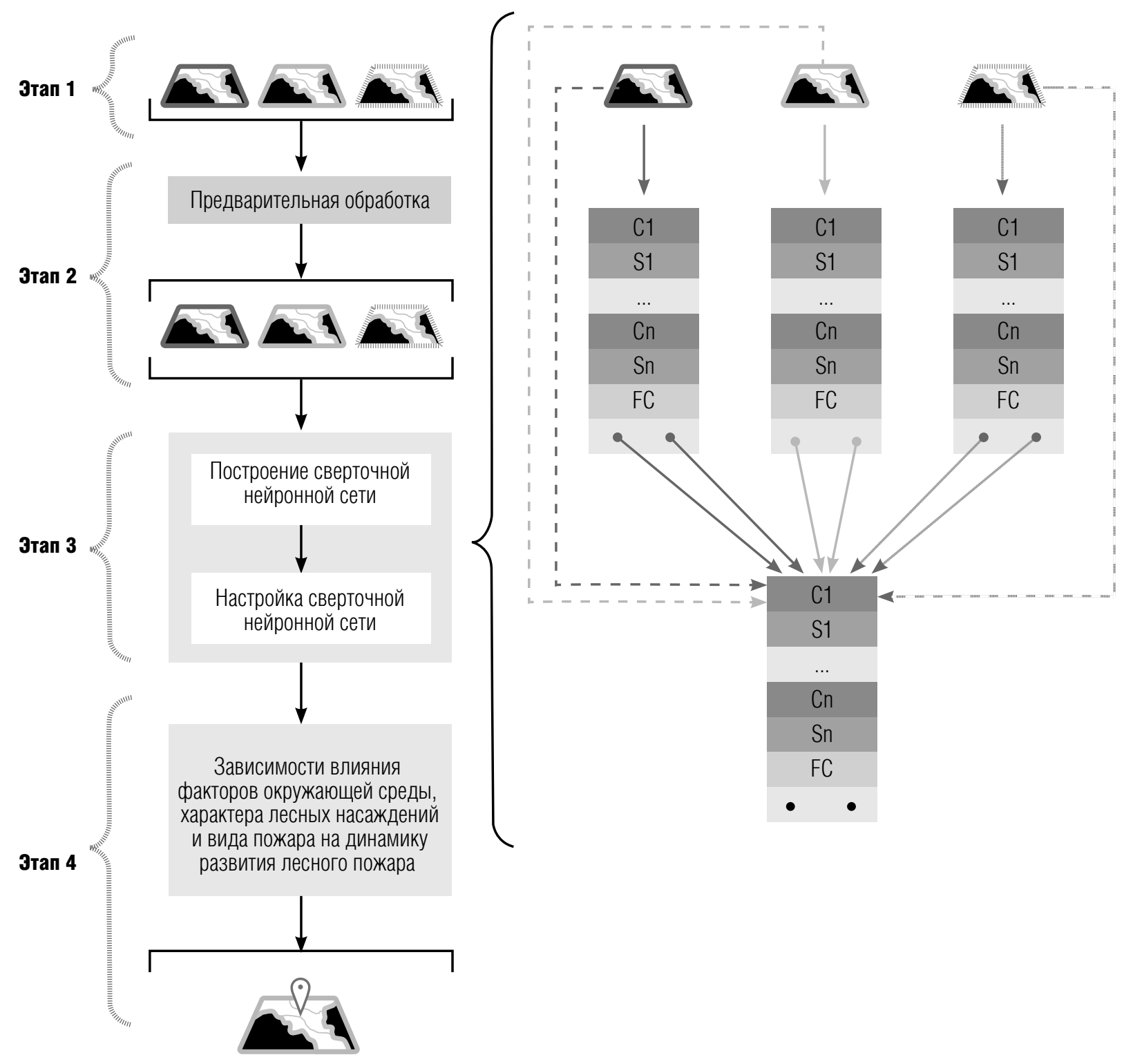

Pис. 1. Общая логическая схема метода оперативного прогнозирования динамики лесных пожаров (C1, Cn - слои свертки; S1, Sn - субдискретизирующие слои; FS - полносвязный слой)

где формируются зависимости влияния факторов окружающей среды, характера лесных насаждений и вида пожара на динамику развития лесного пожара.

Таким образом, выполнена разработка метода оперативного прогнозирования динамики лесных пожаров в условиях нестационарности и неопределенности на основе передовых информационных технологий - искусственного интеллекта и глубокого машинного обучения (сверточной нейронной сети). Этот тип сети позволяет анализировать визуальные данные, определять ключевые зависимости распространения лесного пожара от факторов окружающей среды, характера лесных насаждений и типа лесных пожаров и формировать оперативный прогноз развития пожара. Главной особенностью предложенного метода является построение дерева сверточных нейронных сетей.

\section{3. Построение визуальной базы данных о динамике лесных пожаров}

Поскольку качество сверточной нейронной сети зависит от набора данных, на базе которых производится построение и обучение сети, необходимо формирование соответствующей базы данных. Для этого выполнен анализ моделей баз данных (иерархической, сетевой, реляционной, постреля- 

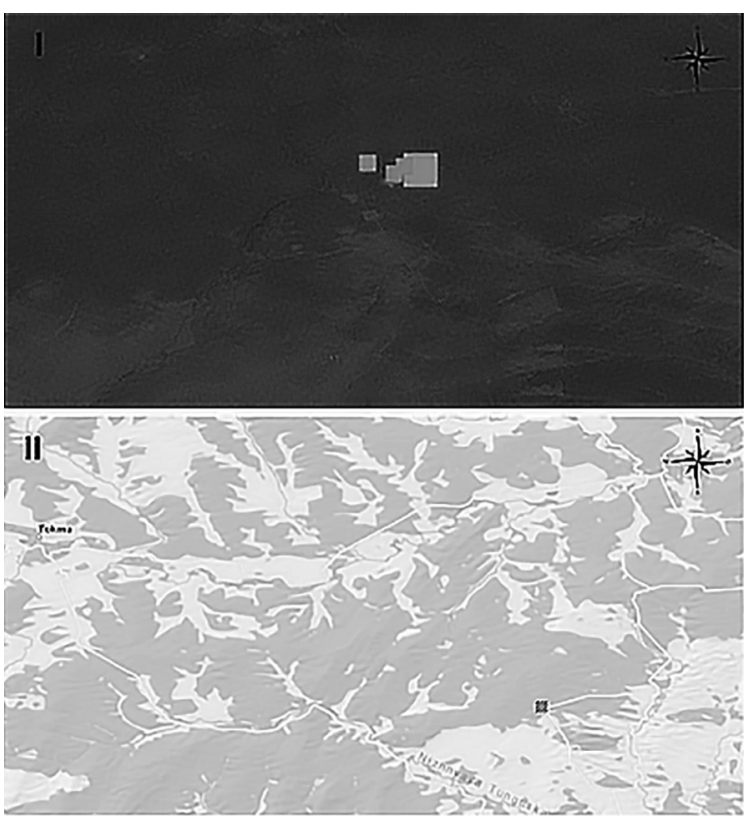

a)
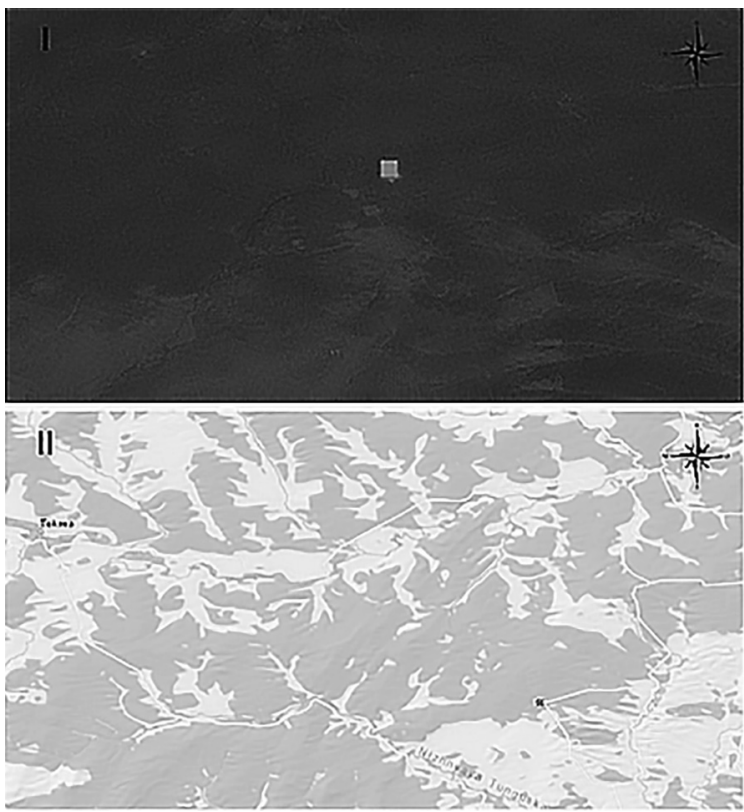
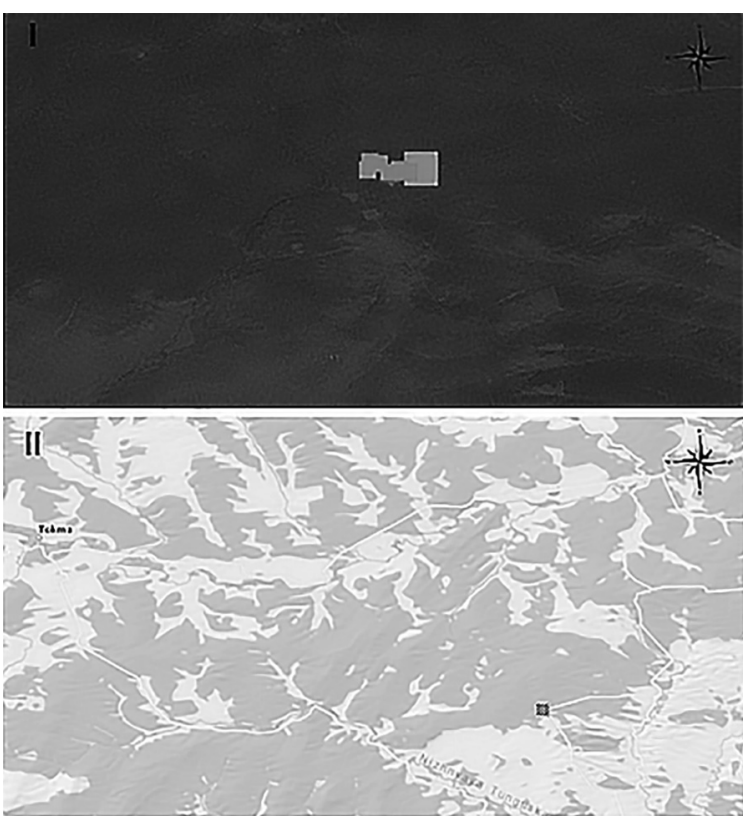

b)
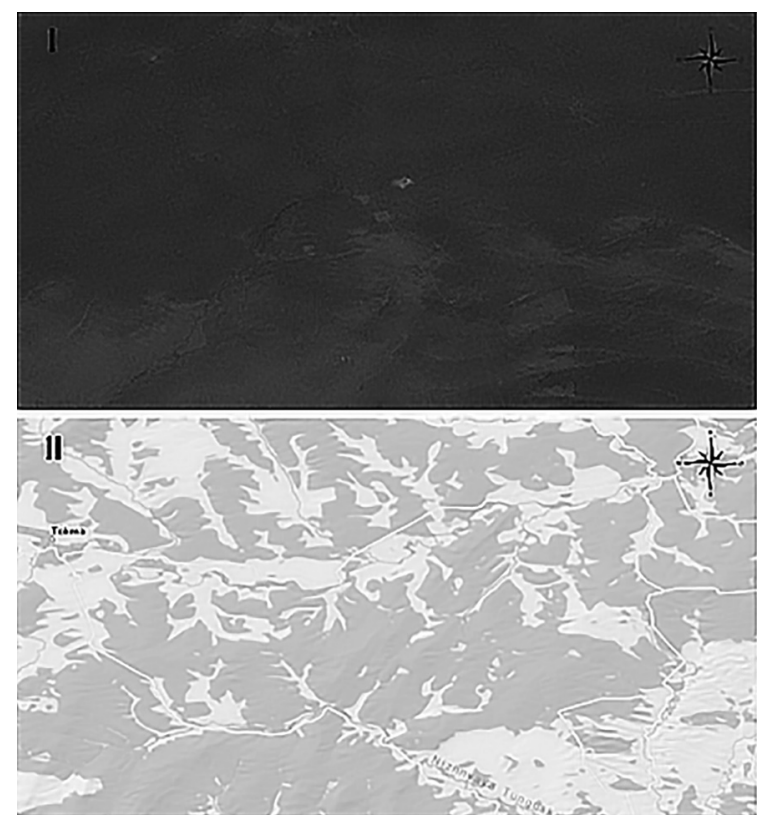

Рис. 2. Космоснимки территории, охваченной лесным пожаром

(вблизи села Токма, Иркутская область, РФ, 58¹5'36" с. ш. $105^{\circ} 52^{\prime 2} 24^{\prime \prime}$ в. д.):
a) 16:00 GMT, 11.05.2018; VIRS $375 \mathrm{~m}$
b) 12:30 GMT, 12.05.2018; VIRS 375 M;
c) 13:48 GMT, 13.05.2018; VIRS $375 \mathrm{M}$
d) 14:42 GMT, 21.05.2018; VIRS 375 M

ционной, объектно-ориентированной, многомерной и объектно-реляционной) с использованием метода экспертного ранжирования и модифицированного метода анализа иерархий. На основе требований к формируемой базе данных (большой объем данных, визуальные данные, возмож- ность быстрого построения/модификации базы с минимальными временными и вычислительными затратами, минимальные временные и вычислительные затраты при работе с базой) предложено разработать реляционную модель базы данных о динамике лесных пожаров. 
Выполнено построение базы визуальных данных о динамике развития лесных пожаров, элементами которой являются таблицы «Лесной пожар», «Факторы окружающей среды» и «Характер лесных насаждений». Таблица «Лесной пожар» предназначена для хранения и вывода в удобном для пользователя виде визуальных данных о развитии пожара во времени, таблица «Факторы окружающей среды» - визуальных данных о факторах окружающей среды, а таблица «Характер лесных насаждений» - визуальных данных о характере лесных насаждений. Созданная база данных охватывает период с 2018 года, а географически - все страны мира. Кроме того, данная база постоянно пополняется. Для оптимизации работы пользователей с базой выполнено формирование соответствующих форм и запросов.

Пример визуальных данных приведен на рисун$\kappa e ~ 2$, где представлено наглядное изменение динамики развития пожара в течение четырех дней в виде космоснимков территории (2a, I; 2b, I; 2c, I; 2d, I) с использованием карты Blue Marble (разрешение снимков - 1000 м). Также для наглядности приведены космоснимки территории (2a, II; 2b, II; 2c, II; 2d, II) с использованием карты Topographic (разрешение снимков - 10000 м) и добавлен условный знак ориентации в пространстве.

Кроме того, для облегчения работы пользователей с данными предполагается создание webприложения. В настоящее время планируется защита результатов интеллектуальной деятельности посредством подачи заявки на государственную регистрацию базы данных.

\section{Заключение}

В ходе исследования выполнен анализ существующих отечественных и зарубежных моделей прогнозирования распространения лесных пожаров. На основе результатов анализа выявлены основные ограничения применения моделей в условиях реального пожара: высокая степень динамичности и неопределенности входных параметров, необходимость обеспечения минимального времени сбора и ввода входных параметров, а также минимизация времени отклика модели. Обоснована необходимость применения инструментария искусственных нейронных сетей (сверточной нейронной сети) для решения проблемы прогнозирования динамики распространения лесного пожара: возможность формирования прогноза в сложных условиях реального пожара, а также возможность минимизации временных затрат за счет распараллеливания высокопроизводительных вычислений.

Разработан метод оперативного прогнозирования динамики лесных пожаров в условиях нестационарности и неопределенности с использованием сверточной нейронной сети. Описана общая логическая схема разработанного метода (рисунок 1). Главной особенностью предложенного метода является построение дерева сверточных нейронных сетей как ориентированного ациклического графа для анализа значительного количества визуальных данных. Данный граф включает один корневой узел - сеть CNN, выполняющий последний этап прогнозирования, и три промежуточных узла - сети CNNs, где формируются зависимости влияния факторов окружающей среды, характера лесных насаждений и вида пожара на динамику его развития.

Выполнен анализ существующих моделей баз данных и выбран предпочтительный вариант модели базы данных о динамике лесных пожаров реляционной базы данных. Выполнено построение базы визуальных данных о динамике развития лесных пожаров, элементами которой являются таблицы «Лесной пожар», «Факторы окружающей среды» и «Характер лесных насаждений». Для оптимизации работы пользователей с базой реализованы соответствующие формы и запросы.

\section{Литература}

1. Forest fires in Europe, Middle East and North Africa 2016. JRC Science for Policy Report. Luxembourg: European Commission, 2017. [Электронный ресурс]: http://effis.jrc.ec.europa.eu/media/cms_page_media/40/Forest_fires_in_Europe_Middle_east_and_North_ Africa_2016_final_pdf_JZU7HeL.pdf (дата обращения 03.08.2018).

2. Assessment of crown fire initiation and spread models in Mediterranean conifer forests by using data from field and laboratory experiments / F.R. Silva [et al.] // Forest Systems. 2017. Vol. 26. No. 2. [Электронный pecypc]: http://revistas.inia.es/index.php/fs/article/view/10652 (дата обращения 18.10.2018).

3. Sullivan A.L. Wildland surface fire spread modelling, 1990-2007. 1: Physical and quasi-physical models // International Journal of Wildland Fire. 2009. No. 18. P. 349-368.

4. Sullivan A.L. Wildland surface fire spread modelling, 1990-2007. 2: Empirical and quasi-empirical models // International Journal of Wildland Fire. 2009. No. 18. P. 369-386. 
5. Sullivan A.L. Wildland surface fire spread modelling, 1990-2007. 3: Simulation and mathematical analogue models // International Journal of Wildland Fire. 2009. No. 18. P. 387-403.

6. Ходаков В.Е., Жарикова М.В. Лесные пожары: методы исследования. Херсон: Гринь Д.С., 2011.

7. Filippi J.B., Mallet V., Nader B. Evaluation of forest fire models on a large observation database // Natural Hazards and Earth System Sciences. 2014. Vol. 14. No. 11. P. 3077-3091. [Электронный pecypc]: https://www.nat-hazards-earth-syst-sci.net/14/3077/2014/ (дата обращения 18.10.2018).

8. Perminov V., Goudov A. Mathematical modeling of forest fires initiation, spread and impact on environment // International Journal of GEOMATE. 2017. Vol. 13. No. 35. P. 93-99. [Электронный pecypc]: http://www.geomatejournal.com/sites/default/files/articles/93-996704-Valeriy-July-2017-35-a1.pdf (дата обращения 18.10.2018).

9. Graf R. A forest-fire model on the upper half-plane // Electronic Journal of Probability. 2014. №. 19. Р. 1-27. [Электронный pecyрс]: https://projecteuclid.org/download/pdf_1/euclid.ejp/1465065650 (дата обращения 18.10.2018).

10. Lawson B.D., Armitage O.B., Hoskins W.D. Diurnal variation in the Fine Fuel Moisture Code: Tables and computer source code // FRDA Report 245. Victoria, B.C.: Canadian Forest Service, Pacific Forestry Center, 1996. [Электронный pecypc]: https://www.for.gov.bc.ca/hfd/ pubs/Docs/Frr/FRR245.pdf (дата обращения 18.10.2018).

11. Гришин А.М. Математическое моделирование лесных пожаров и новые способы борьбы с ними. Новосибирск: Наука, Сибирское отделение, 1992.

12. Коморовский В.С., Доррер Г.А. Методика расчета параметров лесных пожаров как динамических процессов на поверхности земли с использованием данных космического мониторинга // Вестник Сибирского государственного аэрокосмического университета им. академика М.Ф. Решетнева. 2010. № 3 (29). С. 47-50.

13. Численное моделирование лесного пожара в лесах Высокоборского лесничества Борского района Нижегородской области / О.И. Рылкова и [др.] // Современные проблемы науки и образования. 2013. № 6. [Электронный pecypc]: http://www.scienceeducation.ru/ru/article/view?id=11671 (дата обращения: 30.05.2018).

14. Масленников Д.А., Катаева Л.Ю. Моделирование лесных пожаров в трехмерной системе координат с учетом рельефа // Вестник Нижегородского университета им. Н.И. Лобачевского. 2011. № 4 (5). С. 2338-2340.

15. Перминов В.А. Математическое моделирование возникновения и распространения верховых лесных пожаров в осредненной постановке // Журнал технической физики. 2015. Т. 85. № 2. С. 24-30.

16. Ясинский Ф.Н., Потемкина О.В., Сидоров С.Г., Евсеева А.В. Прогнозирование вероятности возникновения лесных пожаров с помощью нейросетевого алгоритма на многопроцессорной вычислительной технике / Вестник ИГЭУ. 2011. № 2. [Электронный pecypc]: http://ispu.ru/files/str.82-84_0.pdf (дата обращения: 31.03.2018).

17. Vahidnia M.H., Alesheikh A.A., Behzadi S., Salehi S. Modeling the spread of spatio-temporal phenomena through the incorporation of ANFIS and genetically controlled cellular automata: a case study on forest fire // International Journal of Digital Earth. 2013 . Vol. 6. No. 1. P. 51-75.

18. Krizhevsky A., Sutskever I., Hinton G. ImageNet classification with deep convolutional neural networks // Advances in Neural Information Processing Systems 25: 26th Annual Conference on Neural Information Processing Systems 2012 (NIPS 2012). Lake Tahoe, US. 3-8 December 2012. Р. 1097-1105. [Электронный ресурc]: https://www.cs.toronto.edu/ fritz/absps/imagenet.pdf (дата обращения: 03.08.2018).

19. Hamed H.A., Elnaz J.H. Guide to convolutional neural networks. A practical application to traffic-sign detection and classification. Springer International Publishing, 2017.

20. Babu S., Roy A., Prasad R.C. Forest fire risk modeling in Uttarakhand Himalaya using TERRA satellite datasets // European Journal of Remote Sensing. 2016. No. 49. P. 381-395. [Электронный ресурс]: https://doi.org/10.5721/ЕuJRS20164921 (дата обращения 18.10.2018).

21. Spatial modeling of forest fires in Mexico: An integration of two data sources / J.M. Zuniga-Vasquez [et al.] // BOSQUE. 2017. Vol. 38. No. 3. P. 563-574. [Электронный pecypc]: https://scielo.conicyt.cl/pdf/bosque/v38n3/art14.pdf (дата обращения 18.10.2018).

\section{The use of convolutional neural networks to forecast the dynamics of spreading forest fires in real time ${ }^{12}$}

\section{Tatiana S. Stankevich}

Associate Professor, Department of Technosphere Safety

Kaliningrad State Technical University

Address: 1, Sovietsky Prospect, Kaliningrad, 236022, Russia

E-mail: tatiana.stankevich@klgtu.ru

\footnotetext{
${ }^{12}$ This study was supported by the Russian Foundation for Basic Research, project No. 18-37-00035 “On the dependence of the dynamics of the development of forest fires on the influence of environmental factors, the nature of forest plantations and the type of fire under conditions of nonstationarity and uncertainty"
} 


\begin{abstract}
This work focuses on the relevant task of increasing the efficiency of forecasting the dynamics of forest fires spreading in real time. To address the problem, it was proposed to develop a method for operational forecasting the forest fire spread dynamics in the context of unsteadiness and uncertainty based on some advanced information technologies, i.e. artificial intelligence and deep machine learning (the convolutional neural network). As part of the research, both domestic and foreign models for the spread of forest fires were evaluated, and the key limitations of using models in real fire conditions were identified (high degree of dynamism and uncertainty of input parameters, the need to ensure minimum collection time and input parameters, as well as minimum response time of the model). Based on the data obtained, the need to use artificial neural network tools to solve the problem of predicting the forest fire's spread dynamics was substantiated. A general logic diagram of the method for forecasting the forest fire dynamics in real time has been developed, the main feature of which is the construction of a tree of convolutional neural networks. To enhance the quality of learning convolutional neural networks that implement the function of predicting the spread of forest fires, we propose to create a database of forest fire dynamics.
\end{abstract}

Key words: forest fire; database; visual data; artificial intelligence; deep machine learning; convolutional neural network; big data; real-time forecasting.

Citation: Stankevich T.S. (2018) The use of convolutional neural networks to forecast the dynamics of spreading forest fires in real time. Business Informatics, no. 4 (46), pp. 17-27. DOI: 10.17323/1998-0663.2018.4.17.27

\title{
References
}

1. European Commission (2017) Forest fires in Europe, Middle East and North Africa 2016. JRC Science for Policy Report. Available at: http:// effis.jrc.ec.europa.eu/media/cms_page_media/40/Forest_fires_in_Europe_Middle_east_and_North_Africa_2016_final_pdf_JZU7HeL.pdf (accessed 03 August 2018).

2. Silva F.R., Guijarro M., Madrigal J., Jimenez E., Molina J.R., Hernando C., Velez R., Vega J.A. (2017) Assessment of crown fire initiation and spread models in Mediterranean conifer forests by using data from field and laboratory experiments. Forest Systems, vol. 26, no. 2. Available at: http://revistas.inia.es/index.php/fs/article/view/10652 (accessed 18 October 2018).

3. Sullivan A.L. (2009) Wildland surface fire spread modelling, 1990-2007. 1: Physical and quasi-physical models. International Journal of Wildland Fire, no. 18, pp. 349-368.

4. Sullivan A.L. (2009) Wildland surface fire spread modelling, 1990-2007. 2: Empirical and quasi-empirical models. International Journal of Wildland Fire, no. 18, pp. 369-386.

5. Sullivan A.L. (2009) Wildland surface fire spread modelling, 1990-2007. 3: Simulation and mathematical analogue models. International Journal of Wildland Fire, no. 18, pp. 387-403.

6. Khodakov V.E., Zharikova M.V. (2011) Lesnye pozhary: metody issledovaniya [Forest fires: research methods]. Kherson: Grin’ D.S. (in Russian).

7. Filippi J.B., Mallet V., Nader B. (2014) Evaluation of forest fire models on a large observation database. Natural Hazards and Earth System Sciences, vol. 14. no. 11, pp. 3077-3091. Available at: https://www.nat-hazards-earth-syst-sci.net/14/3077/2014/ (accessed 18 October 2018).

8. Perminov V., Goudov A. (2017) Mathematical modeling of forest fires initiation, spread and impact on environment. International Journal of GEOMATE, vol. 13, no. 35, pp. 93-99. Available at: http://www.geomatejournal.com/sites/default/files/articles/93-99-6704-Valeriy-July2017-35-a1.pdf (accessed 18 October 2018).

9. Graf R. (2014) A forest-fire model on the upper half-plane. Electronic Journal of Probability, no. 19, pp. 1-27. Available at: https://projecteuclid.org/download/pdf_1/euclid.ejp/1465065650 (accessed 18 October 2018).

10. Lawson B.D., Armitage O.B., Hoskins W.D. (1996) Diurnal variation in the Fine Fuel Moisture Code: Tables and computer source code. FRDA Report 245. Victoria, B.C.: Canadian Forest Service, Pacific Forestry Center. Available at: https://www.for.gov.bc.ca/hfd/pubs/Docs/Frr/ FRR245.pdf (accessed 18 October 2018).

11. Grishin A.M. (1992) Matematicheskoe modelirovanie lesnyh pozharov i novye sposoby bor'by s nimi [Mathematical modeling of forest fires and new ways of fighting them]. Novosibirsk: Nauka, Siberian Branch (in Russian).

12. Komorovsky V.S., Dorrer G.A. (2010) Metodika rascheta parametrov lesnyh pozharov kak dinamicheskih protsessov na poverhnosti zemli $\mathrm{s}$ ispol'zovaniem dannyh kosmicheskogo monitoringa [Method of calculating parameters of forest fires as dynamic processes on the earth's surface using space monitoring data]. Vestnik SibGAU, no. 3 (29), pp. 47-50 (in Russian).

13. Rylkova O.I., Kataeva L.Yu., Maslennikov D.A., Romanova N.A., Rylkov I.V., Loshchilov A.A. (2013) Chislennoe modelirovanie lesnogo pozhara v lesah Vysokoborskogo lesnichestva Borskogo rayona Nizhegorodskoy oblasti [Numerical modeling of forest fire in the forests of Vysokoborsky forestry in the Bor District of the Nizhny Novgorod Region]. Modern Problems of Science and Education, no. 6. Available at: http://www.science-education.ru/ru/article/view?id=11671 (accessed 30 May 2018).

14. Maslennikov D.A., Kataeva L.Yu. (2011) Modelirovanie lesnyh pozharov v trekhmernoy sisteme koordinat s uchetom rel'efa [Modeling of forest fires in a three-dimensional coordinate system taking into account the landform]. Vestnik of Lobachevsky University of Nizhni Novgorod, no. 4 (5), pp. 2338-2340 (in Russian). 
15. Perminov V.A. (2015) Matematicheskoe modelirovanie vozniknoveniya i rasprostraneniya verhovyh lesnyh pozharov v osrednennoy postanovke [Mathematical modeling of forest fires emergence and spread in the averaged setting]. Journal of Technical Physics, vol. 85, no. 2, pp. 24-30 (in Russian).

16. Yasinsky F.N., Potemkina O.V., Sidorov S.G., Evseeva A.V. (2011) Prognozirovanie veroyatnosti vozniknoveniya lesnyh pozharov s pomoshch'yu neyrosetevogo algoritma na mnogoprotsessornoy vychislitel'noy tekhnike [Predicting the probability of forest fires using neural network algorithm and multiprocessor computers]. Vestnik IGEU, no. 2. Available at: http://ispu.ru/files/str.82-84_0.pdf (accessed 31 March 2018) (in Russian).

17. Vahidnia M.H., Alesheikh A.A., Behzadi S., Salehi S. (2013) Modeling the spread of spatio-temporal phenomena through the incorporation of ANFIS and genetically controlled cellular automata: a case study on forest fire. International Journal of Digital Earth, vol. 6, no. 1, pp. 51-75.

18. Krizhevsky A., Sutskever I., Hinton G. (2012) ImageNet classification with deep convolutional neural networks. Advances in Neural Information Processing Systems 25: 26th Annual Conference on Neural Information Processing Systems 2012 (NIPS 2012). Lake Tahoe, US. 3-8 December 2012. P. 1097-1105. Available at: https://www.cs.toronto.edu/ fritz/absps/imagenet.pdf (accessed 03 August 2018).

19. Hamed H.A., Elnaz J.H. (2017) Guide to convolutional neural networks. A practical application to traffic-sign detection and classification. Springer International Publishing.

20. Babu S., Roy A., Prasad R.C. (2016) Forest fire risk modeling in Uttarakhand Himalaya using TERRA satellite datasets. European Journal of Remote Sensing, no. 49, pp. 381-395. Available at: https://doi.org/10.5721/EuJRS20164921 (accessed 18 October 2018).

21. Zuniga-Vasquez J.M., Cisneros-Gonzalez D., Pompa-Garcia M., Rodriguez-Trejo D.A., Perez-Verdin G. (2017) Spatial modeling of forest fires in Mexico: An integration of two data sources. BOSQUE, vol. 38, no. 3, pp. 563-574. Available at: https://scielo.conicyt.cl/pdf/bosque/ v38n3/art14.pdf (accessed 18 October 2018). 


\section{Развитие цифровых компетенций государственных гражданских служащих Российской Федерации ${ }^{1}$}

\section{E.В. Васильева}

доктор экономических наук

профессор кафедры бизнес-информатики

Финансовый университет при Правительстве РФ

Адрес: 105187, г. Москва, ул. Щербаковская, д. 38

E-mail: evvasileva@fa.ru

\section{В.Н. Пуляева}

кандидат экономических наук

доцент кафедры управления персоналом и психологии

Финансовый университет при Правительстве РФ

Адрес: 127083, г. Москва, ул. В. Масловка, д.15

E-mail: vnpulyaeva@fa.ru

\section{В.А. Юдина}

кандидат экономических наук

доцент кафедры менеджмента, информатики и общегуманитарных наук

Финансовый университет при Правительстве РФ, Пензенский филиал

Адрес: 440052, Пензенская область, г. Пенза, ул. Калинина, д. 33Б

E-mail:vayudina@fa.ru

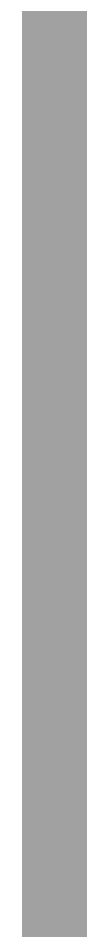

\section{Аннотация}

В мировой практике работы государственных служб компетентностный подход принят в качестве основы развития производительности труда, инновационности и ответственности служащих. В России компетентностный подход занимает центральное место в законодательных и нормативных документах, но так и не стал рабочим инструментом. Переход России на цифровую экономику в соответствии с Федеральной программой обуславливает необходимость трансформации профессиональных качеств и квалификационных требований для замещения должностей государственной гражданской службы. Развитие единого информационного пространства государственной гражданской службы и повсеместное внедрениетехнологий электронногоправительствапредъявляетповышенныетребования к компетенциям чиновников в сфере информационно-коммуникационных технологий. Однако, исследования показали, что до сих пор российские госслужащие на первые места по приоритету ставят такие компетенции, как нацеленность на результат, дисциплинированность, навыки организации собственного времени, стрессоустойчивость, а на последние места - адаптивность, готовность к переменам, креативность, инициативу, навыки применения нововведений и инноваций. Управление компетенциями подразумевает индивидуальный подход, учет особенностей каждого служащего, а также разработку и внедрение моделей компетенций, в которых должны быть отражены все стороны деятельности в условиях работы в цифровом мире.

Целью работы является разработка методических рекомендаций по совершенствованию положений должностного регламента государственных гражданских служащих в части квалификационных требований к компетенциям в сфере информационно-коммуникационных технологий (ИКТ). Использование методов сравнительного анализа при исследовании содержания должностных регламентов государственной гражданской службы различных субъектов РФ, а также экспертного опроса по проблемам содержания и текущего уровня развития ИКТ-компетенций государственных

\footnotetext{
${ }^{1}$ Статья подготовлена по результатам исследований, выполненных за счет бюджетных средств по Государственному заданию Финансового университета 2018 года «Совершенствование информационного обеспечения системы управления кадрами на основе компетентностного подхода и индивидуального трекинга карьеры государственных гражданских служащих», номер государственной регистрации АААА-А18-118052490063-1
} 
гражданских служащих позволили авторам выделить в структуре компетенций базовые, продвинутые и специальные компоненты. Предложены методические рекомендации по трансформации компетенций в области ИКТ в цифровые компоненты, которые предусматривают расширенный комплекс знаний и навыков, необходимых в условиях цифровизации государственной гражданской службы. Данные изменения позволят кадровым службам органов государственной власти субъектов РФ обеспечить унифицированный подход к формированию требований к уровню развития цифровых компетенций претендентов на должности государственной гражданской службы, а также реализовать целевой подход при формировании программ развития кадрового потенциала с учетом требований цифровой грамотности.

Ключевые слова: цифровые компетенции; цифровая экономика; государственный служащий; государственное управление; должностной регламент; метакомпетенции; мягкие навыки.

Цитирование: Васильева Е.В., Пуляева В.Н., Юдина В.А. Развитие цифровых компетенций государственных гражданских служащих Российской Федерации // Бизнес-информатика. 2018. № 4 (46). C. 28-42. DOI: 10.17323/1998-0663.2018.4.28.42

\section{Введение}

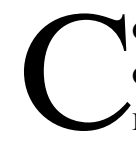
овременный этап развития экономики и общества характеризуется как «новая экономика», «инновационная экономика», «экономика знаний» [1]. Все эти термины подразумевают такой уровень развития хозяйственной жизни общества, когда происходят следующие кардинальные изменения: становится приоритетной сетевая форма координации экономических субъектов, появляется ориентация на внедрение инноваций, человеческий капитал и информация становятся главными факторами конкурентоспособности, в национальной экономике преобладает третичный сектор и т.д. [2]. В 2017 году в Российской Федерации была разработана Федеральная программа «Цифровая экономика», одним из перспективных направлений которой является система государственного управления [3]. В связи с этим становится актуальным изучение процессов расширения модели компетенций государственных гражданских служащих для обеспечения их соответствия вызовам цифровой среды, а также степени готовности госслужащих к цифровой трансформации. Важно пересмотреть квалификационные требования к претендентам на замещение должностей государственной гражданской службы и государственным гражданским служащим Российской Федерации в части информационно-коммуникативных (ИКТ) навыков и знаний, выделив новые требования к знаниям и навыкам служащих, необходимым для их деятельности в цифровой среде.

Целью настоящей работы является определение цифровых компонент ИКТ-компетенций государственных гражданских служащих для внесения их в должностной регламент и Справочник квалификационных требований к претендентам на замещение должностей государственной гражданской службы. Для достижения поставленной цели решены следующие задачи:

\ рассмотрены существующие должностные регламенты и методический инструментарий;

\ в нормативных документах выделены предпосылки к расширению компетентностной модели государственных гражданских служащих для обеспечения эффективной работы госорганов в инновационной среде;

$\checkmark$ проведен опрос специалистов и руководителей государственной гражданской службы для выявления актуальных требований к специалистам различных групп должностей;

- разработаны методические рекомендации по включению цифровых компонент в положения должностного регламента государственных гражданских служащих.

\section{1. Предпосылки изменений компетентностной модели государственных гражданских служащих}

Существует множество определений понятия «компетенция». Многие эксперты и специалисты по управлению персоналом [4-10] предлагают собственные трактовки, но основными считаются два подхода к пониманию компетенций - американский и европейский. Согласно американскому подходу, компетенции определяются как описание поведения сотрудника, когда работник, обладая со- 
ответствующими компетенциями, демонстрирует правильное поведение и добивается желаемых результатов в своей работе [11]. Европейский подход акцентирует внимание на способность работника решать определенные задачи для достижения результатов в соответствии с определенными в организации требованиями и стандартами [12-14]. Таким образом, американский подход предполагает использование индикаторов поведения для оценки работников и в целом опирается на постулаты бихевиоризма, а европейский подход можно назвать функциональным, поскольку в нем делается акцент на решение конкретных профессиональных задач.

Отечественные ученые до недавнего времени занимались вопросами компетенций, в первую очередь, с позиции педагогической науки, в разрезе приобретаемых знаний, умений и навыков. Так, по мнению И.А. Зимней [15], социально-профессиональная компетентность - это совокупная интегральная личностная характеристика человека, получившего квалификацию и характеризующегося определенным уровнем профессионализма. Компетентность, как профессиональная характеристика индивида, основана на его личностных качествах, интеллекте и опыте. Социально-профессиональная компетентность представляется в виде четырех блоков, два из которых являются базовыми: это интеллектуальные способности и личностные качества, формирующиеся у человека до начала профессионального обучения, на основе которых развиваются частные компетенции, свойственные данной профессии [15].

В последнее время в отечественной практике наблюдается интеграция существующих подходов к пониманию профессиональных компетенций, что обусловлено функционированием большого числа транснациональных компаний, применяющих зарубежные технологии управления, а также завершением перехода профессионального образования от оценки знаний, умений и навыков к оценке компетенций [16].

О необходимости применять компетентностный подход в системе государственной гражданской службе впервые было упомянуто в Указе Президента Российской Федерации от 7 мая 2012 года № 601 «Об основных направлениях совершенствования системы государственного управления», согласно которому предусматривалось формирование перечня квалификационных требований для замещения должностей государственной гражданской службы на основе компетентностного подхода, в зависимости от конкретных должностных обязанностей и функций, а также от принадлежности к определенным профессиональным группам [17]. Впоследствии в Указе Президента РФ от 11 августа 2016 года № 403 «Об Основных направлениях развития государственной гражданской службы Российской Федерации на 2016-2018 годы» были намечены основные направления развития государственной гражданской службы, включающие создание в системе гражданской службы единого информационно-коммуникационного пространства посредством использования единой информационной системы управления кадровым составом гражданской службы, электронного кадрового документооборота и создания единого специализированного информационного ресурса для непрерывного профессионального развития госслужащих.

В соответствии с вышеприведенными нормативно-правовыми актами Министерством труда и социальной защиты Российской Федерации были разработаны следующие документы, носящие рекомендательный характер:

Методика всесторонней оценки профессиональной служебной деятельности государственного гражданского служащего [18] (далее - Методика);

^ Методический инструментарий по установлению квалификационных требований для замещения должностей государственной гражданской службы (версия 3.2) [19] (далее - Методический инструментарий);

Согласно Методическому инструментарию «компетенция - комплекс проявляемых в поведении гражданского служащего профессиональных и личностных качеств, свидетельствующий о наличии необходимых для эффективного и результативного исполнения должностных обязанностей знаний, умений, а также опыта профессиональной деятельности» [19]. При этом под профессиональным качеством понимается проявляемая в поведении гражданского служащего характеристика, отражающая единство его стремлений, способностей, знаний, навыков и личностных качеств, необходимых для эффективного и результативного исполнения должностных обязанностей.

\section{1. Профессиональные качества государственных гражданских служащих: российская практика}

Сегодня выделяются три группы профессиональных качеств гражданского служащего - общие, прикладные и управленческие (таблица 1). 
Профессиональные качества государственных гражданских служащих

Таблица 1.

\begin{tabular}{|c|c|c|}
\hline $\begin{array}{c}\text { Общие } \\
\text { профессиональнье } \\
\text { качества }\end{array}$ & $\begin{array}{c}\text { Прикладные } \\
\text { профессиональные качества }\end{array}$ & $\begin{array}{c}\text { Управленческие } \\
\text { профессиональные качества }\end{array}$ \\
\hline Ориентация на результат & Сбор и анализ информации & Планирование деятельности и ресурсов \\
\hline $\begin{array}{l}\text { Укрепление авторитета } \\
\text { гражданских служащих }\end{array}$ & Качественная подготовка документов & Постановка задач и организация деятельности \\
\hline \multirow{6}{*}{$\begin{array}{l}\text { Межличностное } \\
\text { понимание, } \\
\text { стиль общения }\end{array}$} & $\begin{array}{l}\text { Ориентация на обеспечение защиты законных интересов } \\
\text { граждан }\end{array}$ & Контроль и оценка исполнения \\
\hline & Творческий подход, инновационность & Мотивация и развитие подчиненных \\
\hline & Убедительность коммуникаций & Принятие управленческих решений \\
\hline & Работа в команде & Стратегическое видение \\
\hline & Просрессиональное саморазвитие (далее - саморазвитие) & Управление изменениями \\
\hline & Передача опыта и знаний & Публичные выступления и внешние коммуникации \\
\hline
\end{tabular}

*) «мягкие» навыки (soft skills) [20]

Вместе с тем, как видно из таблицы, выделенные Минтрудом профессиональные качества (компетенции) госслужащих не учитывают современных тенденций цифровизации экономики и общества (единственное в этой области прикладное профессиональное качество «сбор и анализ информации» носит общий характер). Данный пробел в законодательстве, а также и другие описанные ранее предпосылки обусловили необходимость проведения исследования с целью формирования модели цифровых компетенций государственных гражданских служащих, а также выявления степени готовности госорганов к работе в инновационной среде.

\section{2. Должностной регламент} государственных гражданских служащих: российская практика

В соответствии с п. 7 статьи 12 Федерального закона «О государственной гражданской службе Российской Федерации» квалификационные требования к знаниям и умениям, необходимым для исполнения должностных обязанностей, устанавливаются в зависимости от области и вида профессиональной служебной деятельности гражданского служащего его должностным регламентом. Должностным регламентом гражданского служащего (далее - должностной регламент) могут также предусматриваться квалификационные требования к специальности и направлению подготовки, которые необходимы для замешения должности гражданской службы.
Статья 47 настоящего закона говорит о том, что профессиональная служебная деятельность гражданского служащего осуществляется в соответствии с должностным регламентом, утверждаемым представителем нанимателя и являющимся составной частью административного регламента государственного органа. В должностном регламенте содержатся необходимые квалификационные и иные требования, предъявляемые к государственным гражданским служащим, а также приводится характеристика содержания и результатов деятельности служащего при осуществлении им профессиональной служебной деятельности согласно замещаемой должности. Положения должностного регламента учитываются при проведении конкурса на замещение вакантной должности гражданской службы, аттестации, квалификационного экзамена, а также планировании профессиональной служебной деятельности гражданского служащего [21].

Результаты исполнения гражданским служащим должностного регламента учитываются при проведении конкурса на замещение вакантной должности гражданской службы или включении гражданского служащего в кадровый резерв, оценке его профессиональной служебной деятельности при проведении аттестации, квалификационного экзамена, либо поощрении гражданского служащего.

Примерные должностные регламенты утверждаются соответствующим органом по управлению государственной службой. 


\section{3. Анализ требований к профессиональным компетенциям государственных гражданских служащих}

В 2015 году был создан Федеральный портал государственной службы и управленческих кадров ${ }^{2}$, который представляет собой информационный ресурс с базой вакансий и резюме госслужбы. На данном сайте размещается информация о вакансиях в органах государственной власти с указанием квалификационных требований к кандидатам. По некоторым вакансиям также можно найти должностные регламенты.

В рамках исследования авторами проведен анализ десяти должностных регламентов различных органов государственной власти из различных субъектов Российской Федерации, размещенных на портале «Госслужба». Целью анализа было выявление требований к профессиональным знаниям и навыкам в области информационно-коммуникационных технологий, которые в настоящие время предъявляются к кандидатам.

Половина из проанализированных регламентов содержит только самое общее описание профессиональных навыков, которыми необходимо обладать претенденту на данные должности. Вместе с тем почти во всех регламентах упоминаются требования к знаниям систем межведомственного взаимодействия и управления государственными информационными ресурсами. Кроме того, в должностном регламенте главного государственного таможенного инспектора Московской таможни представлен обширный перечень знаний и навыков, которыми необходимо обладать для работы в данной должности: это и информационная безопасность (включая не только работу со служебной информацией, но и личной почтой и аккаунтами в социальных сетях), персональные данные, система документооборота, электронная подпись, а также работа с персональным компьютером (создание текстов, таблиц и презентаций, работа с сетевыми ресурсами и многое другое).

Проведенный анализ позволяет сделать вывод об отсутствии единых шаблонов для оформления требований к профессиональным знаниям и навыкам в сфере информационно-коммуникационных технологий для должностей государственной гражданской службы: в одних должностных регламентах они отнесены к «профессиональным умениям», в других к «базовым знаниям и умениям» и т.д. Также нет унифицированного подхода к полноте раскрытия

\footnotetext{
2 https://gossluzhba.gov.ru/
}

данных требований: в одних регламентах это занимает всего несколько строк, в других - страницу.

Вместе с тем Министерством труда и социальной защиты Российской Федерации совместно с федеральными государственными органами подготовлен Справочник квалификационных требований к претендентам на замещение должностей государственной гражданской службы и государственным гражданским служащим (далее - Справочник), включающий базовые и функциональные квалификационные требования. При этом базовые квалификационные требования, определяющие общий уровень квалификации для замещения должностей государственной гражданской службы, включают следующие требования к знаниям и навыкам в области ИКТ:

1. Общие знания информационных технологий и применения персонального компьютера (далее - ПК):

а) знание составляющих ПК, включая аппаратное и программное обеспечение, устройства хранения данных;

б) общие знания современных коммуникаций, сетевых приложений, программного обеспечения;

в) знания основ обеспечения охраны здоровья во время работы с ПК, вопросов безопасности и защиты данных;

\section{2. Знания и навыки применения ПК:}

a) знание основных команд при применении ПК;

б) знание основных принципов работы с рабочим столом;

в) знание принципов организации файловой структуры;

г) навыки создания, перемещения и удаления файлов;

д) навыки печати электронных документов;

3. Знания и навыки работы с офисными программами:

a) навыки по созданию и форматированию текстовых документов, включая копирование, вставку и удаление текста;

б) навыки работы с таблицами и картинками в текстовых и графических редакторах;

в) навыки по подготовке презентаций в программах для работы с презентациями и слайдами;

г) создание, отсылка, получение электронных сообщений, написание ответов, пересылка ранее полученных сообщений, работа с вложениями в программах для работы с электронной почтой;

4. Знания и навыки работы с информационно-телекоммуникационной сетью «Интернет» (далее сеть «Интернет»): 
а) понимание основных принципов функционирования сети «Интернет», принципов защиты информации;

б) использование поисковых систем сети «Интернет» для работы с ресурсами сети «Интернет», в том числе получения необходимой информации [22].

Стоит подчеркнуть, что указанные требования к знаниям и навыкам в сфере ИКТ являются минимальными и не отражают специфику работы органов государственной власти в условиях формирования цифровой экономики, функционирования электронного правительства и создания единой информационной системы государственной гражданской службы.

\section{4. Результаты анкетирования государственных гражданских служащих по вопросам практики управления компетентностным уровнем кадрового состава}

Высокая экономическая и социальная значимость результатов деятельности органов государственной власти требует использования не только характерных для сферы управления экономических количественных критериев и показателей, но и качественных. Учитывая специфику деятельности государственных гражданских служащих, предпочтительным методом исследования является метод экспертных оценок в сочетании с анкетным опросом.

Эксперты были сформированы из представителей различных категорий и групп должностей государственной гражданской службы трех субъектов РФ (Пензенская, Московская и Ленинградская области). Органы государственной власти данных субъектов РФ вошли в выборочную совокупность, поскольку они представляют различные органы власти на федеральном и региональном уровнях. При этом руководство органов государственной власти выразило заинтересованность в проведении исследования, необходимого для формирования модели компетенций государственных служащих, а также в разработке информационных систем, поддерживающих управление персоналом в системе государственной гражданской службы на основе компетентностного подхода и их внедрении в обследуемых органах государственной власти. В исследование приняли участие эксперты пяти групп четырех категорий должностей Министерства экономического развития РФ, Министерства финансов РФ, Администрации губернатора СанктПетербурга, Межрегионального ресурсного центра, Министерства экономики Пензенской области, Министерства финансов Пензенской области, Правительства Пензенской области, УФК по Пензенской области, Законодательного собрания Пензенской области, Министерства труда Пензенской области и др.

Для большей достоверности данных в экспертном обследовании в группы экспертов были включены руководители и специалисты, имеющие значительный опыт работы в системе государственной гражданской службы.

Рейтинг приоритетных информационно-коммуникативных компетенций был определен на основе ранжирования экспертных оценок с учетом значимости (по шкале от -3 до 3).

Поскольку средняя величина суммы баллов по данному блоку компетенций составила 201,71, в качестве наиболее значимых, с точки зрения экспертов, были выделены ИКТ-компетенции, для которых сумма рангов оказалась выше среднего значения. Опрос показал, что, несмотря на усиливающуюся роль процессов цифровизации государственной гражданской службы, только три компетенции в блоке ИКТ были определены как наиболее значимые (рисунок 1). При этом одни из наиболее востребованных и актуальных компетенций, - навыки владения методами проектного управления, - были оценены экспертами как менее значимые по отношению к среднему значению по данному блоку.

Таким образом, анализ Справочника и действующих должностных регламентов в различных органах государственной власти субъектов Российской Федерации, а также опрос государственных гражданских служащих выявил неготовность госорганов к трансформации компетенций государственных гражданских служащих и отсутствие унифицированного подхода к формированию модели компетенций для обеспечения функционирования электронного правительства и реализации национальной программы «Цифровая экономика». В связи с этим предлагается унифицировать квалификационные требования к компетенциям в сфере применения информационнокоммуникационных технологий для государственных гражданских служащих, с учетом современных требований к специалистам различных групп должностей.

2. Изменения в требованиях к профессиональным компетенциям государственных гражданских служащих в условиях цифровой трансформации госслужбы

В XXI веке с развитием цифровой экономики остро встает необходимость в развитии «цифровых компетенций» [23]. На Всемирном экономическом форуме в Давосе в 2016 году горячими темами для обсуждения 


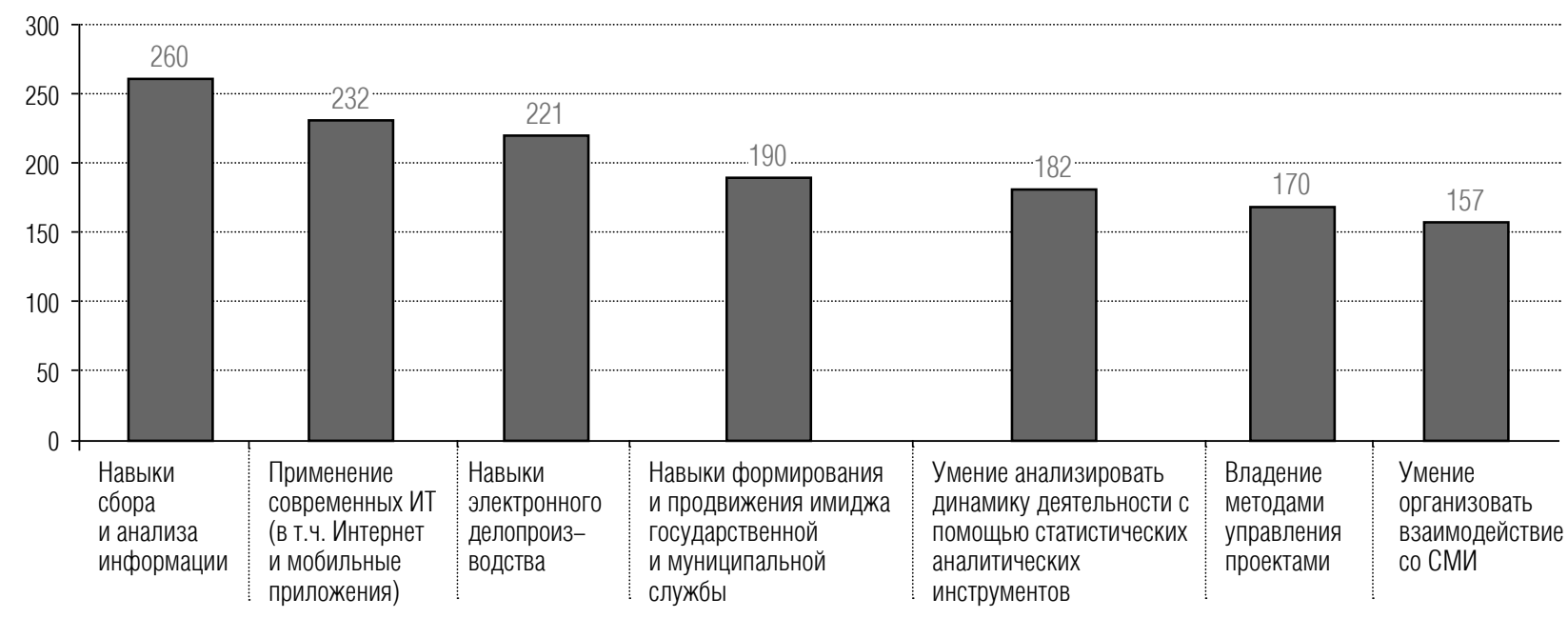

Рис. 1. Ранжирование инсормационно-коммуникативных компетенций по степени значимости (среднее значение - 201,71)

были оценка силы преобразующего влияния четвертой промышленной революции на сферу труда [24], образование, а также основные навыки, которые еще не считаются ключевыми для работы сегодня, но будут необходимы к 2020 г. [25]. Рабочие места индустриальной эпохи уступают место новой практике организации работы в цифровую эпоху, включая удаленный доступ через Интернет-платформы, гибкую форму занятости (flexible work) и работу по требованию (on-demand work). Управление как людьми, так и машинами создаст новые вызовы для организации кадров, в том числе возникнут проблемы переобучения работников и внедрения новых HR-процессов для управления виртуальными командами. «Люди и машины могут развивать симбиотические отношения, каждый со специализированными навыками и способностями» [26], в едином кадровом ландшафте силе, что обеспечит преимущества для бизнеса.

Региональный общественный центр Интернеттехнологий (РОЦИТ) ${ }^{3}$ ежегодно оценивает индекс цифровой грамотности населения Российской Федерации. В рамках данного проекта под цифровой грамотностью понимается набор знаний и умений, которые необходимы для безопасного и эффективного использования цифровых технологий и ресурсов Интернета. Цифровая грамотность включает в себя три элемента - цифровое потребление, цифровые компетенции и цифровую безопасность, каждый из которых также состоит из ряда элементов (таблица 2). Цифровое потребление означает умение использо-

\footnotetext{
3 https://rocit.ru/

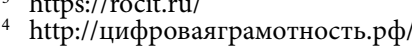

вать Интернет-услуги для работы и жизни, цифровые компетенции - это навыки эффективного пользования технологиями, а цифровая безопасность - основы безопасности в сети Интернет.

\section{Структура цифровой грамотности*)}

Таблица 2.

\begin{tabular}{|c|c|c|}
\hline $\begin{array}{c}\text { Цифровое } \\
\text { потребление }\end{array}$ & $\begin{array}{c}\text { Цифровые } \\
\text { компетенции }\end{array}$ & $\begin{array}{c}\text { Цифровая } \\
\text { безопасность }\end{array}$ \\
\hline $\begin{array}{l}\text { Фиксированный } \\
\text { Интернет }\end{array}$ & Поиск информации & $\begin{array}{l}\text { Защита персональных } \\
\text { данных }\end{array}$ \\
\hline $\begin{array}{l}\text { Мобильный } \\
\text { Интернет }\end{array}$ & $\begin{array}{l}\text { Использование } \\
\text { цифровых устройств }\end{array}$ & Надежный пароль \\
\hline $\begin{array}{l}\text { Цифрровые } \\
\text { устройства }\end{array}$ & $\begin{array}{l}\text { Использование фуннкци- } \\
\text { онала социальных сетей }\end{array}$ & Легальный контент \\
\hline Интернет-СМИ & Финансовые операции & Культура поведения \\
\hline Новости & Онлайн-покупки & Репутация \\
\hline $\begin{array}{l}\text { Социальные } \\
\text { сети }\end{array}$ & $\begin{array}{l}\text { Критическое восприятие } \\
\text { информации }\end{array}$ & Этика \\
\hline Госуслуги & $\begin{array}{l}\text { Производство мульти- } \\
\text { медийного контента }\end{array}$ & $\begin{array}{l}\text { Хранение } \\
\text { информации }\end{array}$ \\
\hline Телемедицина & $\begin{array}{l}\text { Синхронизация } \\
\text { устройств }\end{array}$ & $\begin{array}{l}\text { Создание резервных } \\
\text { копий }\end{array}$ \\
\hline $\begin{array}{l}\text { Облачные } \\
\text { технологии }\end{array}$ & & \\
\hline
\end{tabular}

*) Составлено по материалам проекта «Цифрровая грамотность» ${ }^{4}$

Развитию актуальных в цифровой экономике компетенций в последнее время было посвящено множество исследовательских работ. Среди них особый интерес для нашей темы представляет обобщающая работа «Навыки для цифрового мира» 
[27], а также доклад «Города как рынок труда» [9], сделанный в рамках международного транспортного форума в 2015 году. Эти работы демонстрируют тесную взаимосвязанность процессов цифровой экономики, в том числе в вопросах навыков и обучения рабочей силы. Опираясь на исследования работы [27], можно констатировать, что в настоящее время термин «цифровые навыки» получил международное признание, как и термин «цифровая экономика».

Расширение использования информационно-коммуникационных технологий (ИКТ) и среды Интернет непосредственно на рабочем месте в любой организации, включая государственные службы, вызывает повышение спроса на новые цифровые навыки по трем направлениям.

Во-первых, работникам более широкого спектра профессий необходимо приобрести общие навыки в области ИКТ (общие ИКТ-навыки), чтобы иметь возможность использовать такие технологии в своей повседневной работе (например, чтобы получать доступ к информации в Интернете или использовать программное обеспечение для решения текущих задач).

Во-вторых, очевидна потребность в профессиональных навыках для производства продуктов и услуг ИКТ, т.е. собственно средств труда в новой экономике (программного обеспечения, веб-страниц, средств электронной коммерции, финансовых технологий, облачных данных, Интернета вещей, больших данных). Такие профессиональные ИКТ-навыки раньше считались прерогативой специалистов в области ИКТ, наряду с навыками программирования, разработки приложений, управления данными и сетями. Однако цифровизация деятельности заставляет пересмотреть сложившуюся практику и перенести этот опыт в компетентностную модель большинства других профессий.

В-третьих, использование ИКТ приводит к изменению способов, которыми выполняется работа, что вызывает повышение спроса на комплементарные ИКТ-навыки (complementary skills), поддерживающие выполнение новых задач, связанных с использованием ИКТ на рабочем месте. В частности, к ним относятся использование социальных сетей для коммуникации с коллегами и клиентами, продвижение бренда продуктов на платформах электронной коммерции, анализ больших данных, бизнес-планирование и т.п.

Массовое освоение всех видов ИКТ-навыков ведет к быстрому росту всей цифровой экономики, вследствие чего следует ожидать высокую степень изменя- емости востребованных ИКТ-навыков, их адаптивности к новым условиям работы и наращивания их функциональных возможностей [28, 29].

\section{3. Разработка предложений по совершенствованию положений должностного регламента \\ в части квалификационных требований в области цифровых компетенций}

По результатам проведенного исследования предлагается внести изменения в Справочник квалификационных требований к претендентам на замещение должностей государственной гражданской службы и государственным гражданским служащим в части требований к знаниям и навыкам в области цифровой деятельности (цифровым компетенциям).

Цифровые компетенции входят в состав ИКТкомпетенций как дополнительные компоненты в части умений и навыков обработки цифровой информации, навыков работы с ПК и стандартным офисным программным обеспечением, а также знания технологий информационной аналитики и информационной безопасности. В состав цифровых компетенций целесообразно добавить умения создавать цифровой контент, навыки формирования цифрового сотрудничества, сетевого этикета, навыки цифрового обмена, цифровой безопасности и т.п. Цифровые компоненты ИКТ-компетенций целесообразно разделить на базовые, продвинутые и специальные. Рекомендации по включению цифровых компетенций в нормативные акты государственных органов, которыми утверждены квалификационные требования к профессиональным знаниям и навыкам, необходимым для исполнения государственными гражданскими служащими должностных обязанностей, представлены в таблице 3.

В качестве примечаний отметим следующее:

1. Перечень профессиональных знаний и навыков в области информационно-коммуникационных технологий, которыми должен владеть государственный гражданский служащий в соответствии со специальным уровнем требований в области информационно-коммуникационных технологий, может корректироваться представителем нанимателя с учетом функциональных обязанностей и специфики работы служащих конкретного государственного органа, должностные обязанности которых предполагают работу со специальным программным обеспечением, используемым в соответствующем государственном органе. 
Рекомендуемый перечень квалификационных требований к профессиональным знаниям и навыкам в области цифровых компонент ИКТ-компетенций с учетом категорий и групп должностей государственной гражданской службы

Перечень квалификационных требований к профессиональным знаниям и навыкам в области ИКТ, которыми должен владеть

государственный гражданский служащий
Наименование категорий и групп должностей государственной гражданской службы

категория «руководители» высшей и главной групп должностей государственной гражданской службы

иные категории и

группы должностей государственной

гражданской службы

\section{Знания:}

аппаратного и программного обеспечения

возможностей и особенностей применения современных информационнокоммуникационных технологий в государственных органах, включая использование возможностей межведомственного документооборота

общих вопросов в области обеспечения информационной безопасности Навыки: работы с внутренними и перисрерийными устройствами компьютера работы с информационно-телекоммуникационными сетями, в том числе сетью Интернет работы в операционной системе управления электронной почтой работы в текстовом редакторе работы с электронными таблицами подготовки презентаций использования грасических объектов в электронных документах работы с базами данных

\section{Знания:}

правовых аспектов в области инсормационно-коммуникационных технологий программных документов и приоритетов государственной политики в области инсормационно-коммуникационных технологий

правовых аспектов в сфере предоставления государственных услуг населению и организациям посредством применения информационно-коммуникационных технологий

аппаратного и программного обеспечения

возможностей и особенностей применения современных

инсоормационно-коммуникационных технологий в государственных органах, включая использование возможностей межведомственного документооборота

общих вопросов в области обеспечения инсормационной безопасности основ проектного управления

\section{Навыки:}

стратегического планирования и управления групповой деятельностью с учетом возможностей и особенностей применения современных информационно-коммуникационных технологий в государственных органах работы с внутренними и перифрерийными устройствами компьютера

работы с информационно-телекоммуникационными сетями, в том числе сетью Интернет

работы в операционной системе

управления электронной почтой

работы в текстовом редакторе

работы с электронными таблицами

работы с базами данных

работы с системами управления проектами

\begin{tabular}{l|l|l}
\hline & + & \\
\hline & + & \\
\hline & + & \\
\hline & + & \\
\hline & + & \\
\hline
\end{tabular}


Таблица 3 (продолжение).

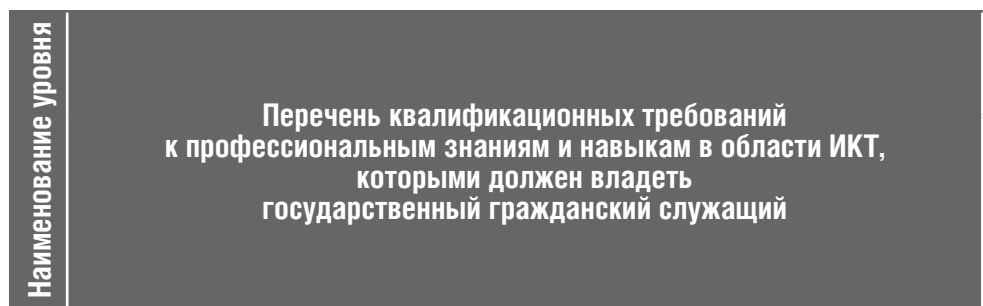

Наименование категорий и групп должностей государственной гражданской службы

категория «руководители»

высшей и главной групп должностей государственной гражданской службы

иные категории и группы должностей государственной гражданской службы

\begin{tabular}{|c|c|c|}
\hline систем взаимодействия с гражданами и организациями & + & + \\
\hline $\begin{array}{l}\text { учетных систем, обеспечивающих поддержку выполнения федеральными } \\
\text { органами государственной власти основных задач и функций }\end{array}$ & + & + \\
\hline систем межведомственного взаимодействия & + & + \\
\hline систем управления государственными информационными ресурсами & + & + \\
\hline $\begin{array}{l}\text { инсрормационно-аналитических систем, обеспечивающих сбор, обработку, } \\
\text { хранение и анализ данных }\end{array}$ & + & + \\
\hline систем управления электронными архивами & + & + \\
\hline систем инфоормационной безопасности & + & + \\
\hline систем управления эксплуатацией & + & + \\
\hline \multicolumn{3}{|l|}{ Навыки: } \\
\hline работы с системами взаимодействия с гражданами и организациями & + & + \\
\hline работы с системами межведомственного взаимодействия & + & + \\
\hline $\begin{array}{l}\text { работы с системами управления государственными информационными } \\
\text { ресурсами }\end{array}$ & + & + \\
\hline $\begin{array}{l}\text { работы с инфрормационно-аналитическими системами, обеспечивающими сбор, } \\
\text { обработку, хранение и анализ данных }\end{array}$ & + & + \\
\hline работы с системами управления электронными архивами & + & + \\
\hline работы с системами информационной безопасности & + & + \\
\hline работы с системами управления эксплуатацией & + & + \\
\hline
\end{tabular}

2. К базовым цифровым компетенциям стоит отнести те, которые в настоящее время уже указаны в Справочнике, поскольку на уровне младшей группы должностей государственной гражданской службы этих знаний и навыков будет достаточно. Кроме того, на низшие позиции, как правило, набираются претенденты без опыта работы в органах государственной власти и не владеющие навыками работы со специальными информационными системами.

3. Знания и навыки специального уровня являются дополнительными по отношению к знаниям и навыкам базового и продвинутого уровней квалификационных требований.

В настоящее время бизнес-процессы госслужб большей частью автоматизированы. К основным информационным системам государственной гражданской службы относятся: Единая информационная система управления кадровым составом государственной гражданской службы РФ (15\% опрошенных), «1С: Кадры (Предприятие)» (10\%); АИС «Кадры Минэкономразвития России», Единая информационная система управления кадровым со- ставом государственной гражданской службы РФ , «Консультант +» (по 4\%), Lotus, АИС УПГО, «Парус», ППО ПЗИК Аксиок.Net, Смета-кадры (по 2\%), а также Федеральный портал госслужбы и управленческих кадров. Такое разнообразие информационных систем уже сейчас расширяет список требований к знаниям и навыкам в сфере ИКТ. Более того, в ближайшие годы инфраструктура решений госслужбы претерпит изменения за счет внедрения новых технологий и переноса части бизнес-процессов в цифровое пространство. В связи с этим продвинутые компетенции и ИКТ-навыки должны включать следующие:

1) навыки работы с системами межведомственного взаимодействия и электронного документооборота;

2) умение работать с системами управления государственными информационными ресурсами;

3) навыки работы с информационно-аналитическими системами, обеспечивающими сбор, обработку, хранение и анализ данных;

4) умение работать с нормативно-правовыми информационными системами; 
5) знание основ информационной безопасности в части использования персональных данных, хранения и обработки служебной информации, а также использования сети Интернет в служебных и персональных целях.

Цифровыми компетенциями на продвинутом уровне должны обладать претенденты для зачисления на должности, начиная со старшей группы.

Третий блок - это специальные компетенции и ИКТ-навыки, которые обусловлены спецификой деятельности конкретного органа государственной власти и занимаемой должностью. Например, это могут быть навыки работы с государственной интегрированной информационной системой управления общественными финансами «электронный бюджет», умения работать с системой «zakupki.gov.ru» и т.Д.

Таким образом, предлагается закрепить в должностных регламентах обязательное включение требований к цифровым компетенциям на трех уровнях: базовом, продвинутом и специальном. Это позволит обеспечить унифицированный подход к формированию требований к претендентам на должности государственной гражданской службы, более эффективно формировать курсы повышения квалификации для госслужащих и тех, кто находится в кадровом резерве.

\section{4. Компетенции специалиста цифровой экономики}

Многие профессии, которые ранее считались чисто техническими, вызовут новый спрос на творческие и межличностные навыки. Ожидается, что к 2020 году критически важными для всех отраслей станут аналитика данных (чтобы собирать и успешно использовать все увеличивающиеся информационные потоки), навыки коммерциализации и коммуникации (чтобы уметь объяснить предложения для бизнеса или государственных клиентов и потребителей), а также инженерные знания и опыт управления командой мультидисциплинарных специалистов [30]. Среди базовых профессиональных навыков уже близкого 2020 года на Всемирном экономическом форуме названы когнитивная гибкость, креативность, логическое и математическое рассуждение, чувствительность к проблемам (problem sensitivity), визуализация, активное восприятие и критическое мышление, самоконтроль и эмоциональный интеллект, а также умение координировать и обучать других [31].

В тоже время для большинства рабочих мест требуются разные комбинации навыков. Помимо «жест- ких» навыков (hard skills), где определяющим является предсказуемость контекста и формальной квалификации, которым можно научить и которые легко продемонстрировать и измерить, работодатели часто обеспокоены наличием у персонала практических навыков или компетенций, необходимых для выполнения задач в неопределенной среде в неточной постановке, а также способностями к адаптации в меняющейся среде и к постоянному развитию. «Мягкие навыки» (soft skills), к которым, например, относятся эмоциональный интеллект, управление временем, и лидерство, связаны не с конкретным видом деятельности, а с умением эффективно выстраивать взаимоотношения с коллегами, клиентами и партнерами. Для развития мягких навыков важна основа в виде так называемых метакомпетенций, к которым относятся осознанность своих мыслей и эмоций, эмпатия, способность воспринимать факты без интерпретаций, гибкость поведения, креативность, интегральное мышление, толерантность к различиям, внимательность, искренность и аутентичность в коммуникациях. Такие навыки необходимы как в бизнес-среде, так и в повседневной жизни.

Bce, что выходит за рамки конкретного суждения, набора готовых ответов и уже стандартных кейсов, требует интегративного мышления. Умение рассмотреть проблемы с различных точек зрения, думать в нескольких проекциях, видеть не только очевидные факты, но и раскрывать метафору вещей, опираясь на воображение - это та база, которая важна в мире VUCA, в котором приходится учитывать непрогнозируемое: изменчивость (Volatile), неопределенность (Uncertain), сложность (Complex) и противоречивость (Ambiguous) [32]. Люди с интегративным мышлением знают, как расширить масштабы вопросов, связанных с проблемой, они отказываются от «или/ или» в пользу «и/и» [33].

\section{Заключение}

В настоящее время каждый специалист, желающий быть успешным в организации, должен обладать особыми «цифровыми» компетенциями. Это справедливо и для государственных служащих [34, 35].

Авторами проведено исследование ключевых компетенций государственных гражданских служащих и направлений развития их квалификации в условиях цифровой трансформации экономики, с учетом квалификационных требований к профессиональным знаниям и навыкам государственных гражданских служащих, отраженных в нормативных документах. 
Выполнен анализ правового регулирования процесса формирования квалификационных требований, предъявляемых к государственным гражданским служащим, а также конкретных должностных регламентов части информационно-коммуникативных компетенций. Результаты анализа нормативных и правовых документов, отражающих квалификационные требования к претендентам на замещение должностей государственной гражданской службы и государственным гражданским служащим Российской Федерации, показали неготовность госорганов к трансформации компетенций государственных гражданских служащих и отсутствие унифицированного подхода к формированию модели компетенций в рамках обеспечения функционирования электронного правительства и реализации национальной программы «Цифровая экономика». Выявлено отсутствие единообразного подхода к формированию требований к знаниям и навыкам в информационной сфере деятельности.

Опрос более 100 государственных гражданских служащих из различных субъектов Российской Федерации и органов государственной власти показал неготовность системы государственного управления к переходу на инновационное управление человеческим капиталом, инертность и недооценку важности цифровых компетенций.

Для решения указанных противоречий выдвинуты предложения по унификации квалификационных требований в должностных регламентах в части информационно-коммуникативных навыков и знаний с их подразделением на три уровня, в зависимости от группы должностей и специфики деятельности. Указанные предложения позволят повысить минимальный порог цифровых компетенций госслужащих, а также обеспечат их дальнейшее развитие в будущем при управлении карьерой в системе государственной гражданской службы. Выявлены ключевые компетенции госслужащих в условиях цифровизации, которые имеют разную сложность в зависимости от должностной позиции.

Предложенные рекомендации позволят повысить уровень профессиональных компетенций государственных гражданских служащих, обеспечив государственную службу кадрами, способными быстро адаптироваться к условиям быстрых изменений цифровой экономики в Российской Федерации. Четкая формулировка и прозрачность требований к продвижению в должности обеспечат внедрение тактических приемов в управлении карьерой - карьерных лифтов (иногда их называют карьерными лестницами), являясь, в том числе, информационной базой для формирования индивидуальных программ и содействия в обучении и повышении компетентности через различные форматы, включая наставничество, коучинг, управление знаниями и внедрение инструментов дизайн-мышления для развития метакомпетенций и интегративного мышления.

\section{Литература}

1. Эффективность управления кадрами государственной гражданской службы в условиях развития цифровой экономики и общества знаний / Под общ. ред. Е.В. Васильевой, Б.Б. Славина. М.: ИНФРА-М, 2018.

2. Бабкин А.В., Буркальцева Д.Д., Костень Д.Г., Воробьев Ю.Н. Формирование цифровой экономики в России: сущность, особенности, техническая нормализация, проблемы развития // Научно-технические ведомости Санкт-Петербургского государственного политехнического университета. Экономические науки. 2017. Т. 10. № 3. С. 9-25.

3. Петров М., Буров В., Шклярук М., Шаров А. Государство как платформа. (Кибер)государство для цифровой экономики. Цифровая трансформация. М.: Центр стратегических разработок, 2018.

4. Васильева Е.В. Дизайн-мышление: немного о подходе и много об инструментах развития креативного мышления, изучения клиентских запросов и создания идей. М.: РУСАЙНС, 2018.

5. Вербицкий А.А., Ларионова О.Г. Личностный и компетентностный подходы в образовании. Проблемы интеграции. М.: Логос, 2009.

6. Ветошкина Т. Роль компетенций в управлении персоналом // Кадровик. Кадровый менеджмент. 2008. № 3. С. 11-18.

7. Вольпян Н. Модели компетенций. Международный опыт в ИТ-сфере // Рождение коллективного разума. М.: ЛЕНАНД, 2013. C. 201-229.

8. Пуляева В.Н. Модель компетенций менеджера в клиентоориентированной экономике // Управление персоналом и интеллектуальными ресурсами в России. 2015. № 2 (17). С. 24-30.

9. Bertaud A. Cities as labour markets. Working paper. 2014. № 2 [Электронный pecypc]: https://marroninstitute.nyu.edu/uploads/content/ Cities_as_Labor_Markets.pdf (дата обращения 01.10.2018).

10. Blank S. The four steps to the epiphany: Successful strategies for products that win. Quad/Graphics, 2013.

11. Навыки в цифровой экономике и вызовы системы образования / В.П. Куприяновский и [др.]. // International Journal of Open Information Technologies. 2017. № 1. C. 19-25.

12. Raven J. Competence in modern society: Identification, development and implementation. Unionville, New York: Royal Fireworks Press, 1984.

13. Модель профессиональных компетенций государственных гражданских служащих Ханты-Мансийского автономного округа Югры. Методические рекомендации / под ред. Л.И. Красильниковой. Ханты-Мансийск: Региональный институт управления, 2014.

14. Heene F., Sanchez R. Competence based strategic management. London: John Wiley, 1997. 
15. Зимняя И.А. Единая социально-профессиональная компетентность выпускника университета: понятие, подходы к формированию и оценке. М.: МИСиС, 2008.

16. Легкая Л.Е Компетенции как инструмент управления персоналом на предприятиях малого бизнеса // Государственное управление. Электронный вестник. 2008. № 15. [Электронный pecypc]: http://e-journal.spa.msu.ru/uploads/vestnik/2008/vipusk_15._ijun_2008_g./ legkaya.pdf (дата обращения 27.10.2018).

17. Бондаренко В.В., Юдина В.А., Танина М.А. Повышение эффективности в системе госуправления на основе разработки квалификационных требований к замещению должностей государственных гражданских служащих // Теоретико-методологические подходы к формированию системы развития предприятий, комплексов, регионов / Под общ. ред. В.В. Бондаренко, Ф.Е. Удалова. Пенза: ПГСХА, 2015. С. 40-55.

18. Письмо Минтруда России от 14.06.2016 № 18-1/10/В-3980 «О Методике всесторонней оценки профессиональной служебной деятельности государственного гражданского служащего» [Электронный ресурс]: http://sudact.ru/law/metodika-vsestoronnei-otsenkiprofessionalnoi-sluzhebnoi-deiatelnosti-gosudarstvennogo/ (дата обращения 21.10.2018).

19. Методический инструментарий по установлению квалификационных требований для замещения должностей государственной гражданской службы. Версия 3.2. (утв. Министерством труда и социальной защиты Российской Федерации) [Электронный ресурс]: http://www.garant.ru/products/ipo/prime/doc/71755218/ (дата обращения 21.10.2018).

20. Babbitt M. 7 soft skills we never hear about (but must master) / 2014. [Электронный pecypc]: https://www.careersingovernment.com/tools/ gov-talk/about-gov/education/7-soft-skills-never-hear-must-master/ (дата обращения 21.10.2018).

21. Кудрявцева Е.И. Менеджмент компетенций в системе государственной гражданской службы // Управленческое консультирование. № 6 (54). 2013. С. 22-31.

22. Базовые квалификационные требования / Министерство труда и социальной защиты Российской Федерации, 2015. [Электронный pecypc]: https://rosmintrud.ru/ministry/programms/gossluzhba/11/1 (дата обращения 19.10.2018).

23. Лезина Т.А., Юркова А.Д. Анализ требований работодателей к цифровым компетенциям сотрудников // Российское предпринимательство. 2018. Т. 19. № 5. С. 1623-1632.

24. Gray A. 11 experts at Davos on the future of work. [Электронный pecypc]: https://www.weforum.org/agenda/2016/01/11-experts-at-davoson-the-future-of-work?utm_content=buffer552fe\&utm_medium=social\&utm_source=twitter.com\&utm_campaign=buffer (дата обращения 21.10.2018)

25. McLeod S., Fisch K. Shift happens. [Электронный pecypc]: https://www.theguardian.com/science/punctuated-equilibrium/2010/oct/20/2 (дата обращения 10.10.2018).

26. Tech trends 2018: The symphonic enterprise / Deloitte Insights, 2017. [Электронный pecypc]: https://documents.deloitte.com/insights/ TechTrends2018 (дата обращения 10.10.2018).

27. Skills for a digital world: 2016 ministerial meeting on the digital economy background report / OECD Digital Economy Papers, 2016, No. 250. Paris: OECD Publishing. [Электронный pecypc]: http://www.oecd-ilibrary.org/science-and-technology/skills-for-a-digitalworld_5jlwz83z3wnw-en (дата обращения 15.10.2018)

28. Brown T. Change by design: How design thinking transforms organizations and inspires. N.Y.: Harper Business, 2009.

29. Bricall J.M. Calidad y acreditacion. Universidad 2 Mil. / Conferencia de Rectores de las Universidades Espanolas. Madrid: CRUE, 2000.

30. Ertel C., Solomon L.K. Moments of impact: How to design strategic conversations that accelerate change. N.Y.: Simon \& Schuster, 2014.

31. The future of jobs. Employment, skills and workforce strategy for the Fourth industrial revolution / World Economic Forum, 2016. [Электронный ресурс]: http://reports.weforum.org/future-of-jobs-2016/ (дата обращения 21.10.2018).

32. Kelley T., Kelley D. Creative confidence unleashing the creative potential within us all. Crown Business, 2013.

33. Morin E. La testa ben fatta, riforma dell'insegnamento e riforma del pensiero nel tempo della globalizzazione. Milano: Raffaello Cortina Editore, 2000.

34. Васильева Е.В. Компетентностный подход в государственной службе: какие знания и навыки выбирают госслужащие? // Вопросы государственного и муниципального управления. 2018. № 4. С. 120-144.

35. Алтухова Н.Ф., Васильева Е.В., Мирзоян М.В. Компетентностный подход в управлении кадрами государственной службы на основе онтологий // Бизнес-информатика. № 1 (43). 2018. С. 17-27.

\section{Digital competence development of state civil servants in the Russian Federation ${ }^{5}$}

\section{Elena V. Vasilieva}

Professor, Department of Business Informatics

Financial University under the Government of the Russian Federation

Address: 38, Scherbakovskaya Street, Moscow, 105187, Russia

E-mail: evvasileva@fa.ru

\footnotetext{
5 The article is based on the results of studies carried out using budget funds and the 2018 Financial University State Mission "Improvement of information support for personnel management system based on the competence approach and individual career tracking of civil servants", state registration number AAA-A18-118052490063-1
} 


\title{
Valentina N. Pulyaeva
}

Associate Professor, Department of Human Resources Management and Psychology

Financial University under the Government of the Russian Federation

Address: 15, V. Maslovka Street, Moscow, 127083, Russia

E-mail:vnpulyaeva@fa.ru

\section{Vera A. Yudina}

Associate Professor, Department of Management, Information Science and Humanitarian Science

Financial University under the Government of the Russian Federation, Penza Branch

Address: 33B, Kalinina Street, Penza, 440052, Russia

E-mail: vayudina@fa.ru

\begin{abstract}
In the international field of public services, the competence approach is used as a basis for developing productivity, innovation and responsibility among employees. In Russia, the competence approach is central to legislative and regulatory documents but has not yet become a working tool. Russia's transition to the digital economy in accordance with the Federal Program necessitates the transformation of professional qualities and qualification requirements for positions of the state civil service. The development of a single information space of the state civil service and the widespread introduction of e-government technologies impose increased requirements on public servants' competencies in the field of information and communication technologies. However, studies have shown that until now, Russian civil servants consider as a primary priority only those competencies that focus on results, discipline, time and stress management skills, and to a lesser degree adaptability, willingness to change, creativity, initiative, and adopting new ideas and innovations. Management by competences requires an individual approach, taking into account the characteristics of each employee, as well as the development and implementation of competence models, in which all aspects of work in the digital world should be reflected.

The aim of the study is to develop guidelines for improving official regulations of state civil servants in terms of qualification requirements for competencies in the field of information and communication technologies (ICT). The use of comparative analysis methods in the study of the content of official regulations of state civil service in various subjects of the Russian Federation, as well as an expert survey on the content and current level of development of ICT competencies of civil servants allowed the authors to identify "basic," "advanced" and "special" components in the structure of competencies. We also propose methodological recommendations for the transformation of ICT competences into digital components that provide an expanded set of knowledge and skills required for the digitalization of the civil service. These changes will allow the HR services of public authorities of the Russian Federation to provide a unified approach to the formation of requirements for the maturity level of digital competencies of applicants seeking positions in the state civil service. It also will help to implement a targeted approach in the formation of programs for the development of personnel potential, taking into account the requirements of digital literacy.
\end{abstract}

Key words: digital competencies; digital economy; civil servant; public administration; position regulations; metacompetence; soft skills.

Citation: Vasilieva E.V., Pulyaeva V.N., Yudina V.A. (2018) Digital competence development of state civil servants in the Russian Federation. Business Informatics, no. 4 (46), pp. 28-42. DOI: 10.17323/1998-0663.2018.4.28.42

\section{References}

1. Vasilieva E.V., Slavin B.B., eds. (2018) Effektivnost' upravleniya kadrami gosudarstvennoy grazhdanskoy sluzhby v usloviyah razvitiya tsifrovoy ekonomiki i obschestva znaniy [Efficiency of personnel management of the state civil service in the conditions of development of digital economy and knowledge society]. Moscow: INFRA-M, 2018 (in Russian).

2. Babkin A.V., Burkaltseva D.D., Kosten D.G., Vorobyev Yu.N. (2017) Formirovanie tsifrovoy ekonomiki v Rossii: suschnost', osobennosti, tekhnicheskaya normalizatsiya, problemy razvitiya [Formation of the digital economy in Russia: the essence, features, technical normalization, development problems]. St. Petersburg State Polytechnical University Journal. Economics, vol. 10, no. 3, pp. 9-25 (in Russian).

3. Petrov M., Burov V., Shklyaruk M., Sharov A. (2018) Gosudarstvo kak platforma. (Kiber)gosudarstvo dlya tsifrovoy ekonomiki. Tsifrovaya transformatsiya [State as a platform. (Cyber)state for the digital economy. Digital transformation]. Moscow: Strategic Development Center (in Russian).

4. Vasilieva E.V. (2018) Dizayn-myshlenie: nemnogo o podhode i mnogo ob instrumentah razvitiya kreativnogo myshleniya, izucheniya klientskih zaprosov i sozdaniya idey [Design thinking: A little about the approach and a lot about tools for the development of creative thinking, studies of client requests and ideas creating]. Moscow: RUScience (in Russian).

5. Verbitsky A.A., Larionova O.G. (2009) Lichnostnyy $i$ kompetentnostnyy podhody v obrazovanii. Problemy integratsii [Personal and competence approaches in education: problems of integration]. Moscow: Logos (in Russian).

6. Vetoshkina T. (2008) Rol' kompetentsiy v upravlenii personalom [The role of competences in personnel management]. Kadrovik. Personnel management, no. 3, pp. 11-18 (in Russian). 
7. Volpyan N. (2013) Modeli kompetentsiy. Mezhdunarodnyy opyt v IT-sfere [Competency models. International experience in the IT sphere] The birth of the collective mind. Moscow: LENAND, pp. 201-229 (in Russian).

8. Pulyaeva V.N. (2015) Model' kompetentsiy menedzhera v klientoorientirovannoy ekonomike [Manager competency model in a client-oriented economy]. Personnel and intellectual resources management in Russia, no. 2 (17), pp. 24-30 (in Russian).

9. Bertaud A. (2014) Cities as labour markets. Working paper. № 2. Available at: https://marroninstitute.nyu.edu/uploads/content/Cities_as_Labor_ Markets.pdf (accessed 01 October 2018).

10. Blank S. (2013) The four steps to the epiphany: Successful strategies for products that win. Quad/Graphics.

11. Kupriyanovsky V.P., Sukhomlin V.A., Dobrynin A.P., Raikov A.N., Shkurov F.V., Drozhzhinov V.I., Fedorova N.O., Namiot D.E. (2017) Navyki $\mathrm{v}$ tsifrovoy ekonomike i vyzovy sistemy obrazovaniya [Skills in the digital economy and challenges of the education system]. International Journal of Open Information Technologies, no. 1, pp. 19-25 (in Russian).

12. Raven J. (1984) Competence in modern society: Identification, development and implementation. Unionville, New York: Royal Fireworks Press.

13. Krasilnikova L.I., ed. (2014) Model'professional'nyh kompetentsiy gosudarstvennyh grazhdanskih sluzhaschih Hanty-Mansiyskogo avtonomnogo okruga - Yugry. Metodicheskie rekomendatsii [A model of professional competence of civil servants of the Khanty-Mansiysk Autonomous District Yugra. Methodological recommendations]. Khanty-Mansiysk: Regional Management Institute (in Russian).

14. Heene F., Sanchez R. (1997) Competence based strategic management. London: John Wiley.

15. Zimnyaya I.A. (2008) Edinaya sotsial'no-professional'naya kompetentnost'vypusknika universiteta: ponyatie, podhody k formirovaniyu i otsenke [Unified social and professional competence of a university graduate: concept, approaches to formation and evaluation]. Moscow: MISIS (in Russian).

16. Legkaya L.E. (2008) Kompetentsii kak instrument upravleniya personalom na predpriyatiyakh malogo biznesa [Competences as a tool for personnel management in small businesses]. Public Administration. E-Journal, no. 15. Available at: http://e-journal.spa.msu.ru/uploads/vestnik/2008/ vipusk_15._ijun_2008_g./legkaya.pdf (accessed 27 October 2018) (in Russian).

17. Bondarenko V.V., Yudina V.A., Tanina M.A. (2015) Povyshenie effektivnosti v sisteme gosupravleniya na osnove razrabotki kvalifikatsionnyh trebovaniy k zamescheniyu dolzhnostey gosudarstvennyh grazhdanskih sluzhaschih [Improving efficiency in the system of public administration through the development of qualification requirements for the replacement of civil servants]. Theoretical and methodological approaches to the formation of the system of enterprises, complexes and regions development. Penza: Penza State Agricultural Academy, pp. 40-55 (in Russian).

18. Ministry of Labor of Russia (2016) O Metodike vsestoronney otsenki professional'noy sluzhebnoy deyatel'nosti gosudarstvennogo grazhdanskogo s luzhaschego [On the methodology for the comprehensive assessment of professional performance of a state civil servant]. Letter dated 14 June 2016, no. 18-1/10/B-3980. Available at: http://sudact.ru/law/metodika-vsestoronnei-otsenki-professionalnoi-sluzhebnoi-deiatelnosti-gosudarstvennogo/ (accessed 21 October 2018) (in Russian).

19. Ministry of Labor and Social Protection of Russia (2018) Metodicheskiy instrumentariy po ustanovleniyu kvalifikatsionnyh trebovaniy dlya zamescheniya dolzhnostey gosudarstvennoy grazhdanskoy sluzhby [Methodological toolkit for establishing qualification requirements for filling civil service positions]. Version 3.2. Available at: http://www.garant.ru/products/ipo/prime/doc/71755218/ (accessed 21 October 2018) (in Russian).

20. Babbitt M. (2014) 7 soft skills we never hear about (but must master). Available at: https://www.careersingovernment.com/tools/gov-talk/about-gov/ education/7-soft-skills-never-hear-must-master/ (accessed 21 October 2018).

21. Kudryavtseva E.I. (2013) Menedzhment kompetentsiy v sisteme gosudarstvennoy grazhdanskoy sluzhby [Competency management in public administration]. Management Consulting, no. 6 (54), pp. 22-31 (in Russian).

22. Ministry of Labor and Social Protection of Russia (2015) Bazovye kvalifikatsionnye trebovaniya [Basic qualification requirements]. Available at: https://rosmintrud.ru/ministry/programms/gossluzhba/11/1 (accessed 19 October 2018) (in Russian).

23. Lezina T.A., Yurkova A.D. (2018) Analiz trebovaniy rabotodateley $\mathrm{k}$ tsifrovym kompetentsiyam sotrudnikov [Analysis of employers' requirements to digital competencies of employees]. Russian Journal of Entrepreneurship, vol. 19, no. 5, pp. 1623-1632 (in Russian).

24. Gray A. (2016) 11 experts at Davos on the future of work. Available at: https://www.weforum.org/agenda/2016/01/11-experts-at-davos-on-the-futureof-work?utm_content=buffer552fe\&utm_medium=social\&utm_source=twitter.com\&utm_campaign=buffer (accessed 21 October 2018).

25. McLeod S., Fisch K. (2010) Shift happens. Available at: https://www.theguardian.com/science/punctuated-equilibrium/2010/oct/20/2 (accessed 10 October 2018).

26. Deloitte (2017) Tech trends 2018: The symphonic enterprise. Deloitte Insights. Available at: https://documents.deloitte.com/insights/TechTrends2018 (accessed 10 October 2018).

27. OECD (2016) Skills for a digital world: 2016 ministerial meeting on the digital economy background report. OECD Digital Economy Papers, no. 250. Paris: OECD Publishing. Available at: http://www.oecd-ilibrary.org/science-and-technology/skills-for-a-digital-world_5jlwz83z3wnw-en (accessed 15 October 2018)

28. Brown T. (2009) Change by design: How design thinking transforms organizations and inspires. N.Y.: Harper Business.

29. Bricall J.M. (2000) Calidad y acreditacion. Universidad 2 Mil. Conferencia de Rectores de las Universidades Espanolas. Madrid: CRUE (in Spanish).

30. Ertel C., Solomon L.K. (2014) Moments of impact: How to design strategic conversations that accelerate change. N.Y.: Simon \& Schuster.

31. World Economic Forum (2016) The future of jobs. Employment, skills and workforce strategy for the Fourth industrial revolution. Available at: http:// reports.weforum.org/future-of-jobs-2016/ (accessed 21 October 2018).

32. Kelley T., Kelley D. (2013) Creative confidence unleashing the creative potential within us all. Crown Business.

33. Morin E. (2000) La testa ben fatta, riforma dell'insegnamento e riforma del pensiero nel tempo della globalizzazione. Milano: Raffaello Cortina Editore (in Italian).

34. Vasilieva E.V. (2018) Kompetentnostnyy podhod v gosudarstvennoy sluzhbe: kakie znaniya i navyki vybirayut gossluzhaschie? [Competence approach in public service: what knowledge and skills do civil servants choose?]. Public Administration Issues, no. 4, pp. 120-144 (in Russian).

35. Altukhova N.F., Vasileva E.V., Mirzoyan M.V. (2018) Kompetentnostnyy podhod v upravlenii kadrami gosudarstvennoy sluzhby na osnove ontologiy [Competence-based approach to managing staff in public administration on the basis of ontologies]. Business Informatics, no. 1 (43), pp. 17-27 (in Russian). 


\section{Цифровизация учета профессиональных компетенций граждан на основе технологий распределенных реестров и смарт-контрактов ${ }^{1}$}

\section{С.П. Новиков}

кандидат технических наук

доцент кафедры информационных технологий

Брянский государственный инженерно-технологический университет

Адрес: 241037, г. Брянск, пр. Станке Димитрова, д. 3

E-mail: spnovikov@gmail.com

\section{О.В. Михеенко}

кандидат экономических наук

доцент кафедры государственного управления и финансов

Брянский государственный инженерно-технологический университет Адрес: 241037, г. Брянск, пр. Станке Димитрова, д. 3

E-mail:miheenkoov@mail.ru

\section{Н.А. Кулагина}

доктор экономических наук, профессор директор инженерно-экономического института

Брянский государственный инженерно-технологический университет Адрес: 241037, г. Брянск, пр. Станке Димитрова, д. 3

E-mail: kulaginana2013@yandex.ru

\section{О.Д. Казаков}

кандидат технических наук, доцент заведуюший кафедрой информационных технологий

Брянский государственный инженерно-технологический университет Адрес: 241037, г. Брянск, пр. Станке Димитрова, д. 3

E-mail: kod8383@mail.ru

\section{Аннотация}

В условиях становления цифровой экономики на первый план выходит сохранение и приумножение интеллектуального капитала, который в настоящее время является ключевым фактором общественного развития. Ориентация национальной экономики на использование современных достижений цифровой индустрии будет способствовать скорейшему переходу к информационному обществу в глобальном масштабе. Цифровизация образования позволит использовать последние достижения научной мысли для развития других сфер жизнедеятельности общества.

В работе предложена модель адаптации технологий распределенных реестров на основе блокчейн и смарт-контрактов для надежного хранения и эффективного использования показателей уровня профессиональных компетенций граждан в целях создания единой информационной среды взаимодействия всех субъектов экономической системы. Авторами разработана модель системы учета профессиональных компетенций граждан и траекторий их развития, основанная на использовании современных технологий цифровой экономики. Обоснована эффективность и безопасность использования блокчейн-технологии для хранения и передачи информации.

\footnotetext{
1 Исследование выполнено при финансовой поддержке Российского фонда фундаментальных исследований, проект № 18-410-320002\18 «Концепция инновационного управления развитием региональной экономики в условиях цифровизации: проектный подход»
} 
Основными субъектами в представленной системе являются образовательные учебные заведения всех уровней, государственные структуры по надзору в сфере образования и непосредственно сами граждане, принимающие участие в образовательном процессе.

Предложенная модель отражает уровень образования и профессионального мастерства каждого зарегистрированного участника в виде индекса (education index, EI), учитывающего все достижения в сфере образования и профессиональные компетенции на протяжении всей жизни. По мнению авторов, при расчете ЕI целесообразно также учитывать рейтинг образовательного учреждения, принимающего участие в формировании профессиональных компетенций граждан. Введение ЕІ позволит существенно упростить процесс трудоустройства выпускников различных образовательных учреждений, а также проведение вузами приемных кампаний. Кроме того, при помощи инструментов анализа возможно создание рейтингов вузов, кафедр и даже отдельных преподавателей. Разработанная система учета профессиональных компетенций ориентирована на обработку и хранение больших объемов данных (Big Data), что позволит в перспективе подключить к реестру работодателей, фонд пенсионного страхования и иные государственные структуры, заинтересованные в использовании полных и достоверных персональных данных граждан.

Ключевые слова: цифровая экономика; профессиональные компетенции; блокчейн; смарт-контракт; цифровой реестр; цифровизация образования; криптография.

Цитирование: Новиков С.П., Михеенко О.В., Кулагина Н.А., Казаков О.Д. Цифровизация учета профессиональных компетенций граждан на основе технологий распределенных реестров и смарт-контрактов // Бизнес-информатика. 2018. № 4 (46). C. 43-53. DOI: 10.17323/1998-0663.2018.4.43.53

\section{Введение}

A ктивное внедрение современных информационно-телекоммуникационных технологий сопровождается цифровой трансформацией всех сфер человеческой деятельности. Цифровизация сегодня играет важнейшую роль в экономике любого государства, вторгаясь во все отрасли и направления [1]. Это вызывает необходимость разработки качественно новой модели бизнеса, требует изменения формата образования, здравоохранения и государственного управления, а также отражается на способах и интенсивности коммуникационных связей между людьми [2].

Основные направления и этапы формирования цифрового общества определены в программе «Цифровая экономика Российской Федерации на период до 2025 года» [3]. Быстрый доступ в Интернет для каждого гражданина, включая жителей отдаленных населенных пунктов, замена вузовских дипломов и трудовых книжек на траектории развития, «умные города» и даже автоматизированная система принятия государственных решений - это основные цели, определяемые программой развития национального цифрового пространства.

В Указе Президента РФ от 09.05.2017 № 203 «О Стратегии развития информационного общества в Российской Федерации на 2017-2030 годы» под- черкивается, что развитие цифровой экономики является стратегически важным вопросом для страны в целом, определяющим ее конкурентоспособность в мировом масштабе [4].

Переход на «цифровые рельсы» в настоящее время осуществляется и в системе образования, где первоочередной и одной из важнейших задач является практически полная оцифровка документооборота образовательного учреждения (ОУ). Параллельно осуществляется интеграция цифровых технологий в учебный процесс и систему управления ОУ. Очевидно, что в ближайшем будущем документы об образовании (аттестаты, дипломы, сертификаты, удостоверения и т.п.) трансформируются в электронный формат. В связи с этим остро встают вопросы о создании единого цифрового реестра персональных данных, возможности хранения и высокой степени конфиденциальности информации, а также разработки механизма идентификации, обеспечивающего доступ пользователей к реестру.

Решение поставленных задач требует формирования цифровой среды единого информационного пространства и внедрения инновационных технологий работы с цифровыми данными, обеспечивающих исключительную надежность и безопасность хранения информации, ее актуальность, достоверность, доступность и высокую скорость сетевой обработки [5]. 


\section{1. Блокчейн-технология как коммуникационная основа системы управления профессиональными компетенциями}

\section{1. Блокчейн-технология}

Прорывом в области надежного хранения информации в общедоступных сетях стала блокчейн-технология [6]. Блокчейн - это тип распределенной базы данных, где записи группируются в блоки, каждый из которых связан с предыдущим с использованием хэш-ключа [7]. Это обеспечивает невозможность изменения информации внутри блока без изменения информации, хранящейся в последующих блоках. Цепочка блоков хранится на узловом компьютере (Node) у каждого участника системы, образуя распределенный реестр данных. При добавлении нового блока обновляются копии всей цепочки блоков у каждого участника. Консенсус относительно того, какие типы блоков и транзакций могут быть частью блокчейна, автоматически достигается в соответствии с тем, согласны ли большинство держателей блок-цепочек с предложенными блоками.

Новизна технологии блокчейн состоит в том, что появляется возможность устанавливать бизнес-логику в самой транзакции. Блок содержит в себе набор записей, а новые блоки добавляются строго в конец цепочки. Это отличает данную технологию от традиционных баз данных, в которых бизнес-логика устанавливается в самой базе данных или в программном обеспечении.

Выделим существенные преимущества технологии блокчейн:

\ децентрализация, которая минимизирует риски отказа в случае выхода из строя отдельной системы;

^ повышенная степень безопасности за счет использования средств криптографии при осуществлении каждой транзакции;

- невозможность изменения данных утвержденного блока, поскольку хэш идентификатора каждого блока вычисляется на основе кумулятивного хэша данных всего блока и хэша идентификатора предыдущего блока;

\ оперативность за счет автоматизированного обмена данными, при котором отсутствует человеческий фактор;

^ прозрачность, так как все действия документируются и доступны для ознакомления всем участникам системы.
На наш взгляд, последнее является непревзойденным достоинством технологии блокчейн, поскольку позволяет регулятору убедиться, что содержание базы данных не редактировалось и не изменялось мошенническим путем.

\section{2. Практические аспекты цифровизации образования}

В настоящее время интерес к использованию технологии блокчейн в сфере образования объясняется возможностью значительно сократить затраты и время при проведении транзакций, а главное - обеспечить высокую степень безопасности [8]. Внедрение данной технологии в образовательную среду было одобрено в 2017 году, что отражено в докладе Европейской комиссии «Блокчейн в образовании» [9]. Среди ключевых факторов, которые учитывала Комиссия, оказались осуществимость, задачи, преимущества и риски использования данной технологии в школах и университетах. При этом внимание сфокусировано на возможности использования данной технологии для цифровой аккредитации персонального и академического обучения. Еврокомиссия представила восемь сценариев того, как блокчейн может быть использован в целях решения актуальных задач, стоящих сегодня перед образовательным сектором. Среди них - кредитные трансферы, цифровая сертификация, пошаговая аккредитация, а также оплата обучения. К сожалению, подобные технологии в образовательном секторе по-прежнему находятся в зачаточном состоянии.

Тем не менее, в международной практике известны отдельные достижения в данном направлении, среди которых:

^ патентная заявка японского технологического конгломерата SONY на создание образовательной платформы на базе блокчейна для хранения и обмена данными об успеваемости студентов (документ размещен на официальном сайте Ведомства по патентам и торговым знакам США) [10];

$\checkmark$ соглашение министерства образования и занятости Мальты с блокчейн-стартапом Learning Machine Technologies o разработке экспериментальной платформы, которая позволит пользователям безопасно хранить и передавать документы об образовании, а также подтверждать их подлинность [11];

^ выдача более 100 цифровых дипломов выпускникам Массачусетского технологического института на основе применения технологии блокчейн [12].

Все это свидетельствует о неотвратимости процес- 
са цифровизации сферы образования как главнейшего фактора становления цифровой экономики.

\section{3. Эволюция блокчейн-технологии в контексте цифровой экономики}

Технология блокчейн была разработана в 2008 году [13] и прошла большой путь трансформационного развития от совершения отдельных сделок с криптовалютой до базы создания гибких блокчейн-платформ для их последующего внедрения в широкий спектр отраслей.

В книге «Блокчейн. Схема новой экономики» (Blockchain. Blueprint for a new economy), исследователь и основатель института блокчейн-исследований Мелани Свон (Melanie Swan) выделяет три условные области применения данной технологии [14]:

Блокчейн 1.0 - криптовалютные транзакции (крипто-валюты применяются в различных приложениях, имеющих отношение к финансовым транзакциям, например, в системах переводов и цифровых платежей) [15];

Блокчейн 2.0 - смарт-контракты (приложения в области экономики, рынков и финансов, работающие с различными типами инструментов - акциями, облигациями, фьючерсами, закладными, правовыми титулами, активами и контрактами) [16];

Блокчейн 3.0 - приложения, область которых выходит за рамки финансовых транзакций и рынков (распространяются на сферы государственного управления, здравоохранения, науки и др.) [17].

Поскольку сфера применения блокчейн-технологии значительно расширилась, основной тенденцией становится не появление новых криптовалют как платежных средств, а создание многофункциональных платформ, которые выступают как инфраструктура для целого спектра деловых приложений [18]. Целесообразность применения технологии блокчейн начали прорабатывать и разработчики различных комплексных информационных систем, в частности, развивающие методологию создания решений в рамках концепции «Smart City» [19]. Активно ведутся разработки применения технологии блокчейн в системах аутентификации личности [20]. Использование смарт-контрактов позволяет преобразовать распределенный реестр данных в систему управления хранящейся информацией, а технология блокчейн обеспечивает защиту персональных данных и бизнес-логику работы всей системы.

Проведенный в рамках исследования анализ практики использования технологии блокчейн выявил, что на сегодняшний день она выделена как обособленная технология, которая может использоваться за рамками криптовалют. Наиболее обосновано применение данной технологии в тех сферах и областях, где необходимо оптимизировать взаимоотношения между участниками социально-экономических систем [21]. В этом случае можно говорить о создании национальной системы учета профессиональных компетенций граждан и траекторий их развития на основе блокчейн-технологии. Такая система способна стать основой цифровой экономики государства. В дальнейшем она может быть интегрирована с подобными системами на международном уровне.

\section{2. Особенности реализации технологии распределенных реестров и смарт-контрактов в системе учета профессиональных компетенций граждан}

\section{1. Выбор блокчейн-платформы}

Технологию блокчейн можно рассматривать как защищенный от несанкционированного доступа цифровой реестр общего пользования, который ведет учет транзакций в публичной или закрытой одноранговой сети. Распределенный между всеми узлами сети реестр непрерывно записывает историю операций с активами между одноранговыми узлами сети в виде блоков информации. Таким образом, блокчейн выступает в качестве единого источника достоверных данных, а участники блокчейн-цепи видят только те транзакции, которые относятся именно к ним.

На основании вышесказанного авторами предлагается использовать универсальную блокчейнплатформу для организации системы учета профессиональных компетенций граждан. В основу системы положены открытые решения, в частности, в качестве блокчейн-платформы выбран публичный Ethereum, являющийся вторым по популярности блокчейн-проектом в мире после bitcoin [22]. На наш взгляд, данный проект наиболее удобен, поскольку позволяет решать более широкий класс задач, обеспечивая условия выполнения транзакций на основе технологии смарт-контрактов.

Кроме того, к числу достоинств платформы Ethereum относятся:

\ возможность поддержки оптимального уровня безопасности из-за большого развертывания и процессов необратимости;

^ обеспечение прозрачности публичного блокчейна, особенно с помощью франчайзинговых контрактов с открытым исходным кодом; 
\ наличие различных вариантов улучшений, особенно в отношении масштабируемости.

Таким образом, абсолютно объективно, блокчейнплатформа Ethereum предоставляет возможность не только создать безопасный и прозрачный общедоступный реестр, сохраняющий любые профессиональные достижения граждан на протяжении их жизни (профессиональный актив), но и обеспечить их учет с использованием технологии смарт-контрактов.

Факт получения сертификата, аттестата, диплома или любого другого документа об образовании может быть зарегистрирован в реестре любым образовательным учреждением, выдавшим соответствующий документ. В качестве валидаторов такой транзакции могут выступать государственные структуры, осуществляющие контроль в сфере образования.

\section{2. Формирование индивидуального индекса уровня образования с использованием технологии смарт-контрактов}

Технология смарт-контрактов может быть использована для оперативного пересчета индекса уровня образования (education index, EI) граждан, зарегистрированных в системе учета профессиональных компетенций. Смарт-контракт активируется при наступлении определенных событий, связанных с изменением образовательного уровня или профессиональных компетенций граждан. Аналогично смарт-контракты могут быть использованы для пересчета рейтинга образовательных учреждений, центров, кафедр и преподавателей. Технически смарт-контракт представляет собой исходный код, записанный в блокчейн, который размещается в специальном блоке (программный контейнер). Также в блоке объединены все сообщения, имеющие отношение к этому смарт-контракту. Они являются входными и выходными данными алгоритма и при необходимости запускают определенные операции за пределами блокчейна.

На рисунке 1 представлен алгоритм выполнения транзакции при активации смарт-контракта для перерасчета образовательного индекса $E I$ граждан на базе блокчейн-платформы Ethereum по факту регистрации изменения образовательного уровня или профессиональных компетенций участников системы.

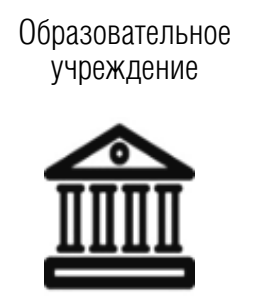

Запрос транзакции

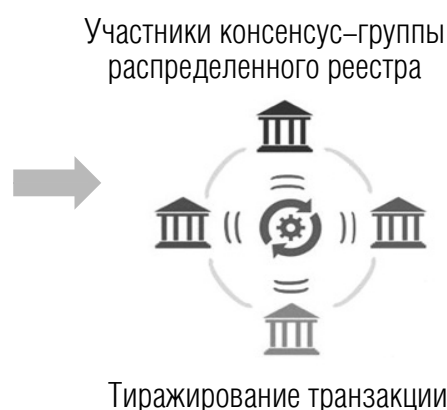

Тиражирование транзакции

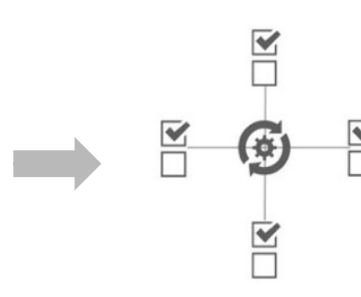

Верификация и регистрация транзакции

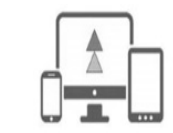

Уведомление о выполнении транзакции

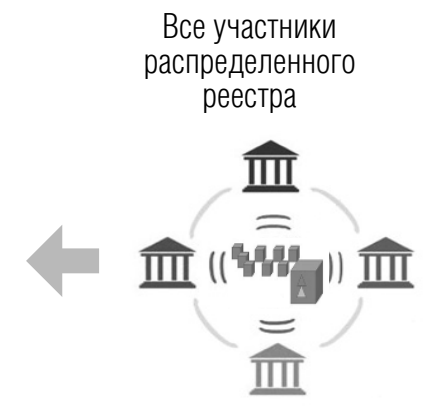

Добавление блока в блокчейн у всех участников системы

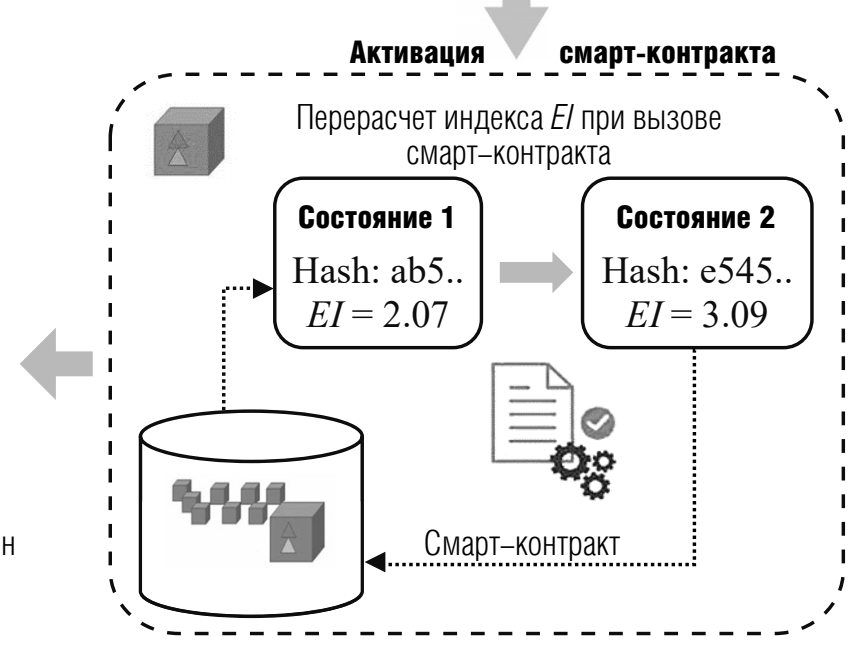

Pис. 1. Схема выполнения транзакции для системы учета компетенций граждан на базе блокчейн-платформы Ethereum 
Инициатором такой транзакции может быть любое образовательное учреждение, зарегистрированное в системе учета профессиональных компетенций граждан и имеющее право на выдачу документа об образовании. Далее транзакция рассылается для верификации участникам распределенного реестра, имеющим право на ее регистрацию. В качестве таких участников могут выступать государственные учреждения, осуществляющие контрольно-надзорные функции в сфере образования. Все упомянутые участники, получая данные о предполагаемой транзакции, подтверждают их корректность путем достижения консенсуса.

В случае успешной регистрации транзакции, отражающей факт получения документа об образовании, автоматически активируется смарт-контракт и осуществляется перерасчет индекса уровня образования $Е$ I участника системы, для которого добавляется профессиональное достижение. Далее значение рассчитанного EI добавляется к транзакции, которая объединяется с другими транзакциями и формирует новый блок цифрового реестра. Этот блок занимает уникальное место в цепочке блокчейна и не поддается изменению. После этого обновленная цепочка тиражируется всем участникам распределенного реестра. Тогда транзакция считается завершенной.

\section{3. Разработка модели балльно-рейтинговой системы учета профессиональных компетенций граждан}

В основу разработанной модели балльно-рейтинговой системы учета профессиональных компетенций граждан положен расчет итогового индекса уровня образования ЕI участника, который целесообразно формировать в виде десятичной дроби. Цифра, стоящая слева от десятичной точки, отражает базовый уровень профессионального образования (basic level of education, $B L E$ ), определенный на законодательном уровне. Цифры, стоящие справа от десятичной точки, - суммарные рейтинговые баллы (educational level rating, $E L R$ ), отражающие профессиональные компетенции граждан. Эти баллы учитывают как значимость полученного документа об образовании, так и статус и образовательного учреждения, выдавшего данный документ.

Авторами работы предложена следующая методика формирования указанных показателей. Показатель $B L E$ соответствует уровню образования, под которым понимается завершенный цикл образования, характеризующийся определенной единой совокупностью требований. Согласно Федеральному закону «Об образовании в Российской Федерации» от 29.12.2012 № 273-Ф3 в России устанавливаются следующие уровни профессионального образования [23]:

1. Среднее профессиональное образование;

2. Высшее образование - бакалавриат;

3. Высшее образование - специалитет, магистратура;

4. Высшее образование - подготовка кадров высшей квалификации.

Следовательно, показатель $B L E$ может принимать значения из диапазона от 1 до 4, отражающие соответствующий завершенный цикл образования.

Показатель $E L R$ отражает суммарные накопленные профессиональные компетенции граждан. На наш взгляд, обосновано начислять определенное количество баллов за каждый выданный документ об образовании, число которых соответствует уровню значимости этого документа (level of the educational document, $L E D$ ), умноженному на весовой коэффициент (rating of educational institution, $R E I$ ), отражающий рейтинг образовательного учреждения, выдавшего соответствующий документ. Тогда показатель $E L R$ может быть рассчитан по формуле:

$$
E L R=\sum_{i=1}^{n} L E D_{i} \cdot R E I_{i},
$$

где $n$ - общее число выданных и зарегистрированных в системе документов об образовании.

Таким образом, итоговый индекс уровня образования $E I$ может быть представлен в следующей форме:

$$
\text { EI: BLE.ELR }
$$

Например, запись $E I$ в виде: 2.13 будет означать, что обладатель данного индекса имеет высшее образование - бакалавриат, и его суммарный образовательный рейтинг составляет 13.

Представленную схему расчета итогового индекса уровня образования $E I$ реализует смарт-контракт, который активируется всякий раз при успешной регистрации транзакции, отражающей факт получения документа об образовании.

Для реализации смарт-контракта на платформе Ethereum был создан язык программирования Solidity, который близок по синтаксису к JavaScript и является Тьюринг-полным. Используя синтаксис языка Solidity, состояние контракта может быть представлено двумя переменными $B L E$ и $E L R$ типа 
uint8, которые обрабатываются и хранятся в состоянии блока независимо. Это связано с тем, что на данный момент числа с фиксированной точкой пока не полностью поддерживаются в Solidity. На будущее зарезервированы ключевые слова fixed / ufixed: знаковое и беззнаковое число с фиксированной точкой различного размера.

Для удобства восприятия индекс $E I$ в любой момент может быть представлен в формате $B L E . E L R$ путем конвертации $B L E$ и $E L R$ в строковый формат.

\section{4. Организация взаимодействия участников системы учета профессиональных компетенций}

Благодаря технологии блокчейн, каждый зарегистрированный участник системы может легко проверить свои достижения и $E I$, выстроив полную хронологическую цепочку. Проблема авторизации решается за счет использования криптографии с открытым ключом. Каждому пользователю системы выдается пара из секретного и открытого ключа. Открытый ключ может быть без проблем опубликован для определения цифровой личности пользователя, так как секретный ключ невозможно вывести из открытого. Таким образом, будет сформирован цифровой реестр интеллектуальных активов при соблюдении принципа неизменности и достоверности всех внесенных в него данных.

В тоже время следует отметить сложность прямой адаптации открытого блокчейна для организации оптимального взаимодействия всех участников системы, а главное - для обеспечения контроля со стороны надзорных органов в сфере образования. В этом случае целесообразно создать более контролируемую среду управления распределенными реестрами при построении системы учета профессиональных компетенций граждан. Здесь надо учитывать, что технология блокчейн может использоваться для организации реестров двух форм: открытой и закрытой [24]. Каждая из форм организации реестра определяет доступ к данным и имеет свою архитектуру. В работе [25] раскрыто понятие эксклюзивного блокчейна (permissioned blockchain), в котором обработка транзакций осуществляется определенным списком субъектов с установленными личностями. Создание блоков в эксклюзивном блокчейне не требует «доказательства работы» по алгоритму proof-of-work [26]. Здесь могут использоваться хорошо изученные алгоритмы консенсуса с аутентифицированными участни- ками, например, Practical Byzantine Fault Tolerance (PBFT) [27]. Учитывая данные особенности, при создании системы учета профессиональных компетенций граждан, авторами взята за основу технология эксклюзивного блокчейна и предложена следующая организация блокчейн-сети (рисунок 2).

Организационную структуру блокчейн-цепи можно представить тремя уровнями, группирующими ноды по функциональным ролям в системе учета профессиональных компетенций граждан:

1. Уровень консенсуса - узлы, активно участвующие в формировании блокчейна, постоянно группирующие входящие транзакции в блоки и распространяющие их по сети. Эти узлы обладают правами на верификацию и регистрацию новых транзакций в системе. Роль таких узлов могут взять на себя государственные учреждения, осуществляющие надзор в сфере образования.

2. Уровень аудита - узлы, которые не участвуют в процессе консенсуса, однако имеют у себя полную копию блокчейна. Такие узлы автоматически проверяют работу группы консенсуса и занимаются распределением нагрузки по сети, выполняя функцию своеобразной сети доставки контента для данных блокчейна. Роль таких узлов могут взять на себя непосредственно образовательные учреждения, осуществляющие выдачу документа об образовании.

3. Уровень легких клиентов - узлы, не имеющие полной версии блокчейна и содержащие лишь те данные, которые важны для узла. Поэтому они являются хорошим вариантом для конечных пользователей, компетенции которых фиксируются. Такие узлы позволяют эффективно отслеживать индивидуальный ЕI и другие показатели системы учета профессиональных компетенций. Легкие клиенты требуют меньше вычислительных ресурсов и объемов памяти, поэтому могут работать на мобильных платформах.

Таким образом, валидаторами транзакций глобального реестра учета профессиональных достижений граждан должны выступать образовательные учреждения, с одной стороны, и государственные структуры, осуществляющие контроль в сфере образования, с другой. Однако, доступ к данным в реестре целесообразно сделать открытым. Такими данными смогут воспользоваться, например, вузы для принятия решения о перезачете ранее изучаемых дисциплин при смене студентом места обучения, либо работодатели, осуществляющие поиски специалистов на вакантные места. 


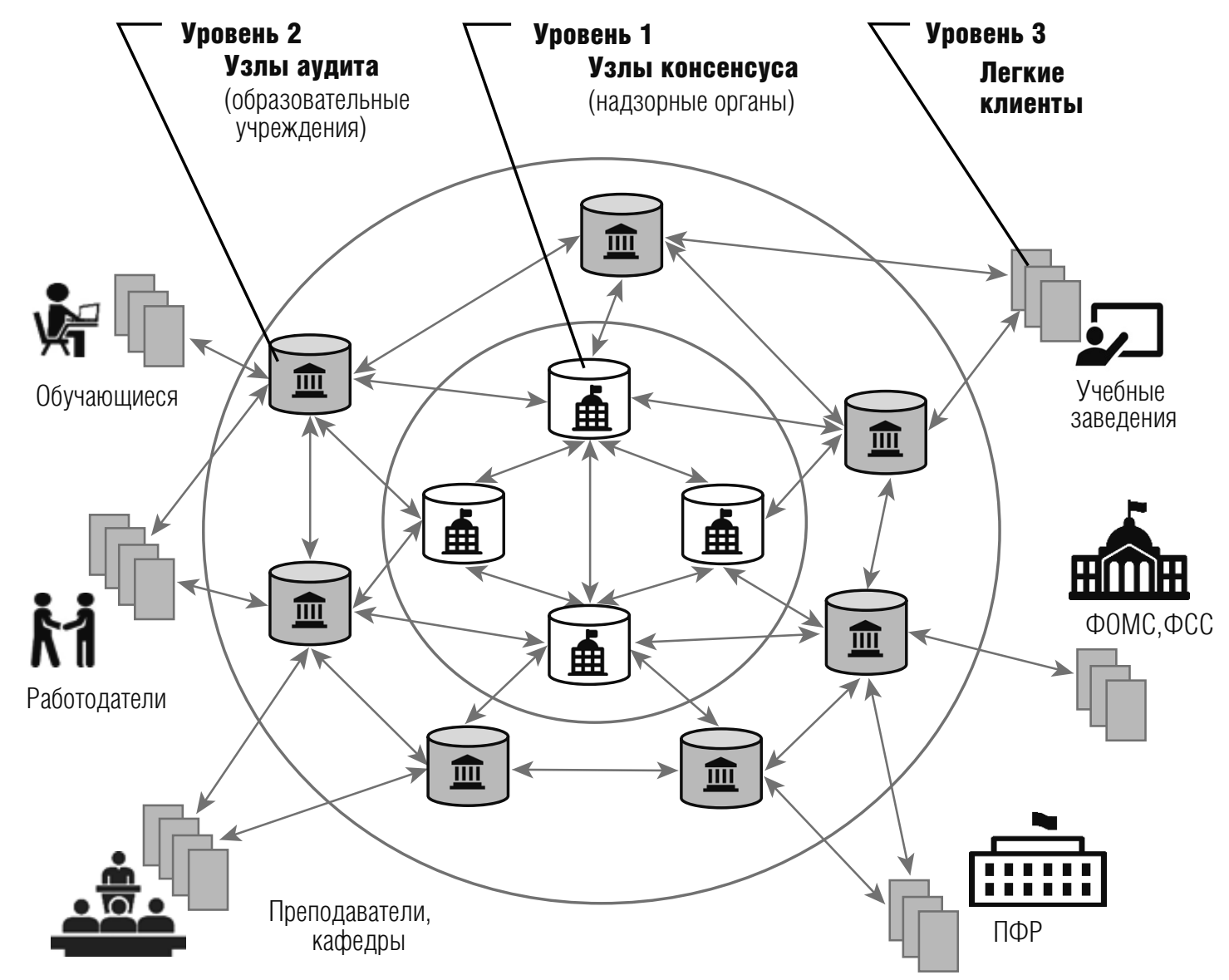

Рис. 2. Модель организационной структуры образовательной сфреры на основе блокчейн-сети

\section{Заключение}

В рамках данного исследования предложена технология организации системы учета профессиональных компетенций граждан. На базе блокчейнплатформы Ethereum рассмотрен алгоритм расчета ключевых показателей индекса уровня образования EI. Также разработана модель балльно-рейтинговой системы формирования этих показателей. Приведена общая структура исходного кода смарт-контракта, написанного на языке Solidity, реализующего предложенный алгоритм.

На основе анализа форм распределенных реестров обосновано применение эксклюзивной формы блокчейна для организации цифрового национального реестра профессиональных достижений граждан, которая имеет определенные преимущества. Во-первых, это низкая стоимость транзакций, поскольку проверка их валидности проводится доверенными и высокопроизводительными узлами вместо десятков тысяч пользовательских устройств, как в случае с общедоступными сетями. Во-вторых, реализуется полный контроль над системой со стороны государственных структур по надзору в сфере образования.

В работе выделены преимущества создания безопасного распределенного реестра, сохраняющего любые профессиональные достижения граждан на протяжении их жизни. В ходе исследования показано, что такой реестр может стать основой национальной системы учета профессиональных компетенций граждан и траекторий их развития. В дальнейшем распределенный реестр профессиональных достижений граждан поможет подтверждать фактическую квалификацию выпускников школ или студентов.

Если учебные заведения будут регистрировать выданные дипломы об образовании или сертификаты об обучении в такой системе, то потенциальному работодателю не составит труда убедиться в том, что соискатели действительно проходили обучение в данном вузе или на курсах, а не представили фальшивый диплом. Такими данными, которые будут находиться в открытом доступе, смогут воспользоваться инвесторы, находящиеся в поиске перспективных 
дипломных работ и кадров. Технология будет полезной и в случае прохождения онлайн-обучения. Создание системы учета профессиональных компетенций граждан на основе блокчейн является важным этапом при переходе к цифровой экономике.
Основная трудность при эксплуатации предложенной системы состоит в достижении баланса между защитой интересов участников системы и удовлетворением более широких интересов и потребностей общества.

\section{Литература}

1. Новикова А.В. Состояние, проблемы и перспективы развития человеческого капитала в научной сфере Российской Федерации // Вестник Брянского государственного технического университета. 2016. № 5 (53). С. 262-266.

2. Новикова А.В. Шлемина И.В., Махова В.В. Человеческий капитал и направления повышения эффективности его использования // Экономика и предпринимательство. 2016. № 4, ч. 2 (69-2) . С. 717-720.

3. Программа «Цифровая экономика Российской Федерации». Утверждена Распоряжением Правительства Российской Федерации от 28 июля 2017 г. № 1632-p.

4. Стратегия развития информационного общества в Российской Федерации на 2017-2030 годы. Утверждена Указом Президента Российской Федерации от 9 мая 2017 г. № 203.

5. Bataev A.V. Analysis and development the digital economy in the world // Proceedings of the 31st IBIMA Conference (IBIMA 2018). Milan, Italy, 25-26 April 2018. P. 61-71.

6. Drescher D. Blockchain basics: A non-technical introduction in 25 steps. Frankfurt am Main: Apress, 2017.

7. Harvey C.R. Cryptofinance // SSRN, 2014. [Электронный pecypc]: https://papers.ssrn.com/sol3/papers.cfm?abstract_id=2438299 (дата обращения 12.09.2018).

8. Russell J. IBM is using the blockchain to speed up and simplify cross-border payments // Оath Tесh Network. 2017. [Электронный pecypc] https://techcrunch.com/2017/10/16/ibm-cross-border-payments-blockchain/ (дата обращения 12.09.2018).

9. Grech A., Camilleri A.F. Blockchain in education / JRC Science for Policy Report. Luxembourg: Publications Office of the European Union, 2017.

10. Heo J.C. Electronic apparatus, audio system and audio output method / U.S. Patent Application No. 15/233,191. 2017.

11. O’Leary R.R. Malta’s government is putting academic certificates on a blockchain / Coindesk, 2017. [Электронный peсурс]: https://www.coindesk.com/maltas-government-putting-academic-certificates-blockchain/ (дата обращения 10.09.2018).

12. Durant E., Trachy A. Digital diploma debuts at MIT // Massachusetts Institute of Technology, 2017. [Электронный ресурс]: http://news.mit.edu/2017/mit-debuts-secure-digital-diploma-using-bitcoin-blockchain-technology-1017 (дата обращения 06.09.2018).

13. Nakamoto S. Bitcoin: A peer-to-peer electronic cash system / 2008. [Электронный ресурc]: https://bitcoin.org/bitcoin.pdf (дата обращения 10.09.2018).

14. Swan M. Blockchain: Blueprint for a new economy. O’Reilly Media, 2015.

15. Grinberg R. Bitcoin: An innovative alternative digital currency // Hastings Science \& Technology Law Journal. 2011. No. 4. P. 160

16. Werbach K., Cornell N. Contracts ex machina // Duke Law Journal. 2017. No. 67. P. 313-382.

17. Aune R.T., Krellenstein A., O’Hara M., Slama O. Footprints on a blockchain: Trading and information leakage in distributed ledgers // Journal of Trading. 2017. Vol. 12. No. 3. P. 5-13.

18. Davidson S., De Filippi P., Potts J. Disrupting governance: The new institutional economics of distributed ledger technology. // SSRN, 2016. [Электронный ресурс]: https://papers.ssrn.com/sol3/papers.cfm?abstract_id=2811995 (дата обращения 12.09.2018).

19. Намиот Д.Е., Куприяновский В.П., Синягов С.А. Инфокоммуникационные сервисы в умном городе // International Јоurnal of Open Information Technologies. 2016. Vol. 4. No. 4. P. 1-9.

20. Михеенко О.В., Новиков С.П., Новиков П.В. Биометрическая аутентификация личности на основе блокчейн-технологии как непременное условие цифровой экономики // Вестник Брянского государственного технического университета. 2018. № 6 (67), C. $76-83$.

21. Olleros F.X., Zhegu M., eds. Research handbook on digital transformations. Edward Elgar Publishing, 2016.

22. Tapscott D., Tapscott A. Blockchain revolution: How the technology behind bitcoin is changing money, business and the world. N.Y.: Portfolio Penguin, 2016.

23. Федеральный закон Российской Федерации «Об образовании в Российской Федерации» от 29 декабря 2012 г. № $273-Ф 3$.

24. Distributed Ledger Technology: beyond block chain / A report by the UK Government Chief Scientific Adviser. London: Government Office for Science, 2016.

25. Garzik J. Public versus private blockchains / BitFury Group, 2015. [Электронный pecypc]: https://bitfury.com/content/downloads/ public-vs-private-pt1-1.pdf (дата обращения 12.09.2018).

26. Can we afford integrity by proof-of-work? Scenarios inspired by the bitcoin currency / J. Becker [et al.] // The economics of information security and privacy. Berlin, Heidelberg: Springer, 2013. P. 135-156.

27. Lamport L., Shostak R., Pease M. The Byzantine generals problem // ACM Transactions on Programming Languages and Systems (TOPLAS). 1982. Vol. 4. No. 3. P. 382-401. 


\title{
Digital registry of professional competences of the population drawing on distributed registries and smart contracts technologies ${ }^{2}$
}

\section{Sergey P. Novikov}

Associate Professor, Department of Information Technology

Bryansk State Technological University of Engineering

Address: 3, Stanke Dimitrov Avenue, Bryansk, 241037, Russia

E-mail:spnovikov@gmail.com

\section{Olga V. Mikheenko}

Associate Professor, Department of Public Administration and Finance

Bryansk State Technological University of Engineering

Address: 3, Stanke Dimitrov Avenue, Bryansk, 241037, Russia

E-mail:miheenkoov@mail.ru

\section{Natalia A. Kulagina}

Professor, Director of Engineering and Economics Institute

Bryansk State Technological University of Engineering

Address: 3, Stanke Dimitrov Avenue, Bryansk, 241037, Russia

E-mail: kulaginana2013@yandex.ru

\section{Oleg D. Kazakov}

Associate Professor, Head of Department of Information Technology

Bryansk State Technological University of Engineering

Address: 3, Stanke Dimitrov Avenue, Bryansk, 241037, Russia

E-mail: kod8383@mail.ru

\begin{abstract}
At a time when the digital economy is emerging, the preservation and multiplication of intellectual capital, which is currently a key factor in social development, are paramount. The national economy's orientation toward the use of modern achievements of the digital industry will contribute to a faster transition to the global information society. Digitalization of education will make it possible to use the latest scientific achievements for the development of other areas of life in society.

This study presents a model that applies distributed registry technologies based on blockchains and smart contracts for the reliable storage and efficient use of date relating to the population's professional competencies. This model aims to create a unified information environment for interaction between all the actors of the economic system. The authors developed the model for registering professional competencies of the population and their developmental paths based on modern digital technologies. We substantiate the efficiency and security assured by blockchain technology for information storage and transmission. Educational institutions of all levels, governmental authorities controlling education, and people taking part in the educational process are the basic actors of the system presented.

The proposed model presents the educational level and professional skills of each registered person as an education index (EI), which keeps track of all educational achievements and professional competencies of the participant over their lifetime. When calculating the EI, the authors also propose to consider ratings of the educational institutions responsible for the participant's professional skills. The implementation of the EI will significantly simplify the process of employing graduates from various educational institutions, as well as the college admissions process. In addition, analytic tools could be used to create ratings of colleges, school departments, and even specific teachers. The registry of professional competencies we developed is directed at the processing and storage of large volumes of data (Big Data). In the future, this will allow us to open access to the registry to employers, pension insurance funds, and other state authorities that require complete and reliable personal data.
\end{abstract}

2 This study was supported by the Russian Foundation for Basic Research, project No. 18-410-
$320002 \backslash 18$ "The concept of innovative management of the development of regional economy $320002 \backslash 18$ "The concept of innovative management
in the digitalization era: a project-based approach" 
Key words: digital economy; professional competencies; blockchain; smart contract; digital registry; digitalization of education; cryptography.

Citation: Novikov S.P., Mikheenko O.V., Kulagina N.A., Kazakov O.D. (2018) Digital registry of professional competences of the population drawing on distributed registries and smart contracts technologies. Business Informatics, no. 4 (46), pp. 43-53. DOI: 10.17323/1998-0663.2018.4.43.53

\section{References}

1. Novikova A.V. (2016) Sostoyanie, problemy i perspektivy razvitiya chelovecheskogo kapitala v nauchnoy sfere Rossiyskoy Federatsii [State, problems and prospects of human capital development in the scientific sphere of the Russian Federation]. Bulletin of Bryansk State Technical University, no. 5 (53), pp. 262-266 (in Russian).

2. Novikova A.V., Shlemina I.V., Makhova V.V. (2016) Chelovecheskiy kapital i napravleniya povysheniya effektivnosti ego ispol'zovaniya [Human capital and ways to improve the efficiency of its use]. Economics and Entrepreneurship, vol. 10, no. 4-2, pp. 717-720 (in Russian).

3. The Government of the Russian Federation (2017) Programma "Tsifrovaya ekonomika Rossiyskoy Federatsii” [Program "Digital economy of the Russian Federation"]. Approved by the Order of the Government of the Russian Federation, 28 July 2017, no. 1632-p (in Russian).

4. The President of the Russian Federation (2017) Strategiya razvitiya informatsionnogo obschestva v Rossiyskoy Federatsii na 2017-2030 gody [The strategy of information society development in the Russian Federation for 2017-2030]. Approved by the Decree of the President of the Russian Federation, 9 May 2017, no. 203 (in Russian).

5. Bataev A.V. (2018) Analysis and development the digital economy in the world. Proceedings of the 31st IBIMA Conference (IBIMA 2018), Milan, Italy, 25-26 April 2018, pp. 61-71.

6. Drescher D. (2017) Blockchain basics: A non-technical introduction in 25 steps. Frankfurt am Main: Apress.

7. Harvey C.R. (2014) Cryptofinance. SSRN. Available at: https://papers.ssrn.com/sol3/papers.cfm?abstract_id=2438299 (accessed 12 September 2018).

8. Russell J. (2017) IBM is using the blockchain to speed up and simplify cross-border payments. Oath Tech Network. Available at: https://techcrunch.com/2017/10/16/ibm-cross-border-payments-blockchain/ (accessed 12 September 2018).

9. Grech A., Camilleri A.F. (2017) Blockchain in education. JRC Science for Policy Report. Luxembourg: Publications Office of the European Union

10. Heo J.C. (2017) Electronic apparatus, audio system and audio output method. U.S. Patent Application No. 15/233,191.

11. O'Leary R.R. (2017) Malta's government is putting academic certificates on a blockchain. Coindesk. Available at: https://www.coindesk.com/ maltas-government-putting-academic-certificates-blockchain/ (accessed 10 September 2018).

12. Durant E., Trachy A. (2017) Digital diploma debuts at MIT. Massachusetts Institute of Technology. Available at: http://news.mit.edu/2017/ mit-debuts-secure-digital-diploma-using-bitcoin-blockchain-technology-1017 (accessed 06 September 2018).

13. Nakamoto S. (2008) Bitcoin: A peer-to-peer electronic cash system. Available at: https://bitcoin.org/bitcoin.pdf (accessed 10 September 2018)

14. Swan M. (2015) Blockchain: Blueprint for a new economy. O’Reilly Media.

15. Grinberg R. (2011) Bitcoin: An innovative alternative digital currency. Hastings Science \& Technology Law Journal, no. 4, p. 160.

16. Werbach K., Cornell N. (2017) Contracts ex machina. Duke Law Journal, no. 67, pp. 313-382.

17. Aune R.T., Krellenstein A., O'Hara M., Slama O. (2017) Footprints on a blockchain: Trading and information leakage in distributed ledgers. Journal of Trading, vol. 12, no. 3. pp. 5-13.

18. Davidson S., De Filippi P., Potts J. (2016) Disrupting governance: The new institutional economics of distributed ledger technology. SSRN. Available at: https://papers.ssrn.com/sol3/papers.cfm?abstract id=2811995 (accessed 12 September 2018).

19. Namiot D.E., Kupriyanovsky V.P., Sinyagov S.A. (2016) Infokommunikatsionnye servisy v umnom gorode [Info-communication services in the Smart City]. International Journal of Open Information Technologies, vol. 4, no. 4, pp. 1-9 (in Russian).

20. Mikheenko O.V., Novikov S.P., Novikov P.V. (2018) Biometricheskaya autentifikatsiya lichnosti na osnove blokcheyn-tekhnologii kak nepremennoe uslovie tsifrovoy ekonomiki [Biometric authentication of personality on the basis of blockchain technology as an indispensable condition of digital economy]. Bulletin of Bryansk State Technical University, no. 6 (67), pp. 76-83 (in Russian).

21. Olleros F.X., Zhegu M., eds. (2016) Research handbook on digital transformations. Edward Elgar Publishing.

22. Tapscott D., Tapscott A. (2016) Blockchain revolution: How the technology behind bitcoin is changing money, business and the world. N.Y.: Portfolio Penguin.

23. Federal Law of the Russian Federation (2012) Ob obrazovanii v Rossiyskoy Federatsii [On education in the Russian Federation], 29 December 2012, no. 273-FZ (in Russian)

24. The UK Government Chief Scientific Adviser (2016) Distributed Ledger Technology: beyond block chain. London: Government Office for Science.

25. Garzik J. (2015) Public versus private blockchains. Available at: https://bitfury.com/content/downloads/public-vs-private-pt1-1.pdf (accessed 12 September 2018).

26. Becker J., Breuker D., Heide T., Holler J., Rauer H.P., Bohme R. (2013) Can we afford integrity by proof-of-work? Scenarios inspired by the bitcoin currency. The economics of information security and privacy. Berlin, Heidelberg: Springer, pp. 135-156.

27. Lamport L., Shostak R., Pease M. (1982) The Byzantine generals problem. ACM Transactions on Programming Languages and Systems (TOPLAS), vol. 4, no. 3, pp. 382-401. 


\section{Оценка эффективности и рисков инвестиционных проектов: интегральный подход}

\section{М.А. Штефан}

кандидат экономических наук

доцент, заведующая кафедрой бухгалтерского учета, анализа и аудита

Национальный исследовательский университет «Высшая школа экономики»

Адрес: 603155, г. Нижний Новгород, ул. Большая Печерская, д. 25/20

E-mail: shtefanmaria@yandex.ru

\section{Ю.М. Елизарова}

студентка магистратуры образовательной программы «Экономика»

Национальный исследовательский университет «Высшая школа экономики»

Адрес: 603155, г. Нижний Новгород, ул. Большая Печерская, д. 25/20

E-mail: elizarova-julia7@yandex.ru

\section{Аннотащия}

В ходе оценки и выбора инвестиционных проектов современные компании сталкиваются с проблемой расстановки приоритетов между ихдоходностью и рискованностью. Выборпроекта только на основании доходности существенно повышает риски финансово-хозяйственной деятельности, увеличивает неопределенность в получении запланированного финансового результата, в то время как ориентация на сокращение рисков инвестиционных проектов не позволяет достичь желаемого уровня рентабельности. Данный факт повышает актуальность разработки многокритериальных интегральных показателей.

В настоящей статье представлены результаты авторской разработки интегрального показателя оценки эффективности и рисков инвестиционных проектов. Интегральный показатель имеет матричную форму. Для его составления используется три группы критериев: количественные критерии эффективности, качественные критерии эффективности и критерии оценки рисков. Количественные и качественные критерии эффективности предлагается подразделить на показатели, характеризующие, во-первых, коммерческую (экономическую) эффективность проектов, во-вторых - их бюджетную эффективность, в-третьих - общественную эффективность. В перечень критериев, характеризующих риски проектов, предлагается включить макроэкономические показатели и показатели отраслевой принадлежности проекта, демонстрирующие всестороннюю оценку внешней экономической ситуации, сложившейся на данном рынке.

При оценке эффективности и рисков конкретных инвестиционных проектов разработанный авторами интегральный показатель преобразуется из матричной формы в количественный индикатор, удобный для интерпретации. С этой целью предлагается использовать метод главных компонент и эвристические методы, в том числе метод ранжирования и метод анализа иерархий.

Результаты исследования могут быть использованы компаниями при выборе инвестиционных проектов.

Ключевые слова: инвестиционный проект; автоматизация управленческих решений; интегральный показатель; оценка эффективности; оценка рисков; метод главных компонент.

Цитирование: Штефан М.А., Елизарова Ю.М. Оценка эффективности и рисков инвестиционных проектов: интегральный подход // Бизнес-информатика. 2018. № 4 (46). С. 54-65.

DOI: $10.17323 / 1998-0663.2018 .4 .54 .65$ 


\section{Введение}

$\Pi$ роблема выбора оптимального инвестиционного проекта из совокупности альтернатив становится все более актуальной для современных компаний. Принятие решения на основании величины доходности проекта с ориентиром на ее повышение повышает риски финансово-хозяйственной деятельности и увеличивает неопределенность в получении запланированного финансового результата. Выбор менее рискованного проекта, в свою очередь, не так оправдан с точки зрения его доходности: подобное решение может отрицательно повлиять не только на рентабельность компании, но и на эффективность ее работы в целом. Значимыми становятся задачи многокритериальной оценки эффективности инвестиционных проектов, а также интегральной оценки эффективности и рисков проектов.

В настоящей статье на основе анализа предложенных в специальной литературе критериев эффективности инвестиционных проектов, а также методов оценки рисков проектов предложен интегральный показатель, включающий в себя три группы критериев оценки эффективности и рисков. Также разработана методика преобразования интегрального показателя в итоговый индикатор с помощью применения эвристических и математических методов. Результаты статьи могут быть использованы при выборе оптимального инвестиционного проекта из совокупности альтернатив.

\section{1. Обзор предлагаемых в специальной литературе критериев и методов оценки инвестиционных проектов}

В настоящее время тема сочетания критериев эффективности и риска с целью комплексной интегральной оценки инвестиционных проектов практически не представлена в специальной литературе. Существует значительное количество статей, рассматривающих проблемы выбора и расчета критериев эффективности инвестиционных проектов, однако вопросы рисков проектов в данных источниках не раскрываются. В частности, общий подход к оценке эффективности и обоснование ее необходимости предложен в статьях [1;2], основные критерии эффективности инвестиционных проектов рассматриваются в учебных пособиях [3; 4], особенности их использования, преимущества и недостатки представлены в статье [5], а многокритериальные при- емы оценки эффективности - в статье [6]. Важно, что исследователи делают акцент на использовании количественных критериев оценки эффективности проектов, в то время как анализ качественных характеристик проекта (потребности в государственной поддержке, необходимости разработки и внедрения дополнительных инноваций и нововведений, потребности в привлечении дополнительных кадров и других) в специальной литературе практически отсутствует. Однако именно качественные характеристики проектов зачастую играют решающую роль в принятии решения о возможности (или невозможности) инвестирования. Также в большинстве своем перечень количественных критериев эффективности в проанализированных источниках ограничивается показателями коммерческой (экономической) эффективности проекта, в то время как вопросы бюджетной и общественной эффективности, столь необходимые для всесторонней оценки инвестиционных проектов, в литературе практически не рассматриваются.

В статье [7] предлагается создать унифицированный интегральный показатель оценки эффективности инвестиционных проектов, в расчет которого, по мнению автора, необходимо включить количественные критерии коммерческой эффективности инвестиционных проектов, оказывающие влияние на финансово-хозяйственную деятельность организации: фондоотдачу, коэффициент прироста прибыли, коэффициент общей ликвидности, коэффициент финансовой устойчивости и т.д. Модель интегрального показателя основывается на подборе и комплексном сочетании различных видов критериев, с последующим сведением результатов анализа в единый показатель на основании весов каждого из используемых критериев.

Более сложный механизм интегральной оценки эффективности проектов приведен в статье [8]. Суть данного механизма сводится к скаляризации показателей, учитывающих основные характеристики инвестиционного проекта: суммарного дисконтированного денежного потока, срока окупаемости и ресурсных затрат на реализацию. Проблемой данного метода, на наш взгляд, является использование ограниченного круга критериев эффективности инвестиционных проектов, что не позволяет произвести комплексную оценку и сделать корректные выводы.

В статье [9] изложен теоретико-вероятностный методологический подход к оценке эффективности инвестиционного проекта на основе сценарного анализа. Рассматриваемый подход основывается 
на использовании показателей, базой для расчета которых служат денежные потоки от различных видов деятельности компании, что, в свою очередь, исключает возможность учета ряда необходимых качественных показателей.

С целью ранжирования критериев эффективности с точки зрения их значимости для принятия решения современные авторы часто предлагают использовать различные алгоритмы экспертного ранжирования: метод анализа иерархий $[4 ; 10]$, простой метод ранжирования [11], алгоритм Штейнгауза [12], алгоритм Штейнгауза-Форда-Джонсона [12], турнирный алгоритм [12].

В части рисков инвестиционных проектов специальная литература ориентирована на изучение специальных методов их оценки без изучения самих критериев оценки рисков. Один из наиболее часто встречающихся методов оценки рисков - использование модели Хиллера, связывающей риск проекта с дисперсиями денежных потоков [13]. В статьях [14-16] рассматриваются такие распространенные приемы, как метод экспертных оценок, статистический метод, метод проверки устойчивости, «сценарный» анализ, метод дерева решений и имитационное моделирование методом Монте-Карло. В статье [17] рассматривается вопрос анализа чувствительности для оценки риска в условиях неопределенности. В статье [18] рассматривает алгоритм выявления различных видов рисков и корректировки ключевого показателя оценки эффективности инвестиционных проектов NPV (net present value) с использованием выявленных групп. Проблема данного подхода заключается в наличии алгоритма рисковой корректировки лишь для одного показателя, исходя из результатов которого нецелесообразно принимать решение по проекту.

Таким образом, анализ специальной литературы показывает, что вопросы интегральной оценки эффективности и рисков инвестиционных проектов в ней практически не представлены. Один из немногих вариантов включения значения риска в оценку эффективности инвестиционных проектов представлен в статье [16]. Автором рассматриваются различные методы оценки риска инвестиционных проектов, даются варианты устранения недостатков их применения. Однако рассмотренный в статье ряд методов не может применяться в качестве критериев для интегральной оценки инвестиционных рисков, что еще раз подчеркивает актуальность настоящей статьи.

\section{2. Формирование и расчет \\ интегрального показателя \\ оценки эффективности и рисков инвестиционного проекта}

Разработка унифицированного интегрального показателя оценки эффективности и рисков инвестиционного проекта начинается с выбора необходимых критериев. Важно включить в показатель не только количественные, но и качественные критерии оценки, что позволит оценивать инвестиционные проекты с разных сторон.

Расчет интегрального показателя выполняется на основании значений трех векторов частных критериев. Размерность каждого из векторов равна $n_{1}, n_{2}$ и $n_{3}$ соответственно:

$$
\begin{gathered}
\mathbf{p}=\left[p_{1}, p_{2}, \ldots, p_{n_{1}}\right] \\
\mathbf{q}=\left[q_{1}, q_{2}, \ldots, q_{n_{2}}\right] ; \\
\mathbf{r}=\left[r_{1}, r_{2}, \ldots, r_{n_{3}}\right] .
\end{gathered}
$$

Элементы векторов $\mathbf{p}, \mathbf{q}$ и $\mathbf{r}$ представляют из себя следующие группы критериев:

p - количественные критерии оценки эффективности; $\mathbf{q}$ - качественные критерии оценки эффективности; $\mathbf{r}$ - критерии оценки риска.

В состав количественных и качественных критериев эффективности инвестиционных проектов (элементов векторов р и q) входят критерии, характеризующие коммерческую (экономическую), бюджетную и общественную эффективность (таблица 1).

Перечень элементов третьей группы, характеризующей риски инвестиционного проекта (r), определяется для каждого проекта индивидуально. В их состав могут войти макроэкономические показатели, а также показатели отраслевой принадлежности проекта, характеризующие всестороннюю оценку внешней экономической ситуации, сложившей на данном рынке.

Для принятия решения о выборе наиболее предпочтительного инвестиционного проекта из совокупности альтернатив необходимо сравнение более значимых элементов векторов р, q и r с менее значимыми элементами тех же векторов. Для возможности подобного сравнения необходимо обеспечить одинаковую размерность всех трех векторов: $n_{1}=n_{2}=n_{3}=n$.

Нормативные (рекомендуемые) значения количественных показателей в таблице 1 определены на основании общепринятых инвестиционных под- 
Группы и критерии оценки

Таблица 1. эффективности инвестиционных проектов

\begin{tabular}{|c|c|c|c|c|}
\hline $\begin{array}{l}\text { Группа } \\
\text { крите- } \\
\text { риев }\end{array}$ & Критерии эфрфективности & Вид критерия & Методика расчета критерия, сущность & $\begin{array}{l}\text { Рекомендуемое } \\
\text { (нормативное) } \\
\text { значение }\end{array}$ \\
\hline \multirow{13}{*}{ 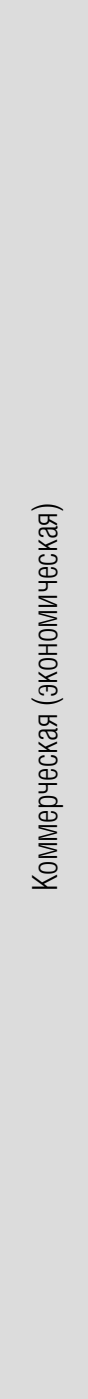 } & Срок окупаемости & Количественный & $\begin{array}{l}\text { Определение срока, в течение которого инвестиции } \\
\text { покрываются чистыми денежными поступлениями } \\
\text { от проекта }\end{array}$ & $\begin{array}{l}<\text { Планируемого } \\
\text { срока реализации } \\
\text { проекта }\end{array}$ \\
\hline & Средняя доходность & Количественный & $\begin{array}{l}\text { Расчет по прогнозируемым величинам усредненного } \\
\text { значения доходности вложенных средств }\end{array}$ & $>0$ \\
\hline & Индекс рентабельности & Количественный & $\begin{array}{l}\text { Сопоставление текущей оценки будущих чистых } \\
\text { денежных потоков и текущих инвестиций }\end{array}$ & $>1$ \\
\hline & $\begin{array}{l}\text { Чистая приведенная стоимость } \\
\text { (net present value, NPV) }\end{array}$ & Количественный & $\begin{array}{l}\text { Сравнение инвестиций с текущей оценкой } \\
\text { всех будущих чистых денежных потоков } \\
\text { по годам реализации проекта }\end{array}$ & $>0$ \\
\hline & $\begin{array}{l}\text { Внутренняя норма } \\
\text { рентабельности } \\
\text { (internal rate of return, IRR) }\end{array}$ & Количественный & $\begin{array}{l}\text { Расчет ставки дисконтирования, при которой } \\
\text { чистая приведенная стоимость (NPV) } \\
\text { становится равной нулю }\end{array}$ & $\begin{array}{l}\text { > WACC (weighted } \\
\text { average cost of capital - } \\
\text { средневзвешенная } \\
\text { стоимость капитала) }\end{array}$ \\
\hline & $\begin{array}{l}\text { Коэфффициент } \\
\text { эффрективности инвестиций } \\
\text { (accounting rate of return, ARR) }\end{array}$ & Количественный & $\begin{array}{l}\text { Сравнение среднегодовой прибыли и средней } \\
\text { величины инвестиций }\end{array}$ & $>$ WACC \\
\hline & $\begin{array}{l}\text { Модифицированная внутренняя } \\
\text { доходность (MIRR) }\end{array}$ & Количественный & $\begin{array}{l}\text { Нахождение ставки дисконтирования, при которой } \\
\text { уравновешивается будущая оценка поступлений } \\
\text { и текущая оценка затрат по проекту }\end{array}$ & $>$ WACC \\
\hline & $\begin{array}{l}\text { Дисконтированный срок } \\
\text { oкyпаемости (discounted } \\
\text { payback period, DPP) }\end{array}$ & Количественный & $\begin{array}{l}\text { Расчет дисконтированного срока окупаемости } \\
\text { инвестиций, который основывается на показателе } \\
\text { срока окупаемости инвестиций, учитывающего } \\
\text { временной аспект }\end{array}$ & $\begin{array}{l}\text { < Планируемого } \\
\text { срока реализации } \\
\text { проекта }\end{array}$ \\
\hline & $\begin{array}{l}\text { Сложность и затратность } \\
\text { проекта }\end{array}$ & Качественный & $\begin{array}{l}\text { Степень необходимости привлечения дополнительных } \\
\text { материальных ресурсов для реализации проекта }\end{array}$ & $\geq 2$ \\
\hline & $\begin{array}{l}\text { Необходимость технологических } \\
\text { нововведений }\end{array}$ & Качественный & $\begin{array}{l}\text { Степень необходимости нововведений на каждом } \\
\text { из этапов реализации проекта }\end{array}$ & $\geq 2$ \\
\hline & Наличие покупателей продукции & Качественный & Информация о наличии потенциальных покупателей & $\geq 2$ \\
\hline & $\begin{array}{l}\text { Необходимость строительства } \\
\text { дополнительных объектов } \\
\text { инфрраструктуры }\end{array}$ & Качественный & $\begin{array}{l}\text { Степень необходимости строительства } \\
\text { дополнительных объектов инфрраструктуры }\end{array}$ & 3 \\
\hline & Конкурентоспособность компании & Качественный & Степень конкурентоспособности компании & $\geq 2$ \\
\hline \multirow{2}{*}{$\begin{array}{l}\text { 뜸 } \\
\text { 픔 } \\
\text { 前 } \\
\text { 옴 }\end{array}$} & $\begin{array}{l}\text { Доля экспортных пошлин } \\
\text { (налогов) в себестоимости } \\
\text { продукции }\end{array}$ & Количественный & $\begin{array}{l}\text { Доля денежных средств, потраченных на экспортные } \\
\text { пошлины (или любые другие виды налогов) }\end{array}$ & $<7 \%{ }^{1}$ \\
\hline & $\begin{array}{l}\text { Степень государственной } \\
\text { поддержки }\end{array}$ & Качественный & $\begin{array}{l}\text { Предоставление налоговых льгот для реализации } \\
\text { проекта }\end{array}$ & $\geq 2$ \\
\hline \multirow{3}{*}{ 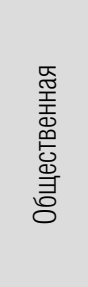 } & $\begin{array}{l}\text { Доля затрат на инновации } \\
\text { (индекс промышленного } \\
\text { производства) }\end{array}$ & Количественный & $\begin{array}{l}\text { Затраты на инновационные общественно значимые } \\
\text { нововведения, сопровождающие проект }\end{array}$ & $<10 \%{ }^{1}$ \\
\hline & $\begin{array}{l}\text { Количество значимых } \\
\text { социальных программ }\end{array}$ & Количественный & $\begin{array}{l}\text { Общественно значимые социальные программы, } \\
\text { внедряемые с целью реализации проекта }\end{array}$ & $>1$ \\
\hline & $\begin{array}{l}\text { Необходимость привлечения } \\
\text { нового персонала }\end{array}$ & Качественный & $\begin{array}{l}\text { Степень необходимости привлечения работников, } \\
\text { которые ранее не были заняты в компании }\end{array}$ & 3 \\
\hline
\end{tabular}

\footnotetext{
${ }^{1}$ Рекомендуемое значение показателя может быть изменено на основе профессионального суждения лиц, принимающих инвестиционные решения (в зависимости от ситуации внутри компании)
} 
ходов, представленных в специальной научной и практической литературе [3]. Значения качественных показателей определены на основе экспертной оценки с использованием трехуровневой градации: значение 3 (наибольшее) является наилучшим, значение 1 (наименьшее) - наихудшим.

Важно отметить, что не все представленные в таблице критерии оценки эффективности являются универсальными: часть из них имеет отраслевую специфику, часть может быть неприемлема при оценке небольших проектов, реализуемых компаниями среднего и малого бизнеса, не оказывающими глобального влияния на экономику города или региона. В связи с этим нами разработаны рекомендации по выбору критериев оценки инвестиционных проектов и их рисков с целью формирования векторов критериев $\mathbf{p}, \mathbf{q}$ и $\mathbf{r}$.

\section{1. Формирование вектора количественных критериев (р)}

Выбор количественных критериев эффективности зависит от качественных характеристик самого про- екта (масштаб, срочность, степень риска и т.д.). Количество критериев, из которых формируется вектор p, определяется в соответствии с рекомендациями, представленными в таблице 2, составленной авторами на основании информации об однокритериальных методах оценки, представленных в специальной литературе [3].

В соответствии с данными рекомендациями необходимо учитывать, что размерность $n_{1}$ вектора р равна суммарному количеству критериев экономической, бюджетной и общественной эффективности.

Критерии экономической эффективности определяются, исходя из рекомендаций, представленных в таблице 2, а критерии бюджетной и общественной эффективности включаются в вектор полностью (таблица 1).

Ранжирование критериев, являющихся элементами вектора р, необходимо для сравнения наиболее важных элементов одного вектора с наиболее важными элементами другого вектора. Такое ранжирование осуществляется при помощи экспертного присвоения весов каждому из рассматриваемых критериев.

\section{Рекомендации по выбору элементов вектора количественных критериев (p) для оценки инвестиционных проектов}

\begin{tabular}{|c|c|c|c|c|c|c|c|c|c|}
\hline & & \multicolumn{8}{|c|}{ Название критерия } \\
\hline & & 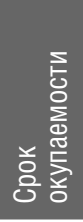 & 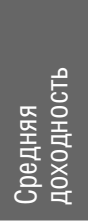 & 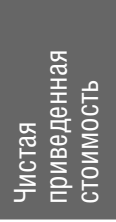 & 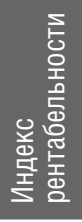 & 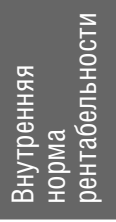 & 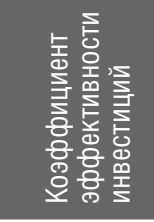 & 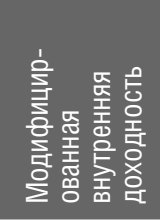 & 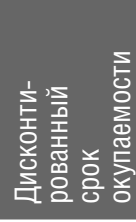 \\
\hline \multirow{4}{*}{$\begin{array}{l}\text { Масштаб } \\
\text { инвестиций }\end{array}$} & Мелкие & + & + & + & + & + & \multirow{4}{*}{$\begin{array}{l}\text { +, если } \\
\text { все проекты } \\
\text { одной } \\
\text { категории }\end{array}$} & \multirow{4}{*}{$\begin{array}{l}\text { +, если } \\
\text { все проекты } \\
\text { одной } \\
\text { категории }\end{array}$} & + \\
\hline & Традиционные & + & + & + & + & + & & & + \\
\hline & Крупные & - & + & + & + & + & & & - \\
\hline & Мегапроекты & - & + & + & + & + & & & - \\
\hline \multirow{3}{*}{ Сроки } & Краткосрочные & - & + & + & + & + & + & \multirow{4}{*}{$\begin{array}{l}\text { +, если } \\
\text { все проекты } \\
\text { одной } \\
\text { категории }\end{array}$} & + \\
\hline & Среднесрочные & + & + & + & + & + & + & & + \\
\hline & Долгосрочные & - & - & + & + & + & - & & + \\
\hline \multirow{2}{*}{$\begin{array}{l}\text { Степень } \\
\text { риска }\end{array}$} & Безрисковые & - & + & + & + & + & - & & + \\
\hline & Рисковые & + & + & + & + & + & + & + & + \\
\hline \multirow{3}{*}{ Состав } & Монопроекты & + & + & + & + & + & + & + & + \\
\hline & Мультипроекты & - & + & + & + & - & + & - & - \\
\hline & Мегапроекты & - & + & + & + & - & + & - & - \\
\hline \multirow{3}{*}{$\begin{array}{l}\text { Степень } \\
\text { взаимосвязи }\end{array}$} & Независимые & + & + & + & + & + & - & + & + \\
\hline & Альтернативные & + & - & + & + & - & - & - & + \\
\hline & Взаимосвязанные & + & + & + & - & + & + & + & + \\
\hline
\end{tabular}




\section{2. Формирование вектора качественных критериев (q)}

Размерность $n_{2}$ вектора q определяется, исходя из размерности $n_{1}$ вектора $\mathbf{p}$, то есть необходимо соблюдать равенство $n_{2}=n_{1}$.

Для выбора подходящего числа элементов вектора q также необходимо ранжирование его элементов для выбора наиболее важных. В данном случае ранжирование поможет решить не только проблему определения размерности вектора, но и проблему присвоения элементам весов для их сравнения.

Для ранжирования, на наш взгляд, наилучшим образом подходит использование метода, который заключается в экспертном определении весов качественных критериев и присвоении им количественных значений от 1 до 3, характеризующих соответствие (или несоответствие) значения данного критерия рекомендуемому (таблица 3).

\section{3. Формирование вектора критериев оценки рисков (r)}

Размерность $n_{3}$ вектора $\mathbf{r}$ определяется по аналогии с размерностью $n_{2}$ вектора q. Ранжирование элементов также целесообразно производить с использованием экспертной оценки.

Веса элементов вектора $\mathbf{r}$ (с целью их дальнейшего ранжирования) целесообразно сделать изменяемыми, поскольку, как уже отмечалось выше, риск в большей степени зависит от макроэкономических показателей, а эти значения могут меняться от одного периода к другому. С этой целью предлагается применять метод главных компонент (МГК), реализуемый в математическом пакете Stata. Для этого необходимо выполнить следующие шаги.

1. Выявить 15-20 видов рисков, присущих анализируемому инвестиционному проекту (например, риски кардинальных изменений макроэкономической ситуации в стране, отраслевые рыночные риски, риски уменьшения спроса на продукцию компании, экологические риски и т.д.).

2. Присвоить выбранным видам рисков измеряемые статистические показатели, следствием изменения которых являются эти риски (например, курсы валют, уровень ВВП, ставка рефинансирования, количество возможных конкурентов на рынке, показатели физического объема выпускаемой продукции и производительных мощностей и т.д.). Источниками информации могут стать данные Росстата, Центрального Банка, а также статистические данные самой компании.

3. Произвести нормирование значений переменных по отношению к отрезку [0, 10], при этом 0 будет соответствовать наименьшей степени риска показателя, а 10 - наибольшей.

4. Определить необходимое количество главных компонент в зависимости от необходимого количества групп рисков с учетом размерности вектора

Значения весов элементов вектора качественных критериев (q)

Таблица 3.

\begin{tabular}{|c|c|c|c|}
\hline Критерий & Низкое значение (1) & Среднее значение (2) & Высокое значение (3) \\
\hline $\begin{array}{l}\text { Сложность и затратность } \\
\text { реализации проекта }\end{array}$ & $\begin{array}{l}\text { Реализация проекта потребует } \\
\text { существенных материальных } \\
\text { вложений }\end{array}$ & $\begin{array}{l}\text { Реализация проекта } \\
\text { потребует не очень больших } \\
\text { материальных вложений }\end{array}$ & $\begin{array}{l}\text { Реализация проекта не потребует } \\
\text { материальных вложений }\end{array}$ \\
\hline $\begin{array}{l}\text { Необходимость } \\
\text { технологических } \\
\text { нововведений }\end{array}$ & $\begin{array}{l}\text { Требуются технологические } \\
\text { нововведения на каждом этапе } \\
\text { реализации проекта }\end{array}$ & $\begin{array}{l}\text { Требуются нововведения } \\
\text { только на первоначальном } \\
\text { этапе реализации проекта }\end{array}$ & Нововведения не требуются \\
\hline $\begin{array}{l}\text { Наличие покупателей } \\
\text { продукции }\end{array}$ & $\begin{array}{l}\text { Неясно, кто будет покупателем } \\
\text { продукции }\end{array}$ & $\begin{array}{l}\text { Есть небольшое количество } \\
\text { потенциальных покупателей }\end{array}$ & $\begin{array}{l}\text { Большое количество } \\
\text { потенциальных покупателей }\end{array}$ \\
\hline $\begin{array}{l}\text { Необходимость } \\
\text { дополнительных вложений } \\
\text { в инсрраструктуру }\end{array}$ & $\begin{array}{l}\text { Необходимо большое } \\
\text { количество дополнительных } \\
\text { вложений в инфраструктуру }\end{array}$ & $\begin{array}{l}\text { Необходимо небольшое } \\
\text { количество дополнительных } \\
\text { вложений в инфраструктуру }\end{array}$ & $\begin{array}{l}\text { Необходимая инфрраструктура } \\
\text { уже существует }\end{array}$ \\
\hline $\begin{array}{l}\text { Уровень конкуренции } \\
\text { на рынке }\end{array}$ & $\begin{array}{l}\text { Компания практически } \\
\text { неконкурентоспособна }\end{array}$ & $\begin{array}{l}\text { На рынке небольшая } \\
\text { конкуренция }\end{array}$ & Компания является лидером рынка \\
\hline $\begin{array}{l}\text { Необходимость } \\
\text { привлечения нового } \\
\text { персонала }\end{array}$ & $\begin{array}{l}\text { Нужно дополнительно } \\
\text { привлечь значительную } \\
\text { часть необходимого персонала }\end{array}$ & $\begin{array}{l}\text { Нужно дополнительно } \\
\text { привлечь небольшую часть } \\
\text { необходимого персонала }\end{array}$ & $\begin{array}{l}\text { Весь необходимый персонал } \\
\text { уже есть в штате }\end{array}$ \\
\hline $\begin{array}{l}\text { Государственная } \\
\text { поддержка }\end{array}$ & Отсутствует & $\begin{array}{l}\text { Могут предоставляться } \\
\text { налоговые льготы }\end{array}$ & $\begin{array}{l}\text { Могут предоставляться налоговые } \\
\text { льготы, государственные гарантии и } \\
\text { скидки на закупки сырья и материалов }\end{array}$ \\
\hline
\end{tabular}


критериев р, определяемой числом количественных критериев эффективности.

5. Построить матрицу корреляций между выделенными главными компонентами и переменными, выбранными на шаге 2. При этом для интерпретации результатов следует использовать только те переменные, корреляция которых с полученными компонентами достаточно велика, т.е. находится в диапазонах $(-\infty ;-0,3]$ и $[0,3 ;+\infty)$.

Следует отметить, что для качественной содержательной интерпретации полученных результатов важно не просто добиться наличия корреляции компонентов с определенным набором переменных, но и получить отдельные кластеры переменных, практически не пересекающихся между собой. Для этого строятся матрицы вращения нагрузок компонент, основными методами вращения являются Varimax, Quartimax, Equimax, Direct oblimin, Promax [19].

6. Убедиться в оправданном использовании МГК относительно использованного набора данных при помощи критерия выборочной адекватности Кайзера-Мейера-Олкина (КМО). Значение КМОстатистики большее 0,5 говорит об оправданном использовании метода.

7. Интерпретировать результаты по каждому виду рисков, присущих анализируемому инвестиционному проекту. Для этого нужно обратиться к составленной матрице корреляций с применением одного из вышеперечисленных методов вращения. Содержательная интерпретация проводится по принципу смыслового объединения соответствующих переменных по каждой компоненте.

8. Произвести расчет значений модифицированных главных компонент, которые являются линейным комбинациями нормированных значений каждого из показателей на данный момент времени с квадратами весов корреляционной матрицы [20].

\section{9. Определить веса каждой из групп рисков.}

После выявления групп рисков, которые могут оказывать влияние на анализируемые инвестиционные проекты, определяются их рекомендуемые значения. Это делается на основе предварительного экспертного заключения, с учетом индивидуальных особенностей проекта.

Таким образом, с использованием эконометрических и эвристических методов формируются три вектора критериев (р, q и r) одинаковой размерности $n_{1}=n_{2}=n_{3}=n$.

\section{4. Формирование интегрального показателя оценки инвестиционных проектов}

Для формирования интегрального показателя введем новый вектор f, который является интегральным по отношению к трем рассмотренным выше группам критериев (p, q и r):

$$
\mathbf{f}=\left[f_{1}, f_{2}, \ldots, f_{n}\right] .
$$

Для формирования вектора $\mathbf{f}$ переведем значения всех критериев оценки инвестиционных проектов и их рисков в бинарную форму:

\ бинарное значение «0» присваивается критерию, величина которого ниже нормативного значения;

\ бинарное значение «1» присваивается критерию, если его величина соответствует рекомендованному значению.

Нормативные значения каждого из элементов векторов р и q были рассмотрены выше, для вектора r нормативные значения формируются в соответствии с отраслевой принадлежностью компании. Значения качественных показателей формируются компанией с использованием экспертных оценок.

Далее осуществляется перевод соответствующих троек показателей (по одному из трех групп критериев) в соответствующие значения вектора f:

$$
p_{i}, q_{i}, r_{i} \rightarrow f_{i}
$$

где $p_{i}, q_{i}, r_{i}-i$-е бинарные значения векторов $\mathbf{p}, \mathbf{q}$ и $\mathbf{r}$ соответственно $(i=1,2, \ldots, n)$.

Преобразование каждой из троек бинарных значений векторов $\mathbf{p}, \mathbf{q}$ и $\mathbf{r}$ в бинарные значения соответствующих элементов вектора $\mathbf{f}$ осуществляется по следующему алгоритму.

Элементы каждого из векторов р, q и r упорядочиваются по убыванию их значимости. После этого каждый из векторов разбивается на две равные части: в первую часть включаются более значимые критерии (с номерами от 1 до $m$, где $m=n / 2$ ), а во вторую - менее значимые (с номерами от $m+1$ до $n)$. Если общее число критериев $n$ является нечетным, то приоритет по количеству критериев отдается первой группе (число $m$ округляется до целого в большую сторону).

Разбиение каждого из векторов $\mathbf{p}, \mathbf{q}$ и $\mathbf{r}$ на две части осуществляется для обеспечения возможности расчета результирующего значения интегрального показателя как арифметической суммы бинарных значений элементов вектора f. При этом для более 
значимых критериев (с номерами от 1 до $m$ ) применяется более жесткое правило получения «положительного» (равного единице) бинарного значения элемента вектора $\mathbf{f}$ : элемент $f$ получает бинарное значение «1», если хотя бы два элемента соответствующей тройки $\left(p_{i}, q_{i}, r_{i}\right)$ имеют единичные бинарные значения (в противном случае элементу $f$ присваивается бинарное значение «0»). В то же время для менее значимых критериев (с номерами от $m+1$ до $n$ ) получение элементами вектора $\mathbf{f}$ бинарных значений «1» возможно при наличии как минимум одного значения «1» для элемента соответствующей тройки $\left(p_{i}, q_{i}, r_{i}\right)$.

В итоге вычисляется значение интегрального показателя $T$, равное арифметической сумме бинарных значений всех элементов вектора f:

$$
T=\sum_{i=1}^{n} f_{i},
$$

где $f_{i}$ - бинарное значение $i$-го элемента вектора $\mathbf{f}$.

Для интерпретации значения интегрального показателя инвестиционного проекта используется простое правило: если $T>n / 2$ (т.е. если большинство бинарных значений $f_{i}$ равно единице), то инвестиционный проект рекомендуется к реализации, в противном случае (если $T \leq n / 2)$ проект отклоняется.

\section{3. Апробация интегрального показателя оценки инвестиционных проектов}

Апробация расчета предложенного интегрального показателя проведена на основе данных инвестиционного проекта нефтегазовой отрасли. Допустим, некоторая нефтяная компания рассматривает проект по закупке, внедрению и использованию безбалансирного станка-качалки для нефтедобычи. Срок реализации проекта составляет 15 лет.

Начнем с формирования вектора количественных критериев оценки эффективности проекта р. Проект имеет следующий набор качественных характеристик: он является традиционным, долгосрочным, рисковым, альтернативным монопроектом. В соответствии с таблицей 2 для оценки экономической эффективности проекта могут быть использованы критерии чистой приведенной стоимости (NPV), индекса рентабельности и дисконтированного срока окупаемости (DPP). Дополнительно предлагается использовать критерии бюджетной и общественной эффективности - долю налога на добычу полезных ископаемых (НДПИ) в выручке, количество значимых социальных программ и долю затрат на инно- вации. Важно отметить, что использование критерия «доля налога на добычу полезных ископаемых (НДПИ) в выручке связано с отраслевой спецификой рассматриваемого инвестиционного проекта.

Количественные критерии эффективности проранжированы при помощи экспертной оценки в порядке убывания: NPV, количество значимых социальных программ, DPP, доля затрат на инновации, индекс рентабельности, доля налога на добычу полезных ископаемых (НДПИ) в выручке. В результате размерность вектора р оказалась равной шести.

Качественные критерии эффективности также были проранжированы в следующем порядке: сложность и затратность реализации проекта, необходимость технологических нововведений, уровень конкуренции на рынке, наличие покупателей продукции, государственная поддержка, необходимость привлечения нового персонала.

Фактические значения выбранных количественных и качественных критериев эффективности представлены в таблице 4.

Таблица 4.

\section{Выявление значимых компонент}

\begin{tabular}{c|c|c} 
Компоненты & $\begin{array}{c}\text { 3начимость } \\
\text { компоненты }\end{array}$ & $\begin{array}{c}\text { Накопленное } \\
\text { значение }\end{array}$ \\
\hline Компонента 1 & 0,4733 & 0,4733 \\
\hline Компонента 2 & 0,1875 & 0,6608 \\
\hline Компонента 3 & 0,1207 & 0,7815 \\
\hline Компонента 4 & 0,0764 & 0,8580 \\
\hline Компонента 5 & 0,0688 & 0,9267 \\
\hline Компонента 6 & 0,0429 & 0,9696 \\
\hline Компонента 7 & 0,0172 & 0,9869 \\
\hline Компонента 8 & 0,0093 & 0,9961 \\
\hline Компонента 9 & 0,0039 & 1,0000 \\
\hline
\end{tabular}

Для выявления и ранжирования критериев оценки рисков будем использовать метод главных компонент. На основе теоретического качественного анализа было выделено 16 видов рисков, которым подвергаются инвестиционные проекты нефтегазовой отрасли, им также были присвоены измеряемые статистические показатели, следствием изменения которых эти риски являются. На основе вычисления дисперсии каждого из показателей выяснилось, что наибольшую изменчивость с 2005 по 2016 годы показывают курс доллара по отношению к рублю (doll), индекс цен производителей промышленной продук- 
ции (ippp), цена на нефть (price), ставка рефинансирования $(r)$, ВВП $(g d p)$, объем экспорта нефтепродуктов (exp), объем добычи нефти (extr), количество действующих организаций отрасли $(q)$, выбросы в атмосферу загрязняющих веществ (pollution). Значение этих переменных были нормированы в отрезок $[0,10]$, где 0 соответствует наименьшей степени риска показателя, а 10 - наибольшей. Для следующего шага выделяем шесть компонент, которые составляют более 96\% выборки.

Далее определяется матрица корреляций между выделенными основными компонентами и всеми переменными. Для интерпретации результатов используются только те переменные, корреляция которых с полученными компонентами достаточно велика: больше 0,3 или меньше $-0,3$. По результатам применения нескольких методов вращения (Varimax, Quartimax, Equimax, Direct Oblimin, Promax), наилучшие для интерпретации результаты были получены при помощи метода Promax (таблица 5).

\section{Матрица вращения компонент методом Promax}

\begin{tabular}{|c|c|c|c|c|c|c|}
\hline 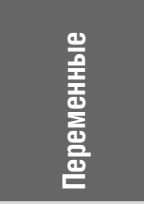 & 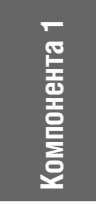 & 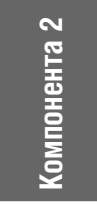 & 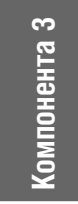 & 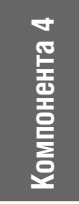 & 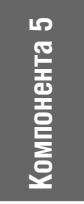 & 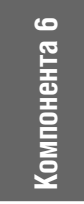 \\
\hline doll & & 0,859 & & & & \\
\hline ippp & & & & 0,984 & & \\
\hline price & 0,716 & $-0,422$ & & & & \\
\hline$g d p$ & 0,476 & & & & & \\
\hline$r$ & $-0,451$ & & & & & \\
\hline $\exp$ & & & 0,968 & & & \\
\hline extr & & & & & & 0,994 \\
\hline$q$ & & & & & & \\
\hline pollution & & & & & 0,991 & \\
\hline
\end{tabular}

При проверке критерия выборочной адекватности Кайзера-Мейера-Олкина (КМО) получилось, что значение КМО-статистики превышает 0,5 , что свидетельствует об оправданном применении метода главных компонент.

В таблице 6 приведена интерпретация каждой из групп рисков и их рекомендуемые значения.

Уравнения для весов для ранжирования групп рисков выглядят следующим образом (расчеты производились с учетом значений параметров на 4 квартал 2017 года):
Таблица 6.

Рекомендуемые значения выделенных критериев оценки рисков

\begin{tabular}{|c|c|c|}
\hline Компоненты & $\begin{array}{l}\text { Наименование } \\
\text { (интерпретация) }\end{array}$ & $\begin{array}{c}\text { Рекомендуемое } \\
\text { (нормативное) значение }\end{array}$ \\
\hline Компонента 1 & $\begin{array}{l}\text { Риски, связанные } \\
\text { с изменением общей } \\
\text { экономической } \\
\text { ситуации в стране }\end{array}$ & $\begin{array}{l}\text { Практически отсутствует } \\
\text { в связи с благоприятными } \\
\text { тенденциями в общей эконо- } \\
\text { мической ситуации в стране }\end{array}$ \\
\hline Компонента 2 & $\begin{array}{l}\text { Риски, связанные } \\
\text { с неустойчивостью } \\
\text { цен }\end{array}$ & $\begin{array}{l}\text { Наблюдается низкая } \\
\text { волатильность цен за } \\
\text { последние несколько лет }\end{array}$ \\
\hline Компонента 3 & $\begin{array}{l}\text { Риски, связанные } \\
\text { с объемом экспорта } \\
\text { нефтепродуктов }\end{array}$ & $\begin{array}{l}\text { Экспорт осуществляется } \\
\text { без перебоев }\end{array}$ \\
\hline Компонента 4 & $\begin{array}{l}\text { Риски изменения } \\
\text { цен при неизменной } \\
\text { структуре произ- } \\
\text { водства }\end{array}$ & $\begin{array}{l}\text { Цены относительно } \\
\text { постоянны при неизменной } \\
\text { структуре производства }\end{array}$ \\
\hline Компонента 5 & $\begin{array}{l}\text { Экологические } \\
\text { риски }\end{array}$ & Отсутствуют \\
\hline Компонента 6 & $\begin{array}{l}\text { Риски изменения } \\
\text { объемов добычи }\end{array}$ & $\begin{array}{l}\text { Не ожидается существенных } \\
\text { изменений в объемах добычи }\end{array}$ \\
\hline
\end{tabular}

$$
\begin{gathered}
v_{1}=0,716^{2} \cdot y_{\text {price }}+0,476^{2} \cdot y_{\text {gdp }}+0,451^{2} \cdot y_{r}= \\
=0,716^{2} \cdot 8,29+0,476^{2} \cdot 0+0,451^{2} \cdot 0,476=4,349 \\
v_{2}=0,859^{2} \cdot y_{\text {doll }}+0,422^{2} \cdot y_{\text {price }}= \\
=0,859^{2} \cdot 10+0,422^{2} \cdot 8,29=8,859 \\
v_{3}=0,968^{2} \cdot y_{\text {exp }}=0,968^{2} \cdot 4,95=4,638 \\
v_{4}=0,984^{2} \cdot y_{\text {ippp }}=0,984^{2} \cdot 4,81=4,657 \\
v_{5}=0,991^{2} \cdot y_{\text {pollution }}=0,991^{2} \cdot 0=0 \\
v_{6}=0,994^{2} \cdot y_{\text {extr }}=0,994^{2} \cdot 1,35=1,334 .
\end{gathered}
$$

Фактические значения, полученные на основании оценок экспертов компании по каждому из видов рисков, а также перевод фактических значений всех критериев оцениваемого проекта в бинарные показатели представлены в таблице 7.

Далее были сформированы векторы $\mathbf{p}, \mathbf{q}$ и $\mathbf{r}$, на основе которых с помощью предложенного алгоритма было рассчитано значение интегрального показателя $T$ :

$$
\begin{gathered}
\mathbf{p}=[1 ; 1 ; 1 ; 1 ; 1 ; 0] \\
\mathbf{q}=[1 ; 1 ; 0 ; 0 ; 1 ; 0] \\
\mathbf{r}=[0 ; 1 ; 0 ; 1 ; 1 ; 1] \\
\quad \downarrow \\
\mathbf{f}=[0 ; 1 ; 0 ; 1 ; 1 ; 0] \\
\downarrow \\
T=3
\end{gathered}
$$


Перевод фактических значений критериев

Таблица 7. эффективности проекта в бинарные

\begin{tabular}{|c|c|c|c|c|}
\hline $\begin{array}{c}\text { Вид } \\
\text { критерия }\end{array}$ & $\begin{array}{l}\text { Ранг } \\
\text { критерия }\end{array}$ & Наименование критерия & $\begin{array}{l}\text { Фактическое } \\
\text { значение }\end{array}$ & $\begin{array}{l}\text { Бинарное } \\
\text { Значение }\end{array}$ \\
\hline \multirow{6}{*}{ 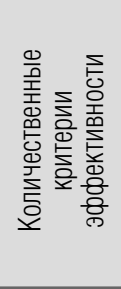 } & 1 & NPV (руб.) & 37328670 & 1 \\
\hline & 2 & Количество социально значимых программ & 2 & 1 \\
\hline & 3 & DPP (лет) & 12 & 1 \\
\hline & 4 & Доля затрат на инновации (\%) & 7 & 1 \\
\hline & 5 & Индекс рентабельности (\%) & 118 & 1 \\
\hline & 6 & Доля НДПИ в выручке (\%) & 8,5 & 0 \\
\hline \multirow{6}{*}{ 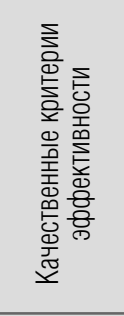 } & 1 & Сложность и затратность разработки нового месторождения & 2 & 1 \\
\hline & 2 & Необходимость технологических нововведений & 3 & 1 \\
\hline & 3 & Уровень конкуренции на рынке & 1 & 0 \\
\hline & 4 & Наличие покупателей продукции & 1 & 0 \\
\hline & 5 & Государственная поддержка & 2 & 1 \\
\hline & 6 & Необходимость привлечения нового персонала & 1 & 0 \\
\hline \multirow{6}{*}{ 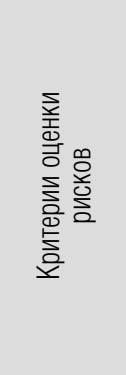 } & 1 & Риски, связанные с неустойчивостью цен & Высокая волатильность цен & 0 \\
\hline & 2 & $\begin{array}{l}\text { Риски изменения цен при неизменной структуре } \\
\text { производства }\end{array}$ & $\begin{array}{l}\text { Цены постоянны при неизменной } \\
\text { структуре производства }\end{array}$ & 1 \\
\hline & 3 & Риски, связанные с объемом экспорта нестепродуктов & Существуют проблемы с экспортом & 0 \\
\hline & 4 & $\begin{array}{l}\text { Риски, связанные с изменением общей экономической } \\
\text { ситуации в стране }\end{array}$ & $\begin{array}{l}\text { Наблюдается благоприятная тенденция } \\
\text { в Экономической ситуации в стране }\end{array}$ & 1 \\
\hline & 5 & Риски изменения объемов добычи нефти & Отсутствуют & 1 \\
\hline & 6 & Экологические риски & Отсутствуют & 1 \\
\hline
\end{tabular}

Поскольку значение интегрального показателя эффективности проекта оказалось равно трем, анализируемый инвестиционный проект не рекомендуется для реализации.

\section{Заключение}

Представленный подход к оценке инвестиционных проектов и выявлению наиболее предпочтительных способов их реализации позволяет решить проблему выбора между более эффективными и менее рискованными проектами, с чем зачастую сталкиваются компании. Разработанный интегральный показатель включает в себя качественные и количественные критерии эффективности, а также критерии оценки рисков. Кроме того, даны рекомендации в части применения метода главных компонент для выявления групп рисков инвестиционных проектов в соответствии с их отраслевой принадлежностью, а также определения весов этих групп.

\section{Литература}

1. Воробьева И.М., Пономарев А.М. Оценка эффективности инвестиционных проектов // Молодой ученый. 2015. № 10. С. 563-567.

2. Mackevicius J., Tomasevic V. Model for evaluating the economic efficiency of investment projects: Architecture and main aspects of application // Ekonomika. 2011. Vol. 90. No. 4. P. 133-149.

3. Теплова Т.В. Финансовый менеджмент: управление капиталом и инвестициями. М.: ГУ ВШЭ, 2000.

4. Макарова Л.Г., Макаров А.С. Экономический анализ в управлении финансами фирмы. М.: Академия, 2008.

5. Хижина М.А. Анализ показателей эффективности инвестиционных проектов // материалы III Международной научной конференции «Проблемы современной экономики». Челябинск, 20-23 декабря 2013 г. С. 52-55.

6. Кривцов С.В. Современные подходы к оценке эффективности инвестиционных проектов // Молодой ученый. 2016. № 12. С. 1324-1327.

7. Кувшинов М.С., Комарова Н.С., Бажанова М.И. Интегральная оценка эффективности инвестиционных проектов на промышленных предприятиях // Вестник ЮУрГУ. 2013. Т. 7. № 4. С. 52-55. 
8. Анисимов Е.Г., Сауренко Т.Н. Интегральный показатель экономической эффективности инвестиционных проектов // Вестник Саратовского государственного социально-экономического университета. 2012. № 5 (44). С. 9-12.

9. Сидоров А.Т., Платонова Ю.В., Желанова Ю.И. Стохастический метод оценки интегрального показателя эффективности инвестиционного проекта // Научный вестник Московского государственного технического университета гражданской авиации. 2005. № 88 (6). С. 198-200.

10. Протасов В.С. Динамическая оценка эффективности инвестиционных проектов с учетом особенности газовой отрасли // Корпоративные финансы. 2012. № 1 (21). С. 58-70.

11. Штефан М.А., Орнатский А.А. Эвристические методы в оценке инвестиционных проектов // Финансы и кредит. 2015. № 5 (629). C. 51-63.

12. Клюшникова Е.В., Шитова Е.М. Методические подходы к расчету интегрального показателя, методы ранжирования // ИнноЦентр. 2016. № 1 (10). С. 4-18.

13. Bonini C.P. Risk evaluation of investment projects // Omega. 1975. Vol. 3. No. 6. P. 735-750.

14. Волков М.В., Грачева И.М. Вероятностные методы анализа рисков // Корпоративный менеджмент, 1999. [Электронный ресурс]: https://www.cfin.ru/finanalysis/monte_carlo2.shtml (дата обращения 15.08.2018).

15. Лукашов А.В. Метод Монте-Карло для финансовых аналитиков: краткий путеводитель // Управление корпоративными финансами. 2007. № 1 (19). С. 22-39.

16. Попова А.Ю. Оценка риска инвестиционного проекта // Научный журнал КубГАУ. 2006. № 19 (03). [Электронный ресурс]: http://ej.kubagro.ru/2006/03/07/ (дата обращения 15.08.2018).

17. Jovanovic P. Application of sensitivity analysis in investment project evaluation under uncertainty and risk // International Journal of Project Management. 1999. Vol. 17. No. 4. P. 217-222.

18. Chen C. Evaluating the investment benefit of multinational enterprises' international projects based on risk adjustment: Evidence from China // Eurasia Journal of Mathematics, Science and Technology Education. 2016. Vol. 12. No. 9. P. 2451-2464.

19. Aaker J.L. Dimensions of brand personality // Journal of Marketing Research. 1997. Vol. 34. No. 3. P. 347-356.

20. Айвазян С.А., Степанов В.С., Козлова М.И. Измерение синтетических категорий качества жизни населения и выявление ключевых направлений совершенствования социально-экономической политики (на примере Самарской области и ее муниципальных образований) // Прикладная эконометрика. 2006. № 2. С. 18-84.

\title{
Investment project efficiency and risk evaluation: an integrated approach
}

\section{Maria A. Shtefan}

Head of Department of Accounting, Analysis and Audit

National Research University Higher School of Economics

Address: 25/12, Bolshaya Pecherskaya Street, Nizhny Novgorod, 603155, Russia

E-mail: shtefanmaria@yandex.ru

\section{Julia M. Elizarova}

Student, Economics MSc Program

National Research University Higher School of Economics

Address: 25/12, Bolshaya Pecherskaya Street, Nizhny Novgorod, 603155, Russia

E-mail: elizarova-julia7@yandex.ru

\begin{abstract}
While evaluating and selecting investment projects, modern companies are confronted with the problem of setting priorities between profitability and riskiness of these projects. Choice of a project on the basis of its profitability significantly increases risks of financial and economic activities and decreases the certainty of achieving the planned financial result. On the other hand, attempts to decrease investment projects risks may not allow one to achieve the desired profitability level. Therefore, it is vital to develop integrated multi-criteria indicators for this purpose.

This article is the result of the authors' development of an integral indicator for evaluating investment project efficiency and risks. The developed integral indicator has a matrix form. To compile the integral indicator, three groups of criteria are used: quantitative efficiency criteria, qualitative efficiency criteria and risk evaluation criteria. We propose to divide the qualitative and quantitative criteria into: 1) those defining the commercial (economic) efficiency of projects, 2) those defining their budgetary efficiency; 3 ) those defining their social efficiency. According to the authors, the list of criteria that define associated risks should include macroeconomic indicators and industry affiliation indicators that provide a comprehensive evaluation of the external economic situation on the corresponding market.
\end{abstract}


While evaluating efficiency and riskiness of the given projects, the integral indicator developed by the authors is converted from matrix form into a quantitative indicator that is easy to interpret. The authors propose to use principal component analysis and heuristic methods (including ranking method and hierarchy analysis method) for this purpose.

The results of this research can be used by companies to select investment projects.

Key words: investment project; automation of management decisions; integral indicator; efficiency evaluation; risk evaluation; principal component analysis.

Citation: Shtefan M.A., Elizarova J.M. (2018) Investment project efficiency and risk evaluation: an integrated approach. Business Informatics, no. 4 (46), pp. 54-65. DOI: 10.17323/1998-0663.2018.4.54.65

\section{References}

1. Vorobiova I.M., Ponomarev A.M. (2015) Otsenka effektivnosti investitsionnyh proektov [Evaluating the effectiveness of investment projects]. Young Scientist, no. 10, pp. 563-567 (in Russian).

2. Mackevicius J., Tomasevic V. (2011) Model for evaluating the economic efficiency of investment projects: Architecture and main aspects of application. Ekonomika, vol. 90, no. 4, pp. 133-149.

3. Teplova T.V. (2000) Finansovyy menedzhment: upravlenie kapitalom i investitsiyami [Financial management: capital and investment management]. Moscow: HSE (in Russian).

4. Makarova L.G., Makarov A.S. (2008) Ekonomicheskiy analiz v upravlenii finansami firmy [Economic analysis in a company's financial management]. Moscow: Academia (in Russian).

5. Khizhina M.A. (2013) Analiz pokazateley effektivnosti investitsionnyh proektov [Analysis of performance indicators of investment project]. Proceedings of the 3rd International Scientific Conference "Problems of modern economics". Chelyabinsk, Russia, 20-23 December 2013, pp. 52-55 (in Russian).

6. Krivtsov S.V. (2016) Sovremennye podhody k otsenke effektivnosti investitsionnyh proektov [Modern approaches to assessing the effectiveness of investment projects]. Young Scientist, no. 12, pp. 1324-1327 (in Russian).

7. Kuvshinov M.S., Komarova N.S., Bazhanova M.I. (2013) Integral'naya otsenka effektivnosti investitsionnyh proektov na promyshlennyh predpriyatiyah [Integrated assessment of the effectiveness of investment projects in industrial enterprises]. Bulletin of South Ural State University, vol. 7, no. 4, pp. 52-55 (in Russian).

8. Anisimov E.G., Saurenko T.N. (2012) Integral'nyy pokazatel' ekonomicheskoy effektivnosti investitsionnyh proektov [Integrated indicator of economic efficiency of investment projects]. Vestnik of Saratov State Socio-Economic University, no. 5 (44), pp. 9-12 (in Russian).

9. Sidorov A.T., Platonova Yu.V., Zhelanova Yu.I. (2005) Stohasticheskiy metod otsenki integral'nogo pokazatelya effektivnosti investitsionnogo proekta [Stochastic method of estimating integral index of an investment project efficiency]. Scientific Bulletin of the Moscow State Technical University of Civil Aviation, no. 88 (6), pp. 198-200 (in Russian).

10. Protasov V.S. (2012) Dinamicheskaya otsenka effektivnosti investitsionnyh proektov s uchetom osobennosti gazovoy otrasli [Dynamic assessment of the efficiency of investment projects considering gas industry peculiarities]. Corporate Finance, no. 1 (21), pp. 58-70 (in Russian).

11. Shtefan M.A., Ornatsky A.A. (2015) Evristicheskie metody v otsenke investitsionnyh proektov [Heuristic methods in the evaluation of investment projects]. Finance and Credit, no. 5 (629), pp. 51-63 (in Russian).

12. Klyushnikova E.V., Shitova E.M. (2016) Metodicheskie podhody k raschetu integral'nogo pokazatelya, metody ranzhirovaniya [Methodological approaches to the integrated index calculation, ranking methods]. InnoCenter, no. 1 (10), pp. 4-18 (in Russian).

13. Bonini C.P. (1975) Risk evaluation of investment projects. Omega, vol. 3, no. 6, pp. 735-750.

14. Volkov M.V., Gracheva I.M. (1999) Veroyatnostnye metody analiza riskov [Stochastic methods of risk analysis]. Corporate management. Available at: https://www.cfin.ru/finanalysis/monte_carlo2.shtml (accessed 15 August 2018) (in Russian).

15. Lukashov A.V. (2007) Metod Monte-Karlo dlya finansovyh analitikov: kratkiy putevoditel' [Monte Carlo method for financial analysts: a quick guide]. Corporate Finance Management, no. 1 (19), pp. 22-39 (in Russian).

16. Popova A.Yu. (2006) Otsenka riska investitsionnogo proekta [Investment project risk assessment]. Scientific Journal of KubSAU. no. 19 (03). Available at: http://ej.kubagro.ru/2006/03/07/ (accessed 15 August 2018) (in Russian).

17. Jovanovic P. (1999) Application of sensitivity analysis in investment project evaluation under uncertainty and risk. International Journal of Project Management, vol. 17, no. 4, pp. 217-222.

18. Chen C. (2016) Evaluating the investment benefit of multinational enterprises' international projects based on risk adjustment: Evidence from China. Eurasia Journal of Mathematics, Science and Technology Education, vol. 12, no. 9, pp. 2451-2464.

19. Aaker J.L. (1997) Dimensions of brand personality. Journal of Marketing Research, vol. 34, no. 3, pp. $347-356$.

20. Aivazyan S.A., Stepanov V.S., Kozlova M.I. (2006) Izmerenie sinteticheskih kategoriy kachestva zhizni naseleniya i vyyavlenie klyuchevyh napravleniy sovershenstvovaniya sotsial'no-ekonomicheskoy politiki (na primere Samarskoy oblasti i ee munitsipal'nyh obrazovaniy) [Measurement of synthetic categories of quality of life of the population and identification of key areas of improvement of socio-economic policy (on the example of the Samara region and its municipalities)]. Applied Econometrics, no. 2, pp. 18-84 (in Russian). 


\title{
Система поддержки
}

принятия решений для устойчивого экономического развития Дальневосточного федерального округа

\section{Г.Л. Бекларян}

кандидат экономических наук старший научный сотрудник

Центральный экономико-математический институт, Российская академия наук

Адрес: 117418 , г. Москва, Нахимовский проспект, д. 47

E-mail: glbeklaryan@gmail.com

\begin{abstract}
Аннотация
В статье представлена система поддержки принятия решений для устойчивого экономического развития Дальневосточного федерального округа (ДФО) Российской Федерации, в состав которого входят несколько регионов. С использованием методов системной динамики и агентного моделирования разработана имитационная модель экономики ДФО. Модель реализована в системе AnyLogic и позволяет исследовать влияние на экономику федерального округа ряда факторов темпов роста инвестиций в основные фонды, темпов роста средней заработной платы, темпов роста дотаций из федерального бюджета, а также динамики цен на нефть, уголь, алмазы, продукцию рыболовства и др. Особенностью данной модели является возможность анализа динамики состояний всех регионов, входящих в состав федерального округа, а также учет влияния внешних макроэкономических факторов.
\end{abstract}

Спроектированная система поддержки принятия решений позволяет визуализировать важнейшие характеристики субъектов Дальневосточного федерального округа на карте России (с помощью геоинформационной системы) и сохранять результаты имитационного моделирования в базе данных. При этом обеспечивается возможность прогнозирования динамики валового регионального продукта федерального округа в зависимости от значений управляющих параметров.

Исследованы различные сценарии развития Дальневосточного федерального округа. Реалистичный сценарий предполагает стабилизацию цен на основные энергоносители (нефть, газ, уголь) и полезные ископаемые, с одновременным ростом инвестиций в основные фонды. Пессимистический сценарий предполагает падение цен на энергоносители, алмазы, продукцию рыболовства и др., а также дальнейшее сокрашение численности экономически активного населения федерального округа. Оптимистический сценарий предполагает устойчивый рост спроса и цен на продукцию всех ключевых отраслей экономики федерального округа, при сохранении текущих темпов роста в промышленности и сельском хозяйстве.

Ключевые слова: система поддержки принятия решений; экономика региона; Дальневосточный федеральный округ; имитационное моделирование; AnyLogic.

Цитирование: Бекларян Г.Л. Система поддержки принятия решений для устойчивого экономического развития Дальневосточного федерального округа // Бизнес-информатика. 2018. № 4 (46). С. 66-75. DOI: $10.17323 / 1998-0663.2018 .4 .66 .75$ 


\section{Введение}

$\mathrm{B}$ настоящее время приобретает все большую актуальность задача поиска сценариев, обеспечивающих устойчивое экономическое развитие регионов Российской Федерации. Сложность данной задачи во многом обусловлена необходимостью учета внутренних обратных связей между основными характеристиками экономических систем регионов. Например, в условиях дефицита экономически активного населения, свойственного, в частности, регионам Дальневосточного федерального округа (ДФО), трудно обеспечить устойчивый рост экономки. Тем не менее, важной особенностью региональной экономической системы является возможность реализации компенсационной стратегии, предполагающей рост валового регионального продукта (ВРП) за счет развития фондоемких отраслей экономики, привлечения внешних трудовых ресурсов, эффективного использования географических преимуществ и имеющихся природных ресурсов.

Объектом исследования в данной работе является экономическая система Дальневосточного федерального округа (ДФО) России. Отметим, что площадь ДФО равна 6952555 кв. км, что составляет 40,6\% площади всей страны (это крупнейший по размерам территории федеральный округ России). При этом плотность населения федерального округа составляет всего 1,18 чел./Кв. Км.

Дальневосточный федеральный округ состоит из следующих регионов: Республика Саха (Якутия), Приморский край, Хабаровский край, Амурская область, Камчатский край, Магаданская область, Сахалинская область, Еврейская автономная область, Чукотский автономный округ. Ведущими отраслями ДФО являются цветная металлургия, добыча драгоценных металлов и камней, горнодобывающая промышленность, рыбная, лесная и деревообрабатывающая промышленность, нефте- и газодобыча, машиностроение. Основу экономики ДФО составляют природные ресурсы. Здесь расположены крупнейшие месторождения углеводородов, золота, алмазов, черных, цветных и редких металлов, олова, угля и других рудных и нерудных полезных ископаемых. На территории Дальнего Востока добывается $100 \%$ всего российского олова, почти $100 \%$ алмазов, более $50 \%$ золота и серебра. Рыбная промышленность ДФО является крупней- шей в России, на ее долю приходится около $70 \%$ добычи всех водно-биологических ресурсов страны и $56 \%$ общероссийского производства рыбной продукции ${ }^{1}$.

Таким образом, имеются все предпосылки для устойчивого экономического развития ДФО. Однако наблюдаются определенные проблемы, связанные, прежде всего, с дефицитом экономически активного населения (всего 3,5 млн чел.), неудовлетворительным состоянием транспортной инфраструктуры (протяженность дорог составляет всего 36971 тыс. км), а также завышенными ценами на потребительские товары и услуги на фоне невысоких средних заработных плат. Поэтому требуется разработка нового подхода, нацеленного на поиск наилучших сценариев развития федерального округа за счет формирования эффективной стратегии управления ключевыми производственными и инвестиционными характеристиками [1]. К таким ключевым характеристикам, в частности относятся темпы роста инвестиций в основные фонды (включая транспортную инфраструктуру), темпы снижения ставок по кредитам, темпы роста заработной платы, темпы снижения инфляции потребительских цен и др. Для реализации данного подхода требуется разработка системы поддержки принятия решений (СППР) [2], основанной на использовании методов имитационного моделирования [3].

Особенностью предлагаемого подхода является использование методов системной динамики, впервые предложенных в работах Дж. Форрестера [4; 5] и Д. Медоуз [6; 7], и впоследствии развитых в работах В.Н. Сидоренко [8], А.С. Акопова [9-12] и др., а также методов агентного моделирования, предложенных в работах Т. Шеллинга [13], Р. Акселорда [14] и развитых в работах ряда российских ученых [15-17].

Среди исследований по рациональному управлению региональными системами следует выделить работы С.А. Айвазяна [1], В.Л. Макарова [18], А.Р. Бахтизина [19], Г.Л. Бекларян [20], а также работы [21-23], в которых особое внимание уделяется сравнительному анализу производственных и инвестиционных характеристик регионов России по отраслям топливно-энергетического комплекса.

Для реализации имитационной модели экономики ДФО используется система AnyLogic. В работах [24; 25] система AnyLogic также исполь-

${ }^{1}$ Регионы России. Социально-экономические показатели 2017. Статистический сборник 
зуется для моделирования деятельности межрегионального центра андеррайтинга, а также поведения толпы в условиях чрезвычайных ситуаций. Особенностью AnyLogic является поддержка методов системной динамики и агентного моделирования в рамках одной модели [3].

Цель данной статьи - разработка системы поддержки принятия решений для устойчивого экономического развития Дальневосточного федерального округа (ДФО) с использованием методов имитационного моделирования, с целью поиска наилучших стратегий управления внутренними характеристики соответствующих регионов.

\section{1. Имитационная модель социально-экономической системы ДФО}

Концептуальная модель социально-экономической системы ДФО представлена на рисунке 1.
Важнейшей характеристикой предложенной модели является состояние социально-экономической системы ДФО, оцениваемое посредством деления регионов федерального округа на три условные группы, в зависимости от значения интегрального показателя, учитывающего темпы роста ВРП, численность населения и реальные доходы населения. Для каждого региона ДФО будем выделять три возможных состояния: благоприятное, удовлетворительное и неблагоприятное. Отметим, что взаимосвязь между ВРП и реальными доходами населения не является устойчивой, поскольку реальные доходы населения формируются с учетом влияния инфляционной составляющей, которая, в свою очередь, зависит от доступности товаров и услуг для населения. Неблагоприятное состояние транспортной и социальной инфраструктуры в ДФО приводит к необоснованному завышению цен и, как следствие, существенно снижает реаль-

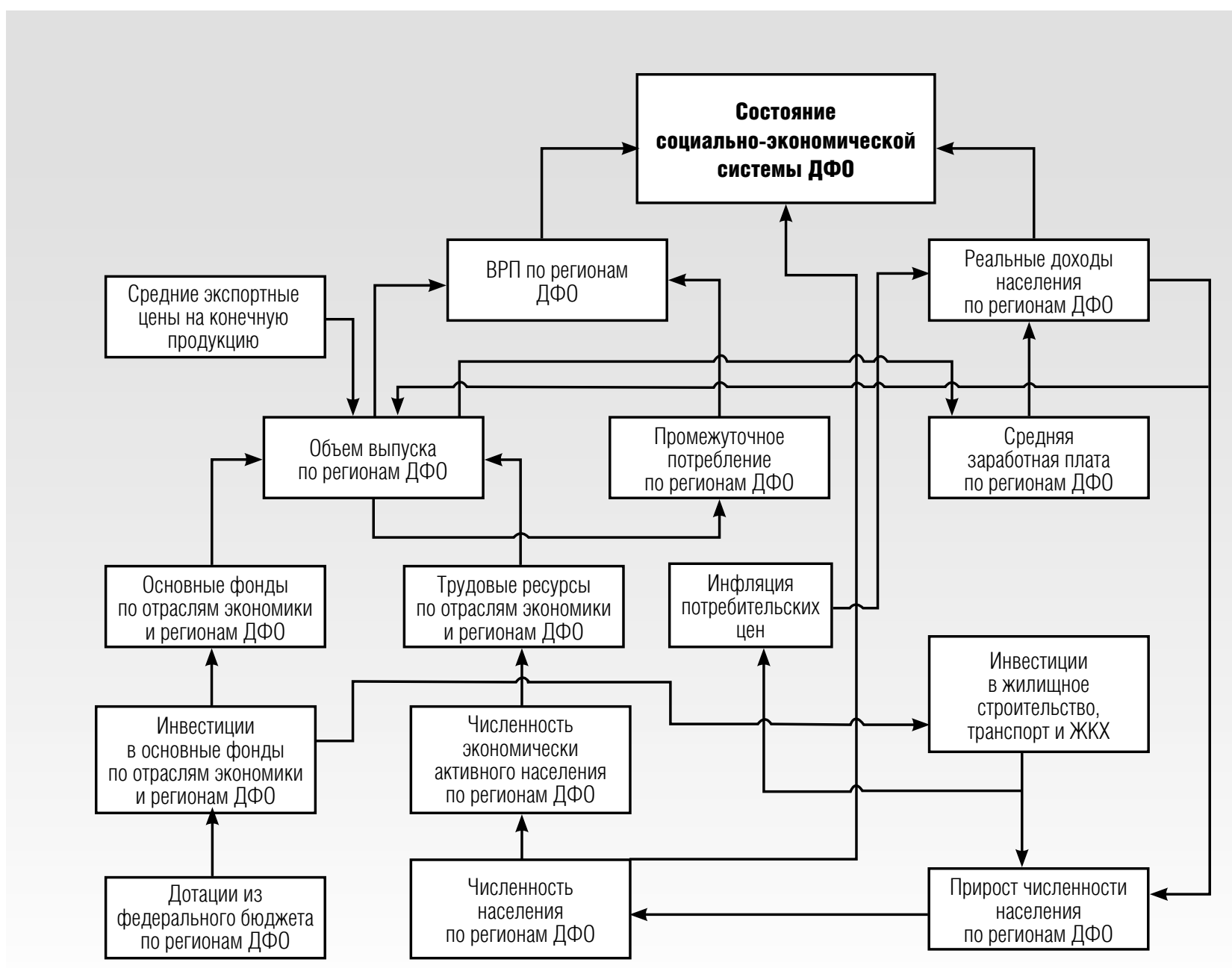

Рис. 1. Концептуальная модель социально-экономической системы ДФ0 
ные доходы населения. Напомним, что по данным Росстата $^{2}$ темпы падения реальных доходов населения в ДФО составили 0,989 в 2015 году и 0,935 в 2016 году. При этом, индекс потребительских цен составил 112,0 и 105,4 соответственно.

Особенностью предложенной модели является принятие во внимание важных обратных связей в социально-экономических системах ДФО, в частности, определяющих зависимость между инвестициями в жилищное строительство, транспорт и жилищно-коммунальное хозяйство, реальными доходами населения и приростом численности населения по регионам федерального округа. Низкая плотность населения является одной из ключевых проблем ДФО, что во многом обусловлено неблагоприятным состоянием транспортной и жилищной инфраструктуры. Дефицит транспортных коммуникаций и географическая удаленность ДФО от центральной и западной частей РФ приводит к высокой стоимости фиксированного набора продуктов, которая, по данным за 2016 год, составила 17650 руб. (для сравнения: в Москве стоимость потребительской корзины в 2016 году составила 20714 руб., а в Санкт-Петербурге - 15 577,9 руб.) ${ }^{3}$. Поэтому для регионов ДФО необходимо наращивание инвестиций в основные фонды всех ключевых отраслей экономики, в том числе промышленности, строительства, сельского хозяйства, транспорта и др. При этом экономика регионов ДФО существенно зависит от средних экспортных цен на конечную продукцию, в частности, нефть, уголь, железную руду, продукцию рыболовства и др. В условиях явного дефицита трудовых ресурсов регионам ДФО необходимо развитие фондоемких предприятий с высокой степенью автоматизации основных производственных процессов. Это возможно только при наличии значительных субсидий из федерального бюджета и относительной низкой стоимости заемного капитала (низких ставок по кредитам).

Далее приведем формальное описание разработанной имитационной модели регионов ДФО.

Введем следующие обозначения:

^ $\tilde{T} \in\left\{t_{1}, t_{2}, \ldots, t_{T}\right\}$ - набор индексов модельного времени по годам, где $T$ - количество лет, относящих к периоду стратегического планирования (10 лет);
\ $\tilde{I} \in\left\{i_{1}, i_{2}, \ldots, i_{I}\right\}$ - набор индексов регионов ДФО, где I- количество регионов ДФО (9);

$\downarrow \tilde{J}_{i} \in\left\{j_{1}, j_{2}, \ldots, j_{J_{i}}\right\}-$ набор индексов отраслей ДФО, где $J_{i}-$ количество отраслей экономики в каждом $i$-м регионе ДФО;

^ $\tilde{Z}_{i}$ - набор индексов суботраслей ДФО, относящихся к жилищному строительству, транспорту и ЖKX;

$\checkmark\left\{K_{j_{i}}(t), L_{j_{i}}(t)\right\}$ - основные фонды и трудовые ресурсы по $j_{i}$-м отраслям экономики ДФО в момент времени $t, j_{i} \in \tilde{J}_{i}, i \in \tilde{I}, t \in \tilde{T}$;

$\downarrow\left\{\alpha_{j_{i}}, \beta_{j_{i}}\right\}-$ производственные факторы (эластичности выпуска по основным фондам и трудовым ресурсам) по $j_{i}$-м отраслям экономики ДФО; $\alpha_{j_{i}}+\beta_{j_{i}}=1, j_{i} \in \tilde{J}_{i}, i \in \tilde{I}$

$\checkmark A_{j_{i}}-$ фактор научно-технического прогресса по $j_{i}$-м отраслям экономики ДФО, $j_{i} \in \tilde{J}_{i}, i \in \tilde{I}$;

\ $\left\{\operatorname{Inv}_{j_{i}}(t), \delta \operatorname{Inv}_{j_{i}}(t), \delta B_{j_{i}}(t), \delta r_{i}(t)\right\}$ - инвестиции в основные фонды по $j_{i}$-м отраслям экономики ДФО, темпы роста инвестиции (из собственных средств), темпы дотаций из федерального бюджета и темпы снижения ставок по кредитам соответственно в момент времени $t, j_{i} \in \tilde{J}_{i}, i \in \tilde{I}, t \in \tilde{T}$;

$\checkmark\left\{V_{j_{i}}(t), \tilde{V}_{j_{i}}(t)\right\}$ - объем выпуска в физическом и денежном выражении по $j_{i}$-м отраслям экономики ДФО в момент времени $t, j_{i} \in \tilde{J}_{i}, i \in \tilde{I}, t \in \tilde{T}$;

$\checkmark\left\{G_{j_{i}}(t), \tilde{G}_{j_{i}}(t)\right\}$ - промежуточное потребление в физическом и денежном выражении по $j_{i}$-м отраслям экономики ДФО в момент времени $t$, $j_{i} \in \tilde{J}_{i}, i \in \tilde{I}, t \in \tilde{T}$

$\checkmark g_{u_{i} j_{i}}(t)$ - доля продукта $u_{i}$-й отрасли экономики $u_{i} \in \tilde{J}_{i}$, необходимая для производства единицы продукции $j_{i}$-й отрасли экономики $j_{i} \in \tilde{J}_{i}$ (матрица «затраты - выпуск»):

$$
\sum_{u_{i}=1}^{J_{i}} g_{u_{i} j_{i}}(t)=1
$$

$\left\{p_{j_{i}}(t), h_{j_{i}}(t)\right\}-$ средние внутренние цены на конечную и промежуточную продукцию по $j_{i}$-м отраслям экономики ДФО в момент времени $t$, $j_{i} \in \tilde{J}_{i}, i \in \tilde{I}, t \in \tilde{T}$

^ $e_{j_{i}}(t)$ - средние экспортные цены по $j_{i}$-м отраслям экономики ДФО в момент времени $t$, $j_{i} \in \tilde{J}_{i}, i \in \tilde{I}, t \in \tilde{T}$

$\downarrow\left\{E x_{j_{i}}(t), \delta e x_{j_{i}}(t)\right\}$ - доля экспорта и темпы роста

\footnotetext{
2 Регионы России. Социально-экономические показатели 2017. Статистический сборник

3 Регионы России. Социально-экономические показатели 2017. Статистический сборник
} 
доли экспорта продукции $j_{i}$-х отраслей экономики ДФО в момент времени $t, j_{i} \in \tilde{J}_{i}, i \in \tilde{I}, t \in \tilde{T}$;

$\downarrow\left\{\inf _{j_{i}}(t), \delta \inf _{j_{i}}(t)\right\}-$ инфляция потребительских цен и темп снижения инфляции по $j_{i}$-м отраслям экономики ДФО в момент времени $t, j_{i} \in \tilde{J}_{i}, i \in \tilde{I}$, $t \in \tilde{T}$

$\checkmark\left\{P_{i}(t), \delta \tilde{P}_{i}(t), \lambda_{i}(t)\right\}$ - общая численность населения, прирост численности экономически активного населения и ее доля в $i$-х регионах ДФО в момент времени $t, i \in \tilde{I}, t \in \tilde{T}$;

$\downarrow\left\{R_{i}(t), \delta s_{i}(t)\right\}$ - реальные доходы населения и темпы роста заработной платы по регионам ДФО в $i$-х регионах ДФО в момент времени $t, i \in \tilde{I}, t \in \tilde{T}$;

$\left\{G D P_{i}(t), S T_{i}(t)\right\}-$ ВРП и состояние социальноэкономической системы в $i$-х регионах ДФО в момент времени $t, i \in \tilde{I}, t \in \tilde{T}$;

$\left\{c_{1 j_{i}}, c_{2 j_{i}}, \ldots, c_{N j_{i}}\right\}-$ коэффициенты регрессии, вычисленные с использованием метода наименьших квадратов (МНК), где $N$ - число коэффициентов;

$\checkmark\left\{\mu_{1 i}, \mu_{2 i}\right\}$ - коэффициенты значимости реальных доходов населения, а также состояния основных фондов в сфере жилищного строительства, транспорта и жилищно-коммунального хозяйства для прироста численности населения.

Объем выпуска конечной продукции в физическом выражении вычисляется с использованием хорошо известной функции Кобба-Дугласа:

$$
\begin{gathered}
V_{j_{i}}(t)=A_{j_{i}}(t)\left(K_{j_{i}}(t)\right)^{\alpha_{j_{i}}}\left(L_{j_{i}}(t)\right)^{\beta_{j_{i}}}, \\
j_{i} \in \tilde{J}_{i}, i \in \tilde{I}, t \in \tilde{T} .
\end{gathered}
$$

Объем выпуска конечной продукции в денежном выражении:

$$
\tilde{V}_{j_{i}}(t)=p_{j_{i}}(t) V_{j_{i}}(t)\left(1-E x_{j_{i}}(t)\right)+e_{j_{i}}(t) V_{j_{i}}(t) E x_{j_{i}}(t)
$$

Цены на конечную продукцию с учетом инфляции:

$$
p_{j_{i}}(t)=\inf _{j_{i}}(t) p_{j_{i}}(t-1)
$$

Доля экспорта:

$$
E x_{j_{i}}(t)=\delta e x_{j_{i}}(t) E x_{j_{i}}(t-1) .
$$

Индекс инфляции вычисляется в зависимости от принадлежности $j_{i}$-й отрасли к жилищному строительству и транспорту либо к прочим отраслям экономики:

$$
\inf _{j_{i}}(t)=\left\{\begin{array}{l}
c_{1 j_{i}} V_{j_{i}}(t), \text { если } j_{i} \in \tilde{Z}_{i} \\
\delta \inf _{j_{i}}(t) \inf _{j_{i}}(t-1), \text { если } j_{i} \notin \tilde{Z}_{i} .
\end{array}\right.
$$

Объем промежуточного потребления в физическом и денежном выражении:

$$
\begin{gathered}
G_{j_{i}}(t)=\sum_{u_{i}=1}^{J_{i}} V_{u_{i}}(t) g_{u_{i} j_{i}}(t), \\
\tilde{G}_{j_{i}}(t)=h_{j_{i}}(t) G_{j_{i}}(t), \\
\sum_{u_{i}=1}^{J_{i}} g_{u_{i} j_{i}}(t)=1, \\
u_{i} \in \tilde{J}_{i}, j_{i} \in \tilde{J}_{i}, t \in \tilde{T} .
\end{gathered}
$$

Объем основных фондов, зависящий от темпа роста инвестиций в основные фонды:

$K_{j_{i}}(t)=K_{j_{i}}(t-1)+\frac{1}{\delta r_{i}(t)} \delta \operatorname{Inv}_{j_{i}}(t) \delta B_{j_{i}}(t) \operatorname{Inv}_{j_{i}}(t-1)$.

Объем трудовых ресурсов, зависящий от прироста численности экономически активного населения:

$$
L_{j_{i}}(t)=L_{j_{i}}(t-1)+c_{2 j_{i}} \delta \tilde{P}_{i}(t),
$$

Прирост численности экономически активного населения зависит от общей численности населения, динамика которой определяется качеством жизни населения в регионе:

$$
\begin{gathered}
\delta \tilde{P}_{i}(t)=\lambda_{i}(t) P_{i}(t), \\
P_{i}(t)=P_{i}(t-1)+\mu_{1 i} P_{i}(t-1) R_{i}(t)+\mu_{2 i} \tilde{K}_{i}, \\
\tilde{K}_{j_{i}}(t)=\left\{\begin{array}{l}
\sum_{j_{i}}^{J_{j}} K_{j_{i}}(t), \text { если } j_{i} \in \tilde{Z}_{i}, \\
0, \text { если } j_{i} \notin \tilde{Z}_{i} .
\end{array}\right.
\end{gathered}
$$

Реальные доходы населения:

$$
R_{i}(t)=\frac{1}{\inf _{j_{i}}(t)} \delta s_{i}(t) R_{i}(t-1) .
$$

Валовой региональный продукт по регионам ДФО, определяемый производственным методом:

$$
G D P_{i}(t)=\sum_{j_{i}=1}^{J_{i}} \tilde{V}_{j_{i}}(t)-\tilde{G}_{j_{i}}(t) .
$$

Значение интегрального показателя, определяющего состояние социально-экономических систем регионов ДФО: 


$$
\begin{gathered}
F_{i}(t)=w_{1} \frac{G D P_{i}(t)}{\sum_{i=1}^{I} G D P_{i}(t)}+w_{2} \frac{P_{i}(t)}{\sum_{i=1}^{I} P_{i}(t)}+w_{3} \frac{R_{i}(t)}{\sum_{i=1}^{I} R_{i}(t)}, \\
i \in \tilde{I}, t \in \tilde{T},
\end{gathered}
$$

где $\left\{w_{1}, w_{2}, w_{3}\right\}$ - коэффициенты, определяющие значимость соответствующих показателей для лица, принимающего решения.

Состояние социально-экономических систем регионов ДФО определяется на основе оценки значения интегрального показателя:

$$
S T_{i}(t)=\left\{\begin{array}{l}
1, \text { если } F_{i}(t) \geq \underline{F}, \\
2, \text { если } \underline{F} \leq F_{i}(t)<\underline{F}, \\
3, \text { если } F_{i}(t)<\underline{\underline{F}}
\end{array}\right.
$$

где $\{\underline{F}, \underline{F}\}$ - пороговые значения для интегрального показателя, определяемые лицом, принимающим решения.

При этом управляющими параметрами модели являются следующие: $\delta \operatorname{Inv}_{j_{i}}(t), \delta B_{j_{i}}(t), \delta r_{i}(t), \delta \inf _{j_{i}}(t)$, $\operatorname{\delta ex}_{j_{i}}(t), \delta s_{i}(t)$. Значения остальных характеристик, в частности, экспортных цен являются экзогенными (внемодельными), и могут рассматриваться как сценарные параметры.

\section{2. Результаты имитационного моделирования}

Разработанная модель социально-экономической системы ДФО (1)-(16) реализована в системе имитационного моделирования AnyLogic, позволяющей комбинировать методы системной динамики и агентного моделирования в рамках одной модели. Это позволило спрогнозировать и визуализировать состояния агентов-регионов в зависимости от оценки значения интегрального показателя (14). При этом, актуальные состояния агентов-регионов отображаются на карте России (рисунок 2).

При этом поддерживается механизм типа «drilldown», позволяющий проанализировать динамику индивидуальных состояний каждого конкретного региона ДФО, например, Хабаровского края (рисунок 3).

Далее были исследованы следующие возможные сценарии развития социально-экономической системы ДФО:

$\downarrow$ Сценарий 1: реалистичный, предполагающий стабилизацию цен на основные энергоносители (в том числе, нефть, газ, уголь) и полезные ископаемые с одновременным ростом инвестиций основные фонды;

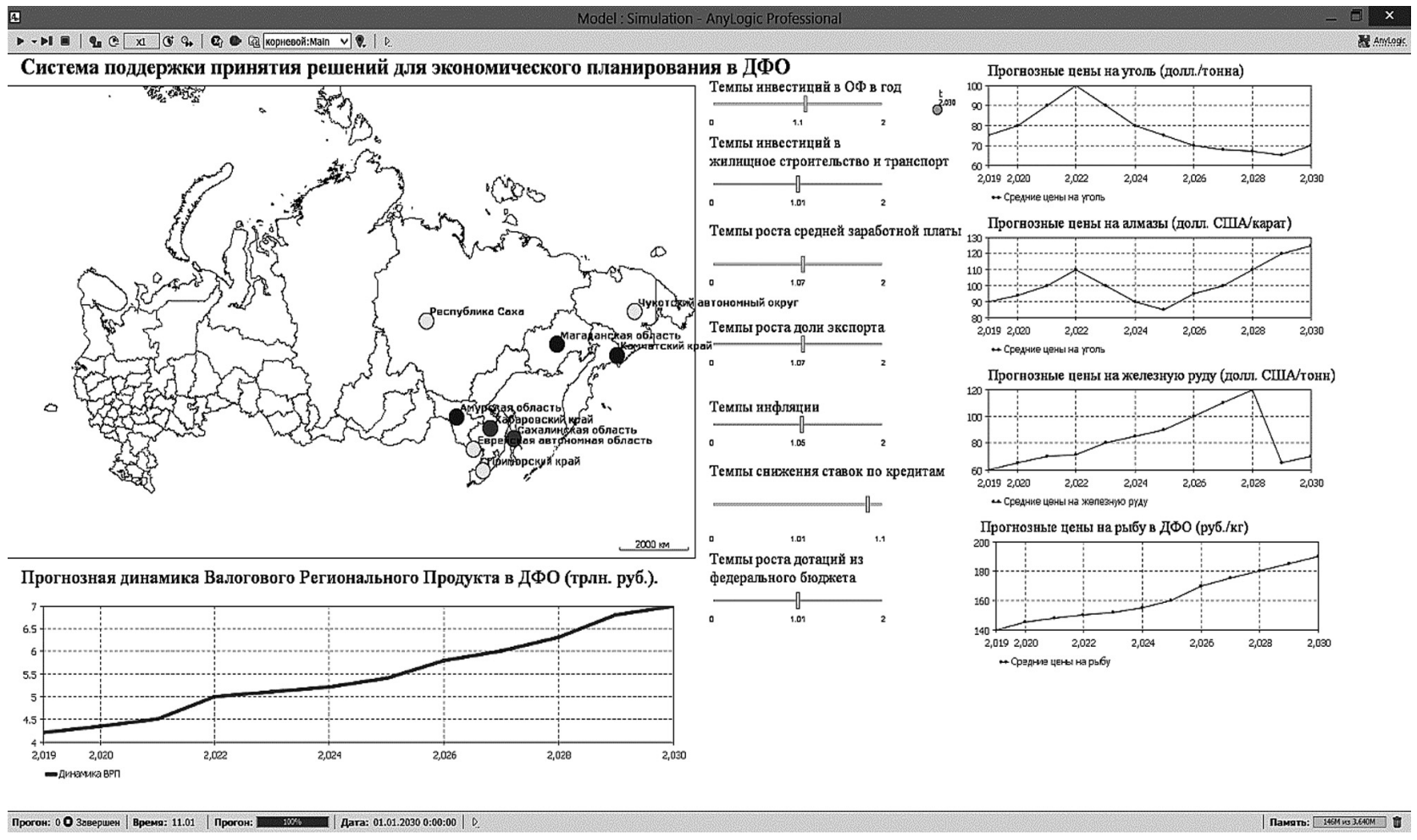

Pис. 2. Имитационная модель социально-экономической системы ДФ0 в AnyLogic 


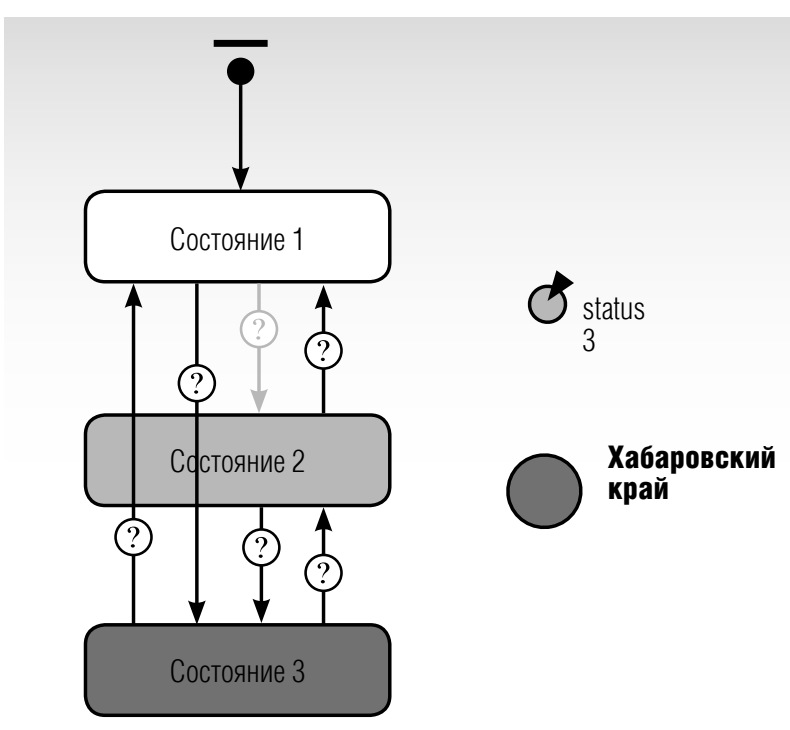

Рис. 3. Визуализация состояния выбранного региона (на примере Хабаровского края)

- Сценарий 2: пессимистический, обусловленный падением цен энергоносители, алмазы, продукцию рыболовства и др. и дальнейшим сокращением численности экономически активного населения ДФО;

^ Сценарий 3: оптимистический, предполагающий устойчивый рост спроса и цен на продукцию всех ключевых отраслей экономики ДФО при сохранении текущих темпов роста в промышленности и сельском хозяйстве.
Результаты прогнозирования динамики ВРП ДФО для рассмотренных сценариев представлены на рисунке 4. Отметим, что все три рассматриваемых сценария обеспечивают устойчивый рост ВРП ДФО, в основном за счет наращивания производственной базы, увеличения темпов роста инвестиций в основные фонды, снижения уровня инфляции и ставок по кредитам. Подобные условия позволяют достичь роста ВРП даже в условиях снижения экспортных цен и спроса на продукцию основных отраслей экономики ДФО. При этом возможно даже некоторое увеличение численности населения, при условии, что реальные доходы и качество жизни населения будут расти.

\section{Заключение}

Таким образом, в статье представлена разработанная система поддержки принятия решений для устойчивого экономического развития Дальневосточного федерального округа (ДФО). Предложена экономико-математическая и имитационная (реализованная в AnyLogic) модель социально-экономической системы ДФО, отличительной особенностью которой является учет важнейших обратных связей между ключевыми характеристиками региональных социально-экономических систем, в частности, определяющих зависимость между инвестициями в жилищное строительство, транспорт и жилищно-коммунальное хозяйство, реальными доходами населения и приростом численности на-

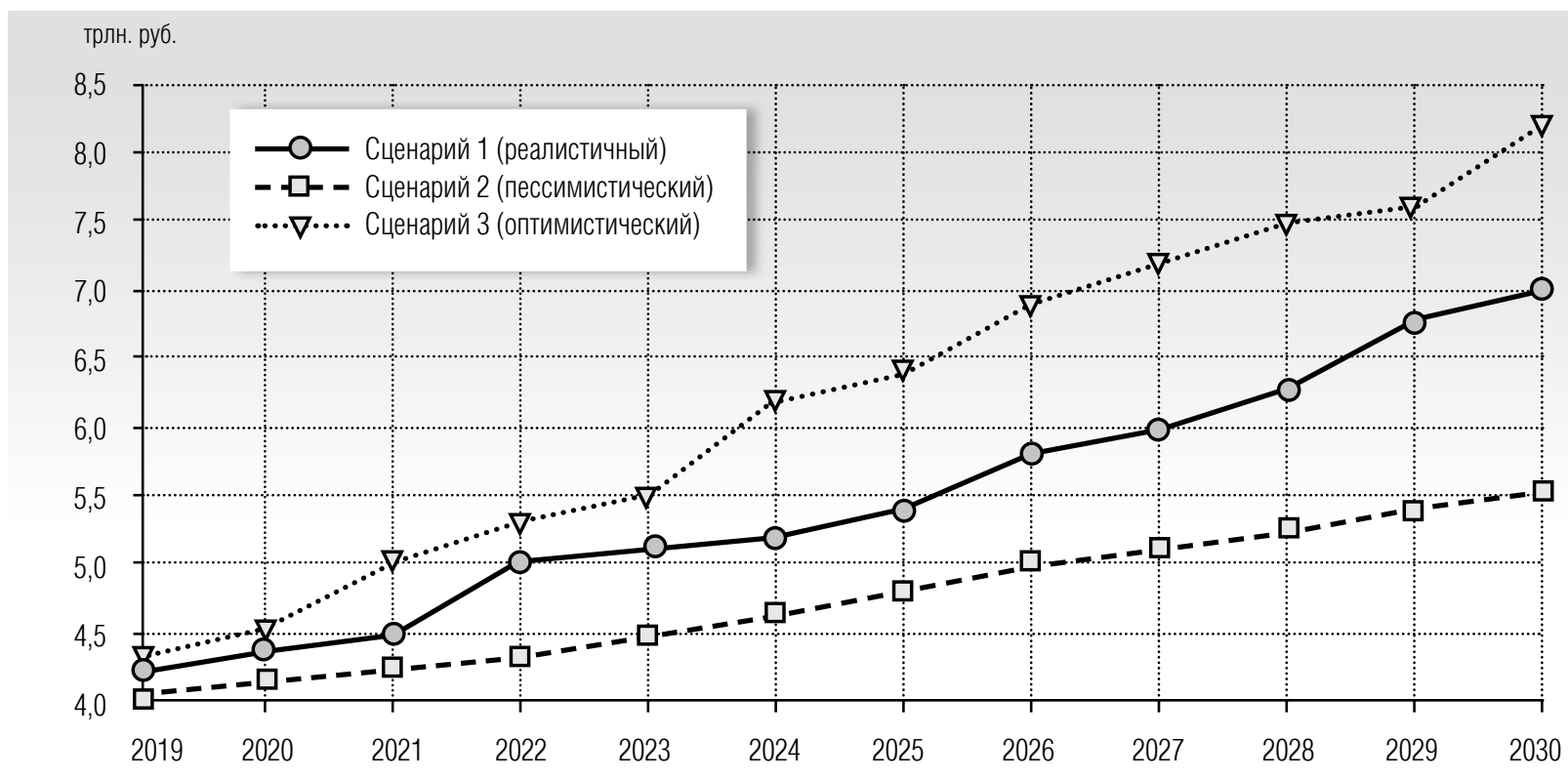

Рис. 4. Прогнозная динамика валового регионального продукта в ДФО, полученная с помощью предложенной имитационной модели 
селения по регионам федерального округа.

Разработанная система позволяет варьировать значения множественных управляющих параметров, например, темпов роста инвестиций в основные фонды, темпов роста средней заработной платы, темпов роста дотаций из федерального бюджета и др., а также визуализировать актуальное состояние агентов-регионов на карте России.

С помощью предложенной модели получена прогнозная динамика ВРП ДФО при различных сце- нариях: реалистичном, пессимистичном и оптимистичном.

Разработанная система поддержки принятий (СППР) может быть использована для моделирования и анализа характеристик других субъектов Российской Федерации. Дальнейшие исследования будут направлены на разработку СППР для всех регионов РФ, а также моделирование соответствующих взаимосвязей между ними - торговых, миграционных, финансовых и др.

\section{Литература}

1. Айвазян С.А., Афанасьев М.Ю., Кудров А.В. Модели производственного потенциала и оценки технологической эффективности регионов РФ с учетом структуры производства // Экономика и математические методы. 2016. Т. 52. № 1. С. $28-44$.

2. Кравченко Т.К., Исаев Д.В. Системы поддержки принятия решений. М.: Юрайт, 2017.

3. Акопов А.С. Имитационное моделирование. М.: Юрайт, 2016.

4. Forrester J.W. Urban dynamics. Waltham, MA: Pegasus Communications, 1969.

5. Forrester J.W. Industrial dynamics: A major breakthrough for decision makers // Harvard Business Review. 1958. Vol. 36. No. 4. P. 37-66.

6. Meadows D.H., Randers J. Meadows D.L. Limits to growth: The 30 year update. London: Earthscan, 2005.

7. Meadows D.H. Limits to growth: A Report for the Club of Rome's project on the predicament of mankind. N.Y.: Universe Books, 1972.

8. Сидоренко В.Н. Системная динамика. М.: ТЕИС, 1998.

9. Акопов А.С., Хачатрян Н.К. Системная динамика. М.: ЦЭМИ, 2014.

10. Akopov A.S. Designing of integrated system-dynamics models for an oil company // International Journal of Computer Applications in Technology. 2012. Vol. 45. No. 4. P. 220-230.

11. Акопов А.С. Системно-динамическое моделирование стратегии банковской группы // Бизнес-информатика. 2012. № 2 (20). C. $10-19$.

12. Акопов А.С. Системно-динамический подход в управлении инвестиционной деятельностью нефтяной компании // Аудит и финансовый анализ. 2006. № 2. С. 165-200.

13. Schelling T.C. Dynamic models of segregation // Journal of Mathematical Sociology. 1971. Vol. 1. No. 2. P. 143-186.

14. Axelrod R. The complexity of cooperation: Agent-based models of competition and collaboration. Princeton: Princeton University Press, 1997.

15. Акопов А.С., Хачатрян Н.К. Агентное моделирование. М.: ЦЭМИ, 2016.

16. Akopov A.S., Beklaryan L.A., Saghatelyan A.K. Agent-based modelling for ecological economics: A case study of the Republic of Armenia // Ecological Modelling. 2017. No. 346. P. 99-118.

17. Beklaryan A.L., Akopov A.S. Simulation of agent-rescuer behaviour in emergency based on modified fuzzy clustering // Proceedings of the 2016 International Conference on Autonomous Agents \& Multiagent Systems (AAMAS'16). Singapore, 9-13 May 2016. Richland: IFAAMAS, 2016. P. 1275-1276.

18. Modeling the development of regional economy and an innovation space efficiency / V. Makarov [et al.] // Foresight and STI Governance. 2016. Vol. 10. No. 3. P. 76-90.

19. Бахтизин А.Р., Бухвальд Е.М., Кольчугина А.В. Экономическая дифференциация регионов России: новые оценки и закономерности // ЭТАП: экономическая теория, анализ, практика. 2017. № 1. С. 41-56.

20. Бекларян Г.Л. Укрупненная имитационная модель внешнеэкономической деятельности РФ // Экономическая наука современной России. 2018. № 4. С. 50-65.

21. Akopov A.S., Beklaryan G.L. Modelling the dynamics of the "Smarter Region" // Proceedings of 2014 IEEE Conference on Computational Intelligence for Financial Engineering \& Economics (CIFEr). London, 27-28 March 2014. P. 203-209. 1972.

22. Акопов А.С., Бекларян Г.Л., Бекларян Л.А. Сравнительный анализ производственных и инвестиционных характеристик нефтедобывающей и нефтеперерабатывающей отраслей экономики по регионам РФ, а также нефтяных компаний // Аудит и финансовый анализ. 2005. № 1. С. 67-72.

23. Акопов А.С., Бекларян Г.Л. Анализ эффективности регулирующей политики государства с помощью региональной ССЕ модели поведения естественных монополий (на примере электроэнергетики) // Экономическая наука современной России. 2005. № 4 (31). C. 130-139.

24. Бекларян А.Л., Акопов А.С. Имитационная модель оптимального распределения потока кредитных заявок для межрегионального центра андеррайтинга коммерческого банка // Вестник компьютерных и информационных технологий. 2018. № 11 (173). С. 46-56.

25 Бекларян А.Л. Имитационная модель поведения толпы в среде разработки AnyLogic // Вестник Бурятского государственного университета. 2015. № 9. С. 40-53. 


\title{
Decision support system for sustainable economic development of the Far Eastern Federal District
}

\author{
Gayane L. Beklaryan \\ Senior Researcher \\ Central Economics and Mathematics Institute, Russian Academy of Sciences \\ Address: 47, Nakhimovsky Prospect, Moscow, 117418, Russia \\ E-mail: glbeklaryan@gmail.com
}

\begin{abstract}
In this paper we present a decision support system for the sustainable economic growth of the Far Eastern Federal District (FEFD) of the Russian Federation that consists of several regions. Using system dynamics and agent-based modeling methods, a simulation model of the FEFD economy is developed. The model is implemented in the AnyLogic system; it makes it possible to investigate the influence of multiple factors influencing the FEFD economy, for example, increasing rates of investment in fixed assets, average wages rates, subsidies from the federal budget, the forecasted price trends of oil, gas, carbon, diamonds and fishing industry products. One feature of the model is the possibility to analyze the dynamics of development of all regions of the FEFD, as well as taking into account the influence of external macroeconomic factors.

The decision support system we designed allows us to visualize important characteristics of the FEFD subjects using the map of Russia (GIS) and to save the results of the simulation modelling to the system database. At the same time, we have the possibility of forecasting the dynamics of the Gross Regional Product (a geographic information system) of the Federal District depending on values of the control parameters.

Different scenarios of the FEFD development are investigated. The realistic scenario assumes stabilization of prices for the main energy resources (oil, gas, coal) and minerals with simultaneous growth of investments in fixed assets. The pessimistic scenario assumes falling prices for energy, diamonds, fishing products, etc., as well as the reduction in the numbers of the economically active population in the Far Eastern Federal district. The optimistic scenario assumes stable increasing demand and prices for the products of all main sectors of the economy of the Federal District, maintaining current growth rates in industry and agriculture.
\end{abstract}

Key words: decision support system; regional economy; Far Eastern Federal District; simulation modeling; AnyLogic.

Citation: Beklaryan G.L. (2018) Decision support system for sustainable economic development of the Far Eastern Federal District. Business Informatics, no. 1 (43), pp. 66-75. DOI: 10.17323/1998-0663.2018.4.66.75

\section{References}

1. Aivazian S.A., Afanasiev M.Yu., Kudrov A.V. (2016) Modeli proizvodstvennogo potentsiala i otsenki tekhnologicheskoy effektivnosti regionov RF s uchetom struktury proizvodstva [Models of productive capacity and technological efficiency evaluations of regions of the Russian Federation concerning the output structure]. Economics and Mathematical Methods, vol. 52, no. 1, pp. 28-44 (in Russian).

2. Kravchenko T.K., Isaev D.V. (2017) Sistemy podderzhki prinyatiya resheniy [Decision support systems]. Moscow: Urait (in Russian).

3. Akopov A.S. (2016) Imitatsionnoe modelirovanie [Simulation modeling]. Moscow: Urait (in Russian).

4. Forrester J.W. (1969) Urban dynamics. Waltham, MA: Pegasus Communications.

5. Forrester J.W. (1958) Industrial dynamics: A major breakthrough for decision makers. Harvard Business Review, vol. 36, no. 4, pp. 37-66.

6. Meadows D.H., Randers J. Meadows D.L. (2005) Limits to growth: The 30 year update. London: Earthscan.

7. Meadows D.H. (1972) Limits to growth: A Report for the Club of Rome's project on the predicament of mankind. N.Y.: Universe Books.

8. Sidorenko V.N. (1998) Sistemnaya dinamika [System dynamics]. Moscow: TEIS (in Russian).

9. Akopov A.S., Khachatryan N.K. (2014) Sistemnaya dinamika [System dynamics]. Moscow: CEMI (in Russian).

10. Akopov A.S. (2012) Designing of integrated system-dynamics models for an oil company. International Journal of Computer Applications in Technology, vol. 45, no. 4, pp. 220-230.

11. Akopov A.S. (2012) Sistemno-dinamicheskoe modelirovanie strategii bankovskoy gruppy [System dynamics modeling of banking group strategy]. Business Informatics, no. 2 (20), pp. 10-19 (in Russian).

12. Akopov A.S. (2006) Sistemno-dinamicheskiy podhod v upravlenii investitsionnoy deyatel'nost'yu neftyanoy kompanii [System dynamic approach in management of a petroleum company's investment activity]. Audit and Financial Analysis, no. 2, pp. 165-200 (in Russian).

13. Schelling T.C. (1971) Dynamic models of segregation. Journal of Mathematical Sociology, vol. 1, no. 2, pp. $143-186$.

14. Axelrod R. (1997) The complexity of cooperation: Agent-based models of competition and collaboration. Princeton: Princeton University Press. 
15. Akopov A.S., Khachatryan N.K. (2016) Agentnoe modelirovanie [Agent-based modeling]. Moscow: CEMI (in Russian).

16. Akopov A.S., Beklaryan L.A., Saghatelyan A.K. (2017) Agent-based modelling for ecological economics: A case study of the Republic of Armenia. Ecological Modelling, no. 346, pp. 99-118.

17. Beklaryan A.L., Akopov A.S. (2016) Simulation of agent-rescuer behaviour in emergency based on modified fuzzy clustering. Proceedings of the 2016 International Conference on Autonomous Agents \& Multiagent Systems (AAMAS'16), Singapore, 9-13 May 2016. Richland: IFAAMAS, pp. 1275-1276.

18. Makarov V., Ayvazyan S., Afanasyev M., Bakhtizin A., Nanavyan A. (2016) Modeling the development of regional economy and an innovation space efficiency. Foresight and STI Governance, vol. 10, no. 3, pp. 76-90.

19. Bakhtizin A.R., Bukhwald E.M., Kolchugina A.V. (2017) Ekonomicheskaya differentsiatsiya regionov Rossii: novye otsenki i zakonomernosti [Economic differentiation of regions of Russia: New estimates and patterns]. ETAP: Economic Theory, Analysis, and Practice, no. 1, pp. 41-56 (in Russian).

20. Beklaryan A.L. (2018) Ukrupnennaya imitatsionnaya model' vneshneekonomicheskoy deyatel'nosti RF [Aggregated simulation model of foreign economic activity of the Russian Federation]. Economic Science of Modern Russia, no. 4, pp. 50-65 (in Russian).

21. Akopov A.S., Beklaryan G.L. (2014) Modelling the dynamics of the "Smarter Region". Proceedings of 2014 IEEE Conference on Computational Intelligence for Financial Engineering \& Economics (CIFEr), London, 27-28 March 2014, pp. 203-209.

22. Akopov A.S., Beklaryan G.L., Beklaryan L.A. (2005) Sravnitel'nyy analiz proizvodstvennyh i investitsionnyh harakteristik neftedobyvayuschey i neftepererabatyvayuschey otrasley ekonomiki po regionam RF, a takzhe neftyanyh kompaniy [Comparative analysis of industrial and investment characteristics of oil extracting and oil refining industries of regions of the Russian Federation, and also petroleum companies]. Audit and Financial Analysis, no. 1, pp. 67-72 (in Russian).

23. Akopov A.S., Beklaryan G.L. (2005) Analiz effektivnosti reguliruyuschey politiki gosudarstva s pomosch'yu regional'noy SSE modeli povedeniya estestvennyh monopoliy (na primere elektroenergetiki) [Analysis of efficiency of adjusting policy of the state by means of regional CCE model of natural monopolies behavior (on the example of electric power industry)]. Economic Science of Modern Russia, no. 4 (31), pp. 130-139 (in Russian).

24. Beklaryan A.L., Akopov A.S. (2018) Imitatsionnaya model' optimal'nogo raspredeleniya potoka kreditnyh zayavok dlya mezhregional'nogo tsentra anderraytinga kommercheskogo banka [Simulation model of the optimal allocation of credit applications for interregional underwriting center of a commercial bank]. Herald of Computer and Information Technologies, no. 11 (173), pp. 46-56 (in Russian).

25. Beklaryan A.L. (2015) Imitatsionnaya model' povedeniya tolpy v srede razrabotki AnyLogic [Simulation model of crowd behavior in the IDE AnyLogic]. Bulletin of Buryat state University, no. 9, pp. 40-53 (in Russian). 
- IEEE 21st IEEE International Conference on Business Informatics (IEEE CBI 2019)

\author{
July 15-17, 2019, Moscow, Russia \\ http://www.cbi2019.moscow/ \\ http://www.cbi-series.org
}

The IEEE Conference Series on Business Informatics is the leading international forum for state-of-the-art research in Business Informatics. The 21st IEEE CBI 2019, held in huge, old and interesting city Moscow, calls for submissions in the multidisciplinary field of Business Informatics, and welcomes a multitude of theoretical and practical perspectives and mind-sets on today's challenges of the digital transformation.

\section{Call for Papers}

The IEEE CBI series encourages a broad understanding of Business Informatics research, and intends to further its many different facets, theoretical foundations and experiential body of knowledge. In doing so, the CBI series has proven to be a fertile ground for research with high impact, and a hub for multidisciplinary research with contributions from Management Science, Organization Science, Economics, Information Systems, Computer Science, and Informatics.

In line with this, the CBI series aims to provide a forum for researchers and practitioners from various fields and backgrounds that contribute to the construction, use and maintenance of information systems and their organizational use contexts. A dedicated goal of the CBI series of conferences is to bring together researchers from different fields and disciplines to stimulate discussion, synergy and collaboration. Accordingly, CBI conferences use a format that enables in depth discussions among researchers during the conference. The benefits of such a crossdisciplinary conception are contrasted by a challenge: Authors who submit a paper take the risk to be assessed by standards that are different from those they are used to in their own research communities. The conference organisation accounts for this challenge by involving renowned track chairs and programme committee members from different fields and disciplines.

\section{List of Tracks}

- Enterprise Modelling, Engineering and Architecture

- Business Process Management
- Information Systems Engineering

- Artificial Intelligence for Business

- Information Management

- Business Analytics and Business Data Engineering

- Industry 4.0 (Industry Applications)

- Business Innovations and Digital Transformation

- Data-Driven Business Applications

- General Topics

\section{Submission}

https://edas.info/newPaper.php?c $=25431$

Manuscripts must be in English and are restricted to 10 pages in IEEE 2-coloumn template (A4).

In the submission form, select the conference track that best fits with your manuscript's topic, or choose "General Topics" if not covered by the tracks.

Review process is double-blind; your names and affiliations must not be explicitly listed in the manuscript. However, you should keep all cited references in the submission's bibliography intact.

Further information for submission:

https://cbi2019.moscow/

Accepted conference content will be submitted for inclusion into IEEE Xplore as well as other Abstracting and Indexing (A\&I) databases.

Selected papers will be invited to submit an extended version to a special issue of the EMISA Journal (subject to separate review).

\section{Important Dates}

Full paper submission

$\rightarrow$ March 1, 2019
Notification of paper acceptance

$\rightarrow$ May 10, 2019

Camera-ready paper submission

$\rightarrow$ June 1, 2019 


\section{April International Academic Conference} on Economic and Social Development

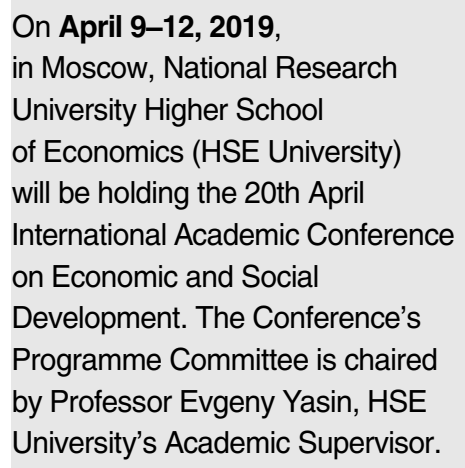

The Conference features a diverse agenda concerning social and economic development in Russia.

The Conference will bring together senior Russian government officials, including representatives of the Presidential Executive Office, the Ministry of Economic Development of the Russian Federation, high-level experts of the World Bank, the OECD, large national and global companies, and leading academics.

Papers included in the programme will have the opportunity of being published in leading Russian journals dedicated to economics, sociology, management, public administration, etc. (subject to additional reviews by the editorial board of a given journal). These journals are either cited in the Scopus and WoS databases or are included in the list published by the Russian Higher Attestation Commission.

The Conference's working languages are Russian and English.

\section{International Student Scientific-Practical Conference «E-business. Internet Project Management. Innovations»}

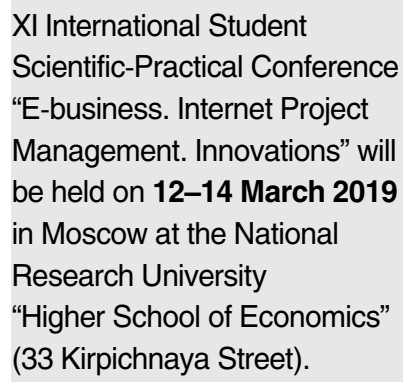

Main topics of the conference

- e-commerce

- experience in organizing business on the Internet

- games, virtual reality

- ICT for business and public administration

- ICT for medicine

- innovation in IT

- Internet economics

- Internet project management

- marketing and advertising on the Internet

- network community

- real Internet

- research on the Internet

- the legal framework of e-business

Participants of the conference have a great opportunity to meet young researchers and well-known experts.

The conference will be held in two languages: Russian and English.

All applications undergo a competitive selection of an expert commission. The best works will be published after the conference in the proceedings of the conference (publication will be indexed in eLIBRARY.RU). 


\section{ABTOPAM}

Представляемая для публикации статья должна быть актуальной, обладать новизной, отражать постановку задачи (проблемы), описание основных результатов исследования, выводы, а также соответствовать указанным ниже правилам оформления.

Текст должен быть тщательно вычитан автором, который несет ответственность за научно-теоретический уровень публикуемого материала.

Материалы представляется в электронном виде по адресу: bijournal@hse.ru.

\section{ТРЕБОВАНИЯ К ОФОРМЛЕНИЮ СТАТЕЙ}

ТЕКСТ СТАТЬИ представляется в редакцию в электронном виде (в формате MS Word, версия 2003 или выше).

ОБЪЕМ. Ориентировочный объем статьи составляет 20-25 тысяч знаков (с пробелами).

\section{ШРИФТ, ФОРМАТИРОВАНИЕ, НУМЕРАЦИЯ СТРАНИЦ}

ШРИФТ - Times New Roman, кегль набора - 12 пунктов, полуторный интервал, форматирование по ширине. Нумерация страниц вверху по центру, поля: левое - 2,5 cм, верхнее, нижнее и правое по 1,5 см.

НАЗВАНИЕ СТАТЬИ приводится на русСком и английском языках. Название статьи должно быть информативным и раскрывать содержание статьи.

СВЕДЕНИЯ ОБ АВТОРАХ прИВОДятся На русском И английСКом языках и включают следующие элементы:

$\downarrow$ фамилия, имя, отчество всех авторов полностью

$\downarrow$ должность, звание, ученая степень каждого автора

$\downarrow$ полное название организации - места работы каждого автора в именительном падеже, полный почтовый адрес каждой организации (включая почтовый индекс)

$\checkmark$ адрес электронной почты каждого автора.

АННОТАЦИЯ К СТАТЬЕ представляется на русском и английском языках.

$\downarrow$ Объем - 200-300 слов.

$\downarrow$ Аннотация должна быть информативной (не содержать общих слов).

$\downarrow$ Аннотация должна отражать основное содержание статьи и быть структурированной (следовать логике описания результатов в статье).

$\downarrow$ Структура аннотации: предмет, цель, метод или методологию проведения исследования, результаты исследований, область их применения, выводы.

$\rightarrow$ Метод или методологию проведения исследований целесообразно описывать в том случае, если они отличаются новизной или представляют интерес с точки зрения данной работы. В аннотациях статей, описывающих экспериментальные работы, указывают источники данных и характер их обработки.

४ Результаты работы описывают предельно точно и информативно. Приводятся основные теоретические и экспериментальные результаты, фактические данные, обнаруженные взаимосвязи и закономерности. При этом отдается предпочтение новым результатам и данным долгосрочного значения, важным открытиям, выводам, которые опровергают существующие теории, а также информации, которая, по мнению автора, имеет практическое значение.

- Выводы могут сопровождаться рекомендациями, оценками, предложениями, гипотезами, описанными в статье.

$\checkmark$ Сведения, содержащиеся в названии статьи, не должны повторяться в тексте аннотации. Следует избегать лишних вводных фраз (например, «автор статьи рассматривает...»).

$\checkmark$ Исторические справки, если они не составляют основное содержание документа, описание ранее опубликованных работ и общеизвестные положения, в аннотации не приводятся.

\ В тексте аннотации следует употреблять синтаксические конструкции, свойственные языку научных и технических документов, избегать сложных грамматических конструкций.

$\downarrow$ В тексте аннотации следует применять значимые слова из текста статьи.

КЛЮЧЕВЫЕ СЛОВА приводятся на русском И английском яЗЫкаХ. Количество ключевых слов (словосочетаний) - 6-10. Ключевые слова или словосочетания отделяются друг от друга точкой с запятой.

ФОРМУлЫ. При наборе формул, как выключных, так и строчных, должен быть использован редактор формул MS Equation. В формульных и символических записях греческие (русские) символы, а также математические функции записываются прямыми шрифтами, а переменные аргументы функций в виде английских (латинских) букв наклонным курсивом (пример «соs a», «sin b», «min», «max»). Нумерация формул - сквозная (по желанию авторов допускается двойная нумерация формул с указанием структурного номера раздела статьи и, через точку, номера формулы в разделе).

РИСункИ (графики, диаграммы и т.п.) могут быть оформлены средствами MS Word или MS Excel. Ссылки на рисунки в тексте обязательны и должны предшествовать позиции размещения рисунка. Допускается использование графического векторного файла в формате wmf/emf или cdr v.10. Фотографические материалы предоставляются в формате TIF или JPEG, с разрешением изображения не менее 300 точек на дюйм. Нумерация рисунков - сквозная.

ТАБЛИЦЫ оформляются средствами MS Word или MS Excel. Нумерация таблиц - сквозная.

СПИСОК ЛИТЕРАТУРЫ составляется в соответствиИ С требованиями ГОСТ 7.0.5-2008. Библиографическая ссылка (примеры оформления размещены на сайте журнала http://bi.hse.ru/). Нумерация библиографических источников - в порядке цитирования. Ссылки на иностранную литературу - на языке оригинала без сокращений.

СПИСОК ЛИТЕРАТУРЫ ДЛЯ АНГЛОЯЗЫЧНОГО БЛОКА оформляется в соответствии с требованиями SCOPUS (примеры оформления размещены на сайте журнала http://bi.hse.ru/). Для транслитерации русскоязычных наименований можно воспользоваться сервисом http://translit.ru/.

\section{ЛИЦЕНЗИОННЫЙ ДОГОВОР}

Для размещения полнотекстовых версий статей на сайте журнала с авторами заключается лицензионный договор о передаче авторских прав.

Плата с авторов за публикацию рукописей не взимается. 


\section{AUTHORS GUIDELINES}

Articles should be topical and original, should outline tasks (issues), describe key results of the author's research and appropriate conclusions.

Manuscripts are submitted via e-mail: bijournal@hse.ru.

\section{MANUSCRIPT REQUIREMENTS}

TEXT FILES should be submitted in electronic form, as a MS Word document (version 2003 or higher).

LENGTH. Articles should be between 20 and 25 thousand characters (incl. spaces).

FONT, SPACING, MARGINS. The text should be in Times New Roman 12 pt, 1.5 spaced, fit to the width, margins: left -25 $\mathrm{mm}$, all other - $15 \mathrm{~mm}$.

TITLE of the article should be submitted in native language and English.

AUTHORS' DETAILS are presented in native language and English. The details include:

$\downarrow$ Full name of each author

$\downarrow$ Position, rank, academic degree of each author

$\downarrow$ Affiliation of each author, at the time the research was completed

$\downarrow$ Full postal address of each affiliation (incl. postcode / ZIP)

$\downarrow$ E-mail address of each author.

\section{ABSTRACT are presented in native language and English.}

^ The abstract should be between 200 and 300 words.

$\downarrow$ The abstract should be informative (no general words), original, relevant (reflects your paper's key content and research findings); structured (follows the logics of results' presentation in the paper)

- The recommended structure: purpose (mandatory), design / methodology / approach (mandatory), findings (mandatory), research limitations / implications (if applicable), practical implications (if applicable), originality / value (mandatory)

$\downarrow$ It is appropriate to describe the research methods/methodology if they are original or of interest for this particular research. For papers concerned with experimental work the data sources and data procession technique should be described.

- The results should be described as precisely and informatively as possible. Include your key theoretical and experimental results, factual information, revealed interconnections and patterns. Give special priority in the abstract to new results and long-term impact data, important discoveries and verified findings that contradict previous theories as well as data that you think have practical value.

- Conclusions may be associated with recommendations, estimates, suggestions, hypotheses described in the paper.

$\checkmark$ Information contained in the title should not be duplicated in the abstract. Authors should try to avoid unnecessary introductory phrases (e.g. «the author of the paper considers...»).

$\downarrow$ Authors should use the language typical of research and technical documents to compile your abstract and avoid complex grammatical constructions.

$\downarrow$ The text of the abstract should include key words of the paper.

KEYWORDS are presented in native language and English. The number of key words / words combinations are from 6 to 10 (separated by semicolons).

FORMULAE should be prepared using Math Type or MS Equation tool.

FIGURES should be of high quality, black and white, legible and numbered consecutively with Arabic numerals. All figures (charts, diagrams, etc.) should be submitted in electronic form (photo images - in TIF, PSD or JPEG formats, minimum resolution $300 \mathrm{dpi})$. Appropriate references in the text are required.

REFERENCES should be presented in Harvard style and carefully checked for completeness, accuracy and consistency.

The publication is free of charge. 